\title{
Multiple natural hazards at volcanic islands: a review for the Ischia volcano (Italy)
}

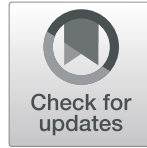

\author{
J. Selva ${ }^{1 *}\left(\mathbb{D}\right.$, V. Acocella ${ }^{2}$, M. Bisson ${ }^{3}$, S. Caliro ${ }^{4}$, A. Costa $^{1}$, M. Della Seta ${ }^{5}$, P. De Martino ${ }^{4}$, S. de Vita ${ }^{4}$, C. Federico ${ }^{6}$, \\ G. Giordano ${ }^{2}$ S. Martino ${ }^{5}$ and C. Cardaci ${ }^{7}$
}

\begin{abstract}
Volcanic islands pose several major types of natural hazards, often interconnected and concentrated in relatively small areas. The quantification of these hazards must be framed from a multi-hazard perspective whilst building on existing single-hazard analyses. Ischia is a densely inhabited volcanic island with a long eruptive history lasting more than $150 \mathrm{ka}$ (last in 1302 AD) characterized by the significant asymmetric resurgence of a caldera block. Here, we review the state-of-art of the natural hazards of Ischia, aiming at building a solid base for future holistic multihazard quantifications. We frame our analysis in three steps: i) review of geological, historical and current activity; ii) review of available hazard models and analyses; iii) development of an interpretative framework for the interdependent hazards. The results highlight that volcanic activity has been quite intense and many volcanorelated hazardous phenomena have affected the island including in very recent times, both for eruptive (phreatic or magmatic eruptions) and non-eruptive (earthquakes, landslides, and tsunamis) phenomena. The effects of some of them (e.g. tsunamis, tephra) are also relevant beyond the island territory. Quantitative hazard assessments are almost absent and should be developed in the future considering the evident interconnections between hazards. To this end, we propose a conceptual interpretative multi-hazard framework that highlights the fundamental role played by the resurgent block in controlling and connecting the different hazards, in terms of both spatial distribution of the sources and temporal clustering.
\end{abstract}

Keywords: Ischia island, Volcanic hazards, Multi-hazard, Conceptual model, Resurgence

\section{Introduction}

The management of long-term volcanic risks is particularly crucial in volcanic islands, which are characterized by multiple hazards concentrated in a relatively small area, often associated with a large seasonality of exposure due to tourism. Volcanic islands are indeed particularly fragile environments due to their special geological formation and their societal development concentrated in relatively small areas, in which cascading events also connect emerged and submarine environments (e.g., Carey et al. 1996; Marti et al. 2010; Giachetti et al. 2012; Casalbore et al. 2018; Hunt et al. 2018; Rosi et al. 2019). The scientific challenges are mainly the quantification and the characterization of the interactions among the multiple hazardous phenomena that may occur during

\footnotetext{
* Correspondence: jacopo.selva@ingv.it

'Istituto Nazionale di Geofisica e Vulcanologia, Sezione di Bologna, Bologna, Italy

Full list of author information is available at the end of the article
}

the different "states of the volcano" (quiescence, unrest, eruption) and the definition of robust methods to forecast the transition between these states. This requires the development of multi-disciplinary studies targeted to comprehensive multi-hazard quantifications (e.g., Marzocchi et al. 2012; Selva 2013; Mignan et al. 2014; Liu et al. 2015) that, for volcanic islands, are fundamentally underrepresented in the literature. In addition, for these topics, the emerging scientific knowledge is often rather limited and uncertain and, also when well constrained, difficult to communicate to decision makers due to its intrinsic complexity.

In this paper, we discuss the experience gained by one working group in charge of reviewing the state of knowledge about volcanic hazards for Ischia, Italy, established within the agreement between DPC (Italian Department of Civil Protection) and INGV (Istituto Nazionale di Geofisica e Vulcanologia; INGV-DPC-T4C 2016-2017).

(c) The Author(s). 2019 Open Access This article is distributed under the terms of the Creative Commons Attribution 4.0 International License (http://creativecommons.org/licenses/by/4.0/), which permits unrestricted use, distribution, and reproduction in any medium, provided you give appropriate credit to the original author(s) and the source, provide a link to the Creative Commons license, and indicate if changes were made. 
Ischia volcano belongs to the Neapolitan volcanic system. It is located to the SW of the Campi Flegrei caldera, and of the volcanic islands of Procida and Vivara, all together forming the Phlegraean volcanic district. Ischia volcano has been the site of a large number of eruptions in historical times, the most recent of which occurred in 1302 AD (Vezzoli 1988; Iacono 1996), and of other interdependent hazardous phenomena connected to its magmatic system. It is also characterized by an active hydrothermal system (Chiodini et al. 2004; Di Napoli et al. 2011 and references therein) that, along with its favourable position within the Neapolitan gulf and its beaches, makes it one of Italy's major touristic hubs. The island is densely populated, with more than 60,000 inhabitants distributed in less than $50 \mathrm{~km}^{2}$. In touristic seasons this population increases substantially. This makes the volcanic and related risks at Ischia very high, also for relatively small events, as demonstrated by the recent $\mathrm{Mw}=3.9$ earthquake occurred in August 2017 (Gruppo di Lavoro INGV sul terremoto dell'isola di Ischia 2017) that caused 2 fatalities, several tens of injured, and substantial damages mainly to the village of Casamicciola Terme, located in the northern part of the island.

Although the potential volcanic and related risks at Ischia are very high, the scientific literature on their quantification is sparse and relatively poor. In particular, a critical review of the basic knowledge regarding the volcanic system and the related natural hazards is still lacking, even in the presence of a relatively rich literature on the geology of the island (Rittmann and Gottini 1980; Vezzoli 1988; de Vita et al. 2010; Sbrana and Toccaceli 2011; Sbrana et al. 2018 and references therein), as well as a relatively large number of studies regarding the phenomena that it may produce (especially on historical earthquakes, landslides and tsunamis, e.g., Cubellis and Lungo 2018; de Vita et al. 2006; Della Seta et al. 2012; Paparo and Tinti 2017). This situation does not even allow establishing solid ground for hazard quantifications in the future.

To fill this gap and prepare the ground for future hazard quantifications, we propose a standardized multihazard review scheme organized in 3 steps. STEP 1 is dedicated to the establishment of the state-of-art on the volcanic system. STEP 2 is focused on the review of the available quantification of all the hazardous phenomena that a volcanic system may be related to. STEP 3 is dedicated to the development of a reference interpretative conceptual framework, focusing on specific topics of interest that emerge during STEPs 1 and 2. All the three steps provide concrete results useful for future developments. In all STEPs, we accounted for i) the hazard/risk separation principle (e.g., Jordan 2014; Papale 2017); ii) the variability of scientifically acceptable opinions (sensu
SSHAC 1997), so the full spectrum of scientific opinions (epistemic uncertainty) retrieved from literature and distilled through a transparent and documented interaction within the review has been treated. Noteworthy, STEPs 2 and 3 are strongly oriented toward a multi-hazard and multi-risk perspective, to meet the requirement of building a holistic multi-hazard framework on which to base future hazard quantification.

STEP 1 consists of the review of the available geological, historical and instrumental data, as well as their interpretations. The main goals are the definition of a reference period and the characterization of the volcanic states (rest/unrest/eruption), allowing us to define a reference catalogue of eruptive and non-eruptive events. This catalogue represents a fundamental input to forecasting tools (e.g., Newhall and Hoblitt 2002; Aspinall et al. 2003; Marzocchi et al. 2008; Newhall and Pallister 2015; Hincks et al. 2014), hazard quantifications in rest, unrest, and eruption periods (e.g., Bonadonna et al. 2005; Costa et al. 2009; Selva et al. 2010, 2014, 2018; Jenkins et al. 2012; Biass and Bonadonna 2012; Tierz et al. 2017), as well as to the definition of potential strategies for risk management (e.g., Marzocchi and Woo 2007; Winson et al. 2014; Woo 2015; Papale 2017; Pallister et al. 2019).

STEP 2 consists of the systematic review of the stateof-art of hazard quantifications for all the potential hazards, adopting a multi-hazard perspective.. We extended the review to all the phenomena defined in IAEA (2012, 2016), including eruptive (new vent, ballistics, tephra fall and atmospheric phenomena, lava flows and pyroclastic density currents) and non-eruptive (hydrothermal phenomena, gases, deformations, seismicity, gravitational instability, and tsunamis). We adopted four reviewing milestones (past observations including the largest known and the most recent events, occurrence in rest/ unrest/eruption, intensities and probabilistic hazard curves, triggering/cascading events) and on a rough discretization of probabilistic and spatial information. Our goal is to provide a homogeneous foundation for future probabilistic single and multi-hazard quantifications, bounding on the already observed natural variability and on the links with the volcanic states and with the other hazards.

STEP 3 develops a conceptual interpretative framework providing a comprehensive and rational interpretation of the system based on the available information provided by STEPs 1 and 2. This type of models, often the basis of hazard quantifications (e.g., IAEA 2012, 2016), reflects the opinion that the authors formed during the review project, and has a more speculative character than the other STEPs. As such, no alternative models were considered, even if theoretically possible. For Ischia, the goal of our conceptual framework is 
investigating the connection among the different hazards in the different states of the volcano.

This review scheme, general and applicable to any volcanic island, is here applied to Ischia Island. In the followings, the 3 stages of this review are described in detail, reporting STEPs 1, 2 and 3 in Sections STEP 1: geological, historical and recent activity and present state of the system, STEP 2: the natural hazards of Ischia, and STEP 3: conceptual interpretative framework, respectively. In Section Discussions and conclusions, we summarize the main results of each STEP and we elaborate some conclusions and final remarks, also identifying some research lines required to improve the present state of knowledge. Given the large number of acronyms, symbols and other abbreviations used, we summarize them in Abbreviations section.

\section{STEP 1: geological, historical and recent activity and present state of the system}

The goal of Section STEP 1: geological, historical and recent activity and present state of the system is the establishment of the state-of-art of the available knowledge and interpretations regarding the Ischia volcanic system and its present state. More specifically, we review geological knowledge (Subsection Background for the tectono-magmatic model of Ischia volcanism: geological history) and the present state of the system (Subsections Present state of the volcanic system of Ischia). Based on these reviews, in Subsection Reference period, states of the volcano and their characterization we define the reference period for the present state of Ischia and discuss the available knowledge in this period, distinguishing quiescence, unrest, and eruptive periods in Ischia.

\section{Background for the tectono-magmatic model of Ischia volcanism: geological history}

The island of Ischia is part of the Phlegraean volcanic district, which is framed in the Tyrrhenian volcanism. This volcanism, in turn, is related to extensional tectonic phases that accompanied the anticlockwise rotation of the Italian peninsula, during the complex interaction between the Africa and Eurasian plates (Ippolito et al. 1973; D'Argenio et al. 1973; Finetti and Morelli 1974; Bartole 1984; Piochi et al. 2004). Along the Tyrrhenian margin, extension was accommodated by the activation of NW-SE normal faults and NE-SW normal to strike-slip transfer faultsystems, which allowed magmas to reach the surface, feeding volcanism (Mariani and Prato 1988; Faccenna et al. 1994; Acocella and Funiciello 2006).

Ischia is the emerged part of an active volcanic field, which rises more than $1,000 \mathrm{~m}$ above the sea floor (Fig. 1; Orsi et al. 1999; Bruno et al. 2002), along the margin of an E-W trending scarp that borders to the south the Phlegraean volcanic district. The island covers an area of
$46.4 \mathrm{~km}^{2}$ and is morphologically dominated by the Monte Epomeo (787 m a.s.l.), in its central portion, and by the NE-SW Monte Vezzi - Monte Cotto alignment of peaks, in the SE corner. The coast is characterized by steep cliffs with interposed promontories on the southern side, and by hilly slopes more gently dipping to the sea, along the other sides. The island is mainly composed of volcanic rocks and landslide deposits, and subordinately of sedimentary terrigenous rocks, which bear witness to a complex history of alternating constructive and destructive phases, due to the interplay between volcanism, volcano-tectonism and slope instability (de Vita et al. 2006, 2010; Della Seta et al. 2012). The Ischia volcanics belongs to the low-K series of the Roman comagmatic province, ranging in composition from shoshonite to latite, trachyte and phonolite; the most abundant exposed rocks are alkali-trachytes (Angiulli et al. 1985; Poli et al. 1987, 1989; Crisci et al. 1989; Civetta et al. 1991).

\section{Volcanological evolution}

Volcanism at Ischia dates back to more than $150 \mathrm{ka}$ and continued, with centuries to millennia of quiescence, until the most recent eruption occurred in $1302 \mathrm{AD}$ (Vezzoli 1988; Sbrana and Toccaceli 2011; Sbrana et al. 2018). The oldest exposed rocks, aged between 150 and $75 \mathrm{ka}$, are lava flows and/or lava domes, and a sequence of pyroclastic deposits with intercalated paleosols, mainly exposed in the S part of the island (Scarrupata di Barano Formation in Vezzoli 1988; Ancient Ischia Syntheme in Sbrana and Toccaceli 2011; Phase 1 in Sbrana et al. 2018; l.c. volcanics older than 75 ka of Fig. 1a). Almost in the same time span, a prevailing effusive activity determined the emplacement of a series of small trachytic and phonolitic lava domes, which are presently exposed at the periphery of the island (Fig. 1a).

A very intense period of explosive activity followed between 74 and $55 \mathrm{ka}$. During this period many volcanic vents were active mainly in the $\mathrm{S}$ sector of the island, likely producing the highest magnitude eruptions recorded at Ischia. The deposits of at least 10 explosive eruptions, fed by phonolitic to trachytic magmas, were interpreted as the product of variably energetic eruptions, which generated pyroclastic density currents, fallout deposits from sustained eruption columns, block and ash flows from collapsing lava domes, explosion breccias and hydromagmatic dilute and turbulent pyroclastic density currents (Brown et al. 2008; Rifugio di San Nicola Syntheme in Sbrana and Toccaceli 2011; Phase 2 in Sbrana et al. 2018). The activity of this period culminated with the caldera forming eruptions of the Monte Epomeo Green Tuff (MEGT) between 60 and 50 ka (Brown et al. 2008, and references therein; Sbrana and Toccaceli 2011; Sbrana et al. 2018; Fig. 1a). This tuff consists mostly of trachytic ignimbrites that partially 


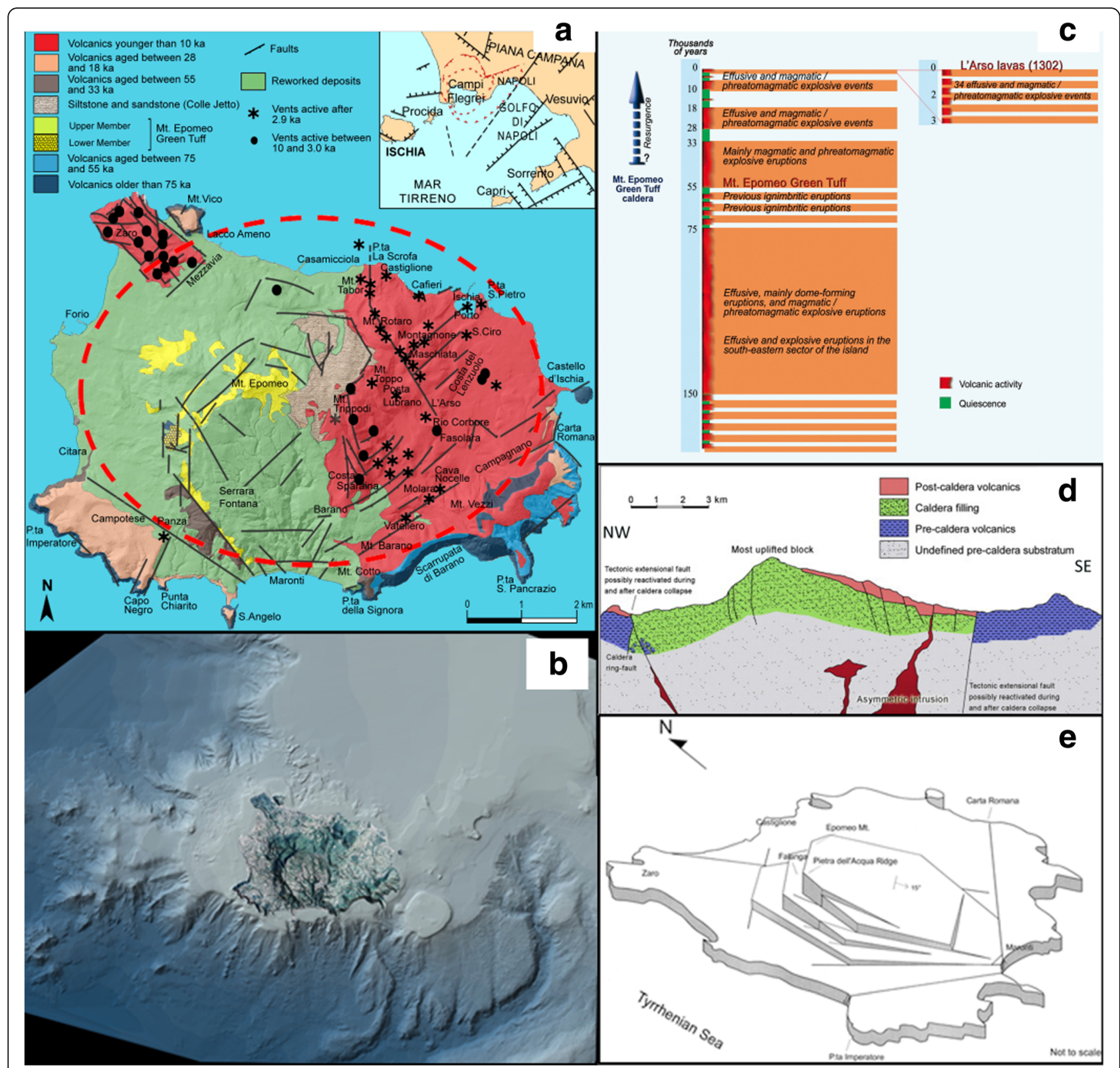

Fig. 1 a geological and structural sketch map of Ischia (modified after de Vita et al. 2010), where the red dashed line indicates the margin of the hypothesized Monte Epomeo Green Tuff caldera; b morphology of the emerged and submerged parts of Ischia (after D'Argenio et al. 2004); c chronogram of the Ischia volcanic activity; d NW-SE structural section, showing the asymmetric block resurgence of Monte Epomeo (after Marotta and de Vita 2014); e structural sketch showing the asymmetric block resurgence and tilting of the Green Tuff caldera floor (after Acocella and Funiciello 1999)

filled the caldera depression in a submarine environment, and were also emplaced on land outside its margins. The caldera depression was later the site of marine sedimentation, which formed a sequence of clays, tuffites, sandstones and siltstones by the reworking of MEGT and sedimentary supply from the mainland (Sbrana and Toccaceli 2011). After the MEGT eruptions, volcanism continued with a series of hydromagmatic and magmatic explosive eruptions up to $33 \mathrm{ka}$. Most of the vents were located along the present SW and NW offshore of the island. Volcanism in this period was fed by latitic and shoshonitic magmas (Brown et al. 2014; Phase 3 in Sbrana et al. 2018), whose injection into the system triggered the asymmetric resurgence of the caldera floor, generating the Monte Epomeo block (Orsi et al. 1991).

After about $5 \mathrm{ka}$ long period of quiescence, volcanism resumed at about $28 \mathrm{ka}$. The beginning of this period of 
activity was marked by the eruption of shoshonitic magmas, isotopically distinct from those characterizing the previous eruptions, suggesting the arrival of a new batch of magma into the feeding system of Ischia, followed by its differentiation and mixing with the resident magma (Poli et al. 1987; Civetta et al. 1991; Casalini et al. 2017). Volcanism continued sporadically until 18 ka (or $13 \mathrm{ka}$, Phase 4 in Sbrana et al. 2018), with the emission of shoshonitic to alkali-trachytic magmas that fed effusive and both hydromagmatic and magmatic explosive eruptions, with the emplacement of lava flows and Strombolian fallout deposits, and the construction of small tuff-cones and scoria-cones, exposed along the SE and SW coasts of the island (Fig. 1b; Campotese Subsyntheme in Sbrana and Toccaceli 2011).

The radiometric dating of the outcropping volcanic products suggests that between 18 and 10 ka there was a period of almost complete quiescence (Vezzoli 1988), whereas other interpretations (Sbrana and Toccaceli 2011; Sbrana et al. 2018) seem to indicate the occurrence of some eruptions in this timespan. In any case, all the authors agree in considering the interval between 18 and $10 \mathrm{ka}$ as a period of quiescence or very reduced volcanic activity (Fig. 1c).

A period of more sustained activity at Ischia started at about $10 \mathrm{ka}$, and was fed by mainly trachytic and subordinately latitic magmas. These are characterized by a $\mathrm{Sr}$ isotopic ratio lower than those of the previous periods, leading to hypothesize the arrival of a new, geochemically distinct magma into the system. Volcanism was mainly concentrated at around $5.5 \mathrm{ka}$ and after $2.9 \mathrm{ka}$, with almost all the vents located in the eastern part of the island (Fig. 1a). Only a few vents are located outside this area, along regional fault systems or along the margins of the resurgent block: these vents generated a multi-vent lava field in the NW corner of the island, a pyroclastic sequence, exposed to the SW, and a lava dome in the N sector of the island. Since $2.9 \mathrm{ka}$, about 34 effusive and explosive eruptions took place: the effusive eruptions emplaced lava domes and high-aspect ratio lava flows, while the explosive eruptions, both magmatic and phreatomagmatic, generated tuff cones, tuff rings and variably dispersed pyroclastic-fall and -current deposits, which had a very variable impact on both the island's environment and human settlements (de Vita et al. 2010, and references therein; Sbrana and Toccaceli 2011; de Vita et al. 2013; Phases 5 and 6 in Sbrana et al. 2018).

As volcanism was not continuous since $10 \mathrm{ka}$, but characterized by the alternation of centuries of quiescence and periods of very intense activity, it has been hypothesized that repeated episodes of magma intrusions occurred intermittently (Tibaldi and Vezzoli 2004; de Vita et al. 2006; Vezzoli et al. 2009; de Vita et al.
2010), likely accompanied by resurgence (see Subsection Resurgence) and periods of slope instability (see Subsection Geological and historical instability of slopes). Even if, since the last eruption, no evidence of renewal of uplift due to fault reactivation has been recorded in concurrence with more recent minor mass movements (see Subsection Geological and historical instability of slopes), the magmatic system of Ischia has to be considered still active, as testified by intense volcanism in historical times and widespread fumaroles and thermal springs.

\section{Resurgence}

Ischia is one of the most evident, better studied and known cases of intracalderic resurgence. With its uplift of the order of about 900-1100 m, very rarely recognized in other volcanic areas, it represents a case quite unique. The resurgent area has a polygonal shape resulting from the reactivation of regional faults and the activation of faults directly related to volcano-tectonism (Orsi et al. 1991; Acocella and Funiciello 1999). The W sector of the resurgent block is bordered by high-angle, N-S NESW and NW-SE trending faults, which were cut by late outward-dipping normal faults due to gravitational readjustment of the slopes. To the east of the resurgent block, vertical or outward-dipping, N-S, NE-SW and NW-SE normal faults, formed a lowland which is connected westward to the resurgent area of Monte Epomeo through a series of differentially displaced blocks (Fig. 1a,d; de Vita et al. 2006, 2010; Della Seta et al. 2012). Toward N-NE the limit of the resurgent area is not well defined, as along the coast beach deposits are exposed, displaced at different height above sea level by E-W and NW-SE trending, vertical faults. Resurgence caused a differential uplift of the bottom of the caldera, through the displacement of variably raised and inclined blocks, with a general tilt around a NE-SW oriented horizontal axis, located in the SE part of the resurgent area. The result is an asymmetrical block structure, with a maximum uplifted block in the NW part of the resurgent area (Fig. 1d,e; Rittmann and Gottini 1980, Vezzoli 1988, Orsi et al. 1991, Acocella and Funiciello 1999; de Vita et al. 2006, 2010; Della Seta et al. 2012).

The intrusion of new magma into the Ischia feeding system has been commonly accepted in the literature as the cause of the uplift that led to the emergence of the Monte Epomeo Green Tuff (MEGT) caldera floor (Rittmann 1930; Rittmann and Gottini 1980; Orsi and Chiesa 1988; Orsi et al. 1991; Luongo et al. 1995; Tibaldi and Vezzoli 1997, 1998; Acocella and Funiciello 1999; Molin et al. 2003; Carlino et al. 2006).

The beginning and duration of the uplift are not well constrained, although the beginning must be older than $33 \mathrm{ka}$, as rocks of this age, emplaced in a subaerial 
environment, are deformed by the resurgence process (Fig. 1c). Geological and volcanological evidence suggests that resurgence was not continuous over time, but took place through intermittent uplifting and tectonic quietness phases (de Vita et al. 2006, 2010; Vezzoli et al. 2009). At present, as discussed with more details in Subsection Active ground deformation field, geodetic data show a generalized subsidence of the Monte Epomeo block, at least in the last decades, suggesting that currently the process of resurgence is at rest (de Vita et al. 2006; Manzo et al. 2006; Sepe et al. 2007).

\section{Magmatic system}

The evolution over time and the possible geometry of the Ischia magmatic system have been reconstructed by numerous authors, based on chemical and isotopic analyses carried out on outcrop rock samples. These reconstructions refer to the last $150 \mathrm{ka}$ of volcanic activity on the island (Rittmann 1930, 1948; Rittmann and Gottini 1980; Poli et al. 1987; Vezzoli 1988; Crisci et al. 1989; Civetta et al. 1991; Piochi et al. 1999; Sbrana and Toccaceli 2011; D'Antonio et al. 2013; Moretti et al. 2013; Brown et al. 2014, and references therein).

As mentioned above, the oldest outcropping rocks (150-75 ka) show a generally trachytic composition, with a progressive decrease in the alkali content and the $\mathrm{Na}_{2} \mathrm{O}$ / $\mathrm{K}_{2} \mathrm{O}$ ratio over time (Sbrana and Toccaceli 2011) and phonolitic composition and higher peralkalinity index for the most explosive eruptions. The volcanism between 75 and $50 \mathrm{ka}$ was characterized by a composite and differentiated magmatic system, filled repeatedly by magmas of deep origin, with distinct isotopic compositions (Brown et al. 2014). The chemical and isotopic variations show that the pre-MEGT eruptions were fed by trachytic and phonolytic magmas poorly enriched in radiogenic $\mathrm{Sr}$ and progressively less radiogenic over time. Immediately before the MEGT eruption, the magmatic reservoir seems to be reloaded by an isotopically distinct magma relatively more enriched in radiogenic Sr, which also fed the eruption of the MEGT (characterized by a phonolytic to trachitic magma accumulated at $4-6 \mathrm{~km}$ depth in about $20 \mathrm{ka}$ ). After the MEGT eruption, the arrival of a new and less differentiated magma (slightly less enriched in radiogenic Sr) characterized the eruptive activity (Civetta et al. 1991; Brown et al. 2008, 2014). The geochemical and isotope variations of $\mathrm{Sr}$ and $\mathrm{Nd}$ over time reflect the ascent of distinct bodies of magmas at variable degrees of contamination with an ercinic crust at $8-12 \mathrm{~km}$ depth.

In the last $50 \mathrm{ka}$ the magma system was characterized by the arrival of new isotopically distinct magmas, with evidence of contamination and mixing. The eruptions of this period show a progressive increase in the magma/ water interaction, which culminates at about $33 \mathrm{ka}$ with the eruptions of the Citara Formation (Rittmann 1930;
Rittmann and Gottini 1980; Vezzoli 1988; Tufi di Serrara in Sbrana and Toccaceli 2011), characterized by a trachyte-trachydesitic and basaltic-trachiandesitic composition, compared to the trachytes and phonolites of the previous period (Brown et al. 2008).

The period between 28 and $18 \mathrm{ka}$ is marked by a significant compositional variation of the erupted magmas, varying through time from shoshonite to alkali trachyte with an increase of the incompatible elements content and of the $\mathrm{Sr}$ isotopic ratio, behaviour compatible with a model that implies the arrival of new basic magma into the volcanic system, and progressive differentiation and mixing with the resident alkali-trachytic magma (Civetta et al. 1991).

The beginning of the last period of activity (10 ka BP $1302 \mathrm{AD}$ ) is marked by a dramatic decrease in the value of the $\mathrm{Sr}$ isotopic ratio interpreted as reflecting the arrival of a geochemically distinct magma into the system. Mostly trachytic and subordinately latitic magmas were erupted during that period. Chemical and isotopic variations of all the rocks and isotopic and mineralogical disequilibria of the less evolved rocks are evidence of mixing processes among magmas of different composition either in a deepest part of the magmatic system or during the ascent of the melts (Piochi et al. 1999). The available geological and petrological data (Civetta et al. 1991; Orsi et al. 1996; Piochi et al. 1999) suggest that the magmatic system of Ischia is presently composed of a deep and poorly-evolved magma reservoir, where mantle-derived magmas stagnate and differentiate, interconnected with shallower, smaller and more-evolved magma batches. During their ascent, magmas mixed and mingled, producing the wide range of observed isotopically distinct products (Piochi et al. 1999).

Several authors (D'Antonio et al. 2013; Moretti et al. 2013) agree to identify, on the basis of studies carried out on the most mafic products of the last $10 \mathrm{ka}$, a process of generation of magmas largely dominated by gas -fluxing of $\mathrm{CO}_{2}$ in a mantle modified by the effect of crustal assimilation, highlighted in the erupted products by the values of the $\delta^{18} \mathrm{O}$ (typically form mantle) and of the $\mathrm{Sr}$ isotopic ratio, which progressively increases towards typically crustal values. Recently, Casalini et al. (2017) show how anomalous Sr isotopic ratios of some samples of all periods of activity are not only compatible with crustal assimilation, but also require long periods of residence in magma chambers with times ranging from a few tens to hundreds or even thousands of years, at relatively low temperatures (approx. $750{ }^{\circ} \mathrm{C}$ ), as assessed on the basis of the contents in $\mathrm{Rb}$ and $\mathrm{Sr}$. In particular, the residence times of the estimated magmas are very variable: from about $34 \mathrm{ka}$ (for pre- $147 \mathrm{ka}$ ) to $27 \mathrm{ka}$ (for magma erupted at $38 \mathrm{ka}$ ) to $4.2 \mathrm{ka}$ (for magma erupted at $5.6 \mathrm{ka})$. 


\section{Geological and historical instability of slopes}

Along with the volcanic activity discussed in the previous subsections, slope instability also played an important role in shaping the present structure of Ischia.

Over the last $10 \mathrm{ka}$ Ischia has experienced intense slope dynamics concentrated mainly along the slopes of the resurgent block of Monte Epomeo and along the coast. At least in the past $5.5 \mathrm{ka}$, minor landslides, but also large lahars and rock- and debris-avalanches were generated in four main phases, dated between 5.5 and $2.9 \mathrm{ka}$, around $2.9 \mathrm{ka}$, between 2.6 and $2.3 \mathrm{ka}$, and between 2.3 and $1.9 \mathrm{ka}$ (de Vita et al. 2006).

Gravitational movement preceded and followed the emplacement of volcanic rocks (Tibaldi and Vezzoli 2004; de Vita et al. 2006), mainly in the $\mathrm{E}$ and S sectors of the island, testifying that slope instability conditions were induced by reactivation of vertical movements, which were also responsible for the generation of faults and fractures that fed volcanism (Della Seta et al. 2012). Furthermore, other landslide deposits contain remnants of artefacts of ancient human settlements, since the island was inhabited by communities as early as the thirteenth century BC (Buchner 1943, 1986; Buchner et al. 1996; Di Martire et al. 2012, and references therein).

Landslide phenomena responsible for deformation of rock masses and/or mobilization of material along the slopes have been grouped in two categories, mainly based on the volumes involved and, secondly, on the mechanism and type of activity (intermittent or continuous):

1. Large Rock and Debris Landslides, including two distinct mechanisms: a) collapse (rock avalanche) of entire portions of slopes already involved in continuous slow deformations of rock masses and b) mobilization of slope portions by sliding or debris avalanches. Rock mass deformation (a) develops over a long-time scale (in the order of $10^{4}-10^{5}$ years) as a result of Mass Rock Creep (MRC; Chigira 1992) and the occurrence of external forcing (earthquakes, eruptions, explosions) may only accelerate the occurrence of the failure event generating a rock avalanche. The second (b) is related only to impulsive triggers that cause the static equilibrium conditions to be overcome by the unstable masses involved. The geological evidence does not always allow a unique attribution of large rock landslides to rock avalanches (a) or debris avalanches (b) (Sbrana and Toccaceli 2011; Della Seta et al. 2012; Scott et al. 2002; McGuire 1996; Vallance and Scott 1997; Lavigne et al. 2000).

2. Impulsive shallow landslides, including: rock failures, roto/translational slides and earth/debris flows, with intermittent activity. The possible triggers can be: a) geophysical events (eruptive events, phreatic explosions, and earthquakes); b) meteorological events (rainfalls and sea storms). In this category can also be included the primary or secondary volcanoclastic debris flows (or lahars) triggered either by very long-lasting rains or by brief but very intense rainfalls.

The temporal distribution of landslides recorded in Ischia, in relation to their typology and trigger, shows how both the debris and rock avalanches are documented only before the II-III century BC (Fig. 2a).

Rock avalanches (category 1a) cover almost entirely the $\mathrm{N}$ and $\mathrm{W}$ emerged sectors of the island (Della Seta et al. 2012) as well as the off-shore, where hummocky deposits have been identified (de Alteriis and Violante 2009; Aiello 2018). The largest and likely most intense phenomenon among them is a rock avalanche detached from the W side of Monte Epomeo (Della Seta et al. 2012; Sbrana and Toccaceli 2011), with a volume estimated at $125 \times 10^{6} \mathrm{~m}^{3}$. A deep-seated gravitational slope deformation, likely related to MRC processes is also reported as affecting the Monte Nuovo (Del Prete and Mele 2006, and references therein; Della Seta et al. 2015; Marmoni et al. 2017) on the western slope of Monte Epomeo (Fig. 2a).

The Ischia Debris Avalanche (IDA) is the largest event of category $1 \mathrm{~b}$ documented for Ischia (Chiocci et al. 2001; Chiocci and de Alteriis 2006; de Alteriis and Violante 2009), covering an area of $250-300 \mathrm{~km}^{2}$, extending from the foot of the submarine escarpment $(-550 \mathrm{~m})$ to $-1100 \mathrm{~m}$, with a runout of $50 \mathrm{~km}$ ). Tibaldi and Vezzoli $(1998,2004)$ associated this event to the recurrent collapse of the $\mathrm{S}$ flank of Monte Epomeo, due to phases of acceleration of the calderic resurgence (uplift rates up to $3 \mathrm{~cm} / \mathrm{yr}$ ). However, the volume, timing and dynamics of emplacement of IDA (single event or multi-event) are still uncertain, with different interpretations provided by the different authors (Tibaldi and Vezzoli 2004; Chiocci and de Alteriis 2006; Tinti et al. 2011).

Geological and historical evidence of impulsive shallow landslides (category 2) are reported by Di Martire et al. (2012), who collected the historical record, consisting in 288 individual landslide events, of which 23 occurred between the fourth century BC and 1924 and 255 between 1970 and 2010, with a temporal registration gap between 1924 and 1970 (Del Prete and Mele 2006). The most recurrent typologies are represented by rock falls/topples, slides, flows and complex landslides (Fig. 2b) (Catenacci 1992; Del Prete and Mele 1999).

Some events were chronologically constrained by stratigraphic relations with other landslide and/or pyroclastic deposits (de Vita et al. 2006), while others were associated with the earthquakes of 1228, 1797, 1828, 


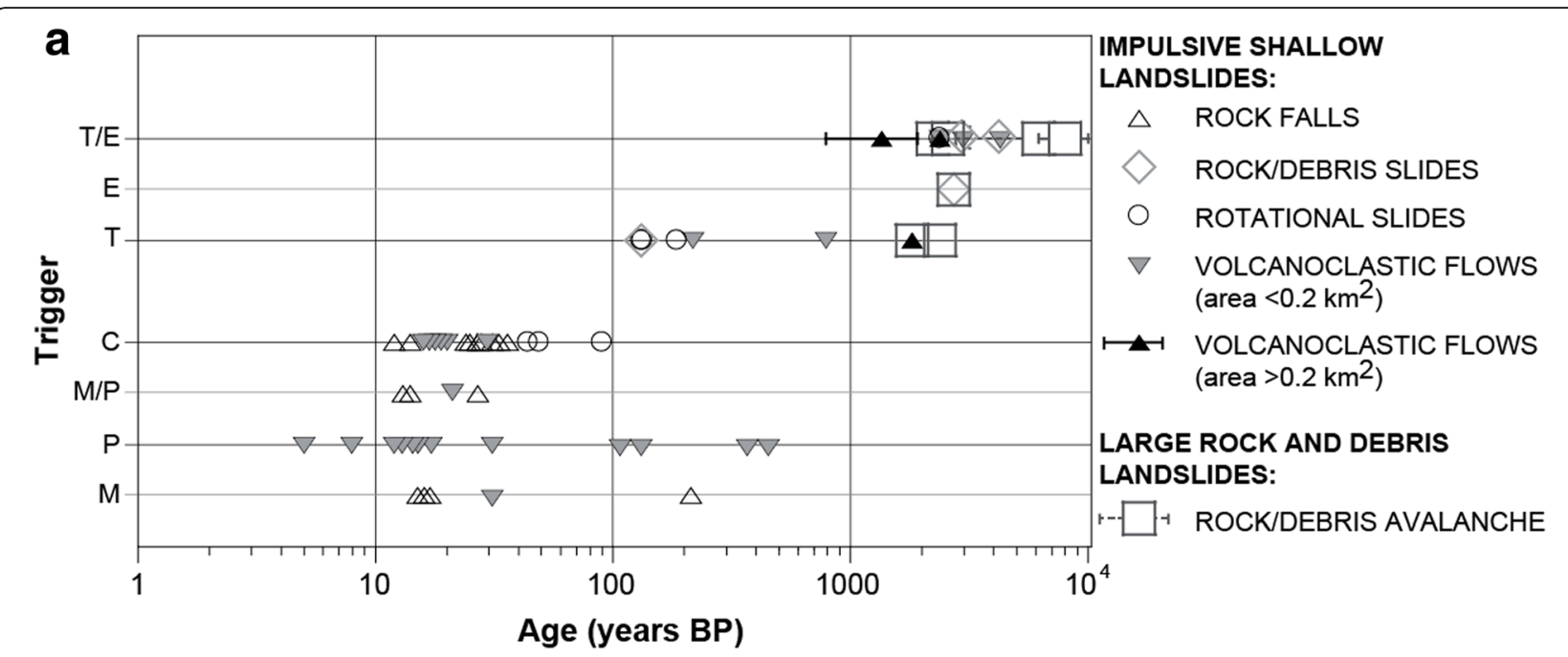

b
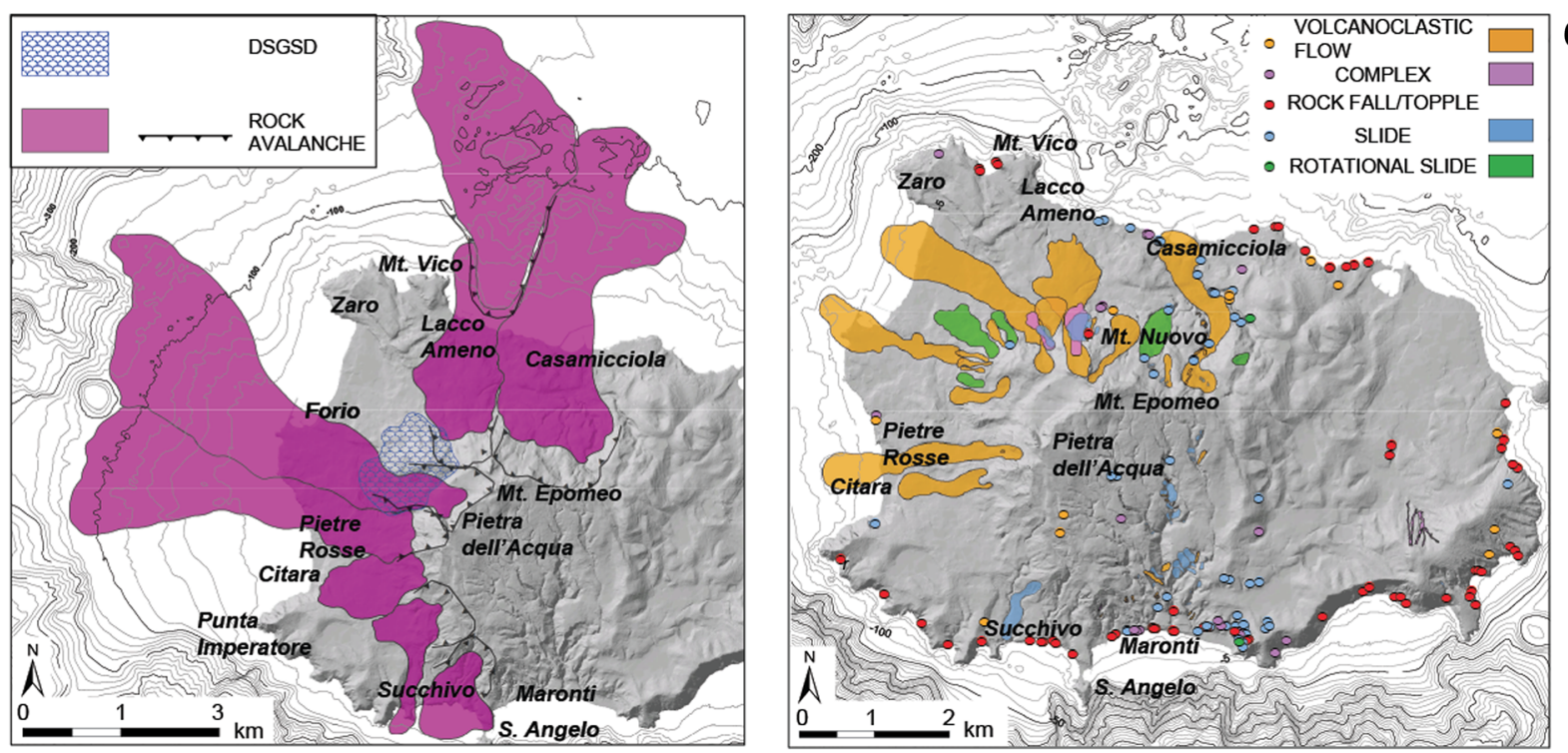

Fig. 2 Review of the evolution of slope instability, reporting: a Time distribution of the slope gravitational events for Ischia, in relation to the type and trigger (T: earthquake; $\mathbf{E}$ : eruption; C: generic meteorological-climatic event; $\mathbf{M}$ : sea storm; P: rainfall). $\mathbf{b}$ Spatial distribution of the rock avalanche deposits and of the ongoing MRC in the W sector of Monte Epomeo. (modified from Della Seta et al. 2012) c Spatial distribution of the impulsive landslides, including the debris avalanche IDA, at Ischia (modified from Di Martire et al. 2012)

1881, 1883 (Della Seta et al. 2012, and references therein). The Italian Catalogue of Earthquake-Induced Ground Failures in Italy (CEDIT - Italian Catalogue of Earthquake-Induced Ground Failures 2017; Fortunato et al. 2012; Martino et al. 2014) reports 8 effects triggered by local earthquakes in the 1828 and 1883 (Mw 4.01 and 4.26, respectively, in Catalogo Parametrico dei Terremoti Italiani 2015 - CPTI15, Rovida et al. 2016). Finally, 9 landslides consisting of rock falls and shallow earth slides have been surveyed (GdL_DST-CentroMS 2018) as triggered by the earthquake occurred on 21st August 2017, Mw3.9 (Gruppo di Lavoro INGV sul terremoto dell'isola di Ischia 2017), with epicentre close to Casamicciola and are inventoried in the CEDIT.

\section{Present state of the volcanic system of Ischia}

The structural setting of Ischia has been the object of several geophysical surveys in recent years (Berrino et al. 1998, 2008; Capuano et al. 2015; Paoletti et al. 2009, 2013; Nunziata and Rapolla 1987; Rapolla et al. 1989; Di Giuseppe et al. 2017). Moreover, the island is monitored by the Italy National Institute of Geophysics and Volcanology (INGV) through a dedicated geophysical and geochemical surveillance system. 


\section{Present structural setting of the island from geophysical surveys}

Seismic tomography and gravity data inversion contributed to the Ischia caldera rim definition (Fig. 3a) and allowed detection of a high velocity and density area inside the caldera, consistent with Monte Epomeo resurgent block geometry (Fig. 3b; Capuano et al. 2015). These results fit well with the analysis and interpretation of magnetic and self-potential data (Fig. 3c,d), which show that the island central-W sector, corresponding approximately to Monte Epomeo, is characterized by a minimum in the magnetization values and a maximum in the positive electric charge occurrence (Paoletti et al. $2009,2013)$. This outcome suggests the presence of an igneous-very likely trachytic-structure, whose top is located at $1200-1750 \mathrm{~m}$ b.s.l., which seems to be demagnetized in its central portion, very likely in connection with the high geothermal gradient measured in the central-W sector of the island (Paoletti et al. 2009).

In order to reach a better definition of volcanotectonic processes affecting the caldera of Ischia, a magnetotelluric survey was carried out in 2016 along two main profiles (deployed in a N-S and a WSW- ENE direction, respectively) through the central-W sector, obtaining an electrical resistivity map to a depth of $3 \mathrm{~km}$ (Di Giuseppe et al. 2017). The resistivity cross sections (Fig. 3e,f) identify the presence of a very shallow magmatic intrusion at a depth of about $1 \mathrm{~km}$, which is probably connected to both the resurgence and volcanic activity. Furthermore, the tectonic structures bordering the resurgent block and the occurrence of a large thermal anomaly in the W sector of the caldera also creates an anomaly in the resistivity cross sections (Di Giuseppe et al. 2017).

\section{Active ground deformation field}

The INGV-OV manages a ground deformation monitoring system of the Ischia Island (Fig. 4a) with the integration of continuous (cGPS and tiltmetric networks) and episodic (Levelling, GPS and gravimetric networks) measurements (Sepe et al. 2007; Del Gaudio et al. 2011; De Martino et al. 2011). Furthermore, several studies based on the DInSAR measurements are available (Manzo et al. 2006; Vilardo et al. 2009; Castaldo et al. 2017).

All the measurements at Ischia Island in the last 30 years (levelling since 1987, GPS since 1998 and SAR since 1992) show a general vertical subsidence with velocities between 1 and $5 \mathrm{~mm} / \mathrm{yr}$. (Fig. 4e, f), with higher values (up to about $1 \mathrm{~cm} / \mathrm{yr}$ ) in the $S$ and central-W sectors (Del Gaudio et al. 2011; De Martino et al. 2011; Manzo et al. 2006; Castaldo et al. 2017). This is also confirmed by the EPOM GPS station, located on top of the Monte Epomeo, which shows a vertical subsidence velocity of about $-9 \mathrm{~mm}$ /year in the period 1998-2010 (De
Martino et al. 2011). Two main zones, located in the NW and Monte Epomeo sectors (Fig. 4c,d), are characterised by maximum values of subsidence velocity of about $1 \mathrm{~cm} / \mathrm{yr}$. (Fig. $4 \mathrm{~g}, \mathrm{~h}, \mathrm{i}$ ). The continuous tiltmetric borehole network of Ischia island (Ricco et al. 2018) shows a predominant NNW tilting direction in 20152017 time span (Fig. 4b), which is consistent with the general subsidence trend of the island (Ricco et al. 2017).

The GPS and DInSAR measurements highlight a complex horizontal displacement field with a different trend in the eastern sector of the island with respect to the central-west one (Fig. 4c,d; De Martino et al. 2011; Manzo et al. 2006; Castaldo et al. 2017).

Ischia ground deformation pattern cannot be explained by a typical volcanic source (e.g., a Mogi model). Some authors attributed the subsidence detected by levelling measurements (Fig. 4h,i) to crack closure processes along two main ENE-WSW and E-W preexisting faults, which represent the preferred $\mathrm{CO}_{2}$ degassing pathway of the hydrothermal system beneath Monte Epomeo (Sepe et al. 2007). More recently, Castaldo et al. (2017) developed a model of Ischia DInSAR measurements for the period 1992-2010 explained by the coupling effects of crust rheology and the gravitational loading of the volcano.

\section{Historical and instrumental seismicity}

Historical seismicity of the island has been studied by several authors (Luongo et al. 1987, 1998; Cubellis and Luongo 1998; Cubellis et al. 2004; Luongo et al. 2006; Cubellis and Marturano 2009; Carlino et al. 2010; Rovida et al. 2016; Luongo and Cubellis 2018). Macroseismic observations show that historical earthquakes are mainly located in the NW sector of the island (Fig. 5a), characterized by shallow hypocentral depths (1-2 km), high intensities rapidly decreasing with distance and local amplification of damage (Carlino et al. 2010). In particular the catastrophic event of 1883 (Imax =XI degree MCS) impacted and damaged an area of about $3 \mathrm{~km}^{2}$ in the $\mathrm{N}$ sector of the island, with an inferred magnitude between 4.3 and 5.2 (Cubellis and Luongo 1998). A subvertical fault (about $2 \mathrm{~km}$ length) with E-W or ENEWSW strike was proposed as the source of the 1883 earthquake (Cubellis and Luongo 1998; Carlino et al. 2010).

After the 1883 event, a time period is characterized by a lack of major events. Since the installation of a modern seismic network by INGV-OV, only few low magnitude $(\mathrm{Md} \leq 2.3)$ seismic events have been recorded. These events were mainly located in the $\mathrm{N}$ sector of the island and at shallow depths $(0-2 \mathrm{~km})$, in the same area affected by the historical seismicity (Fig. 5a; D'Auria et al. 2018). 
a
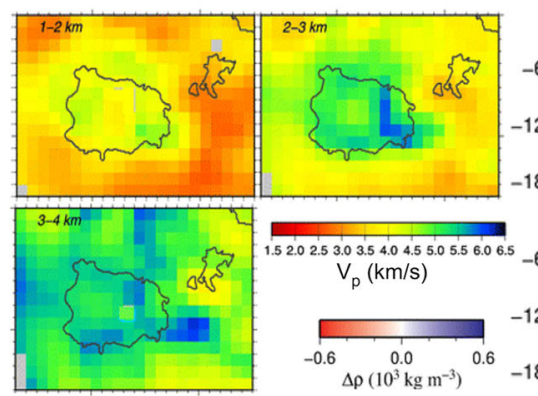

C
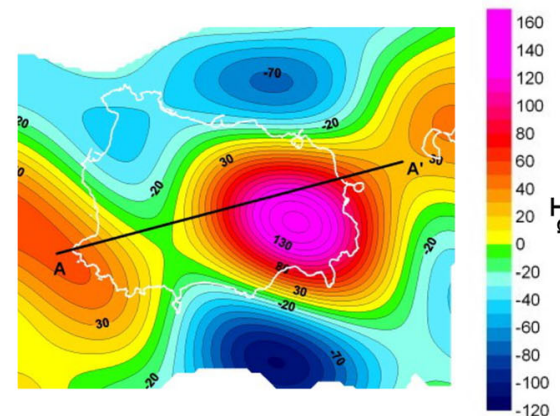

e

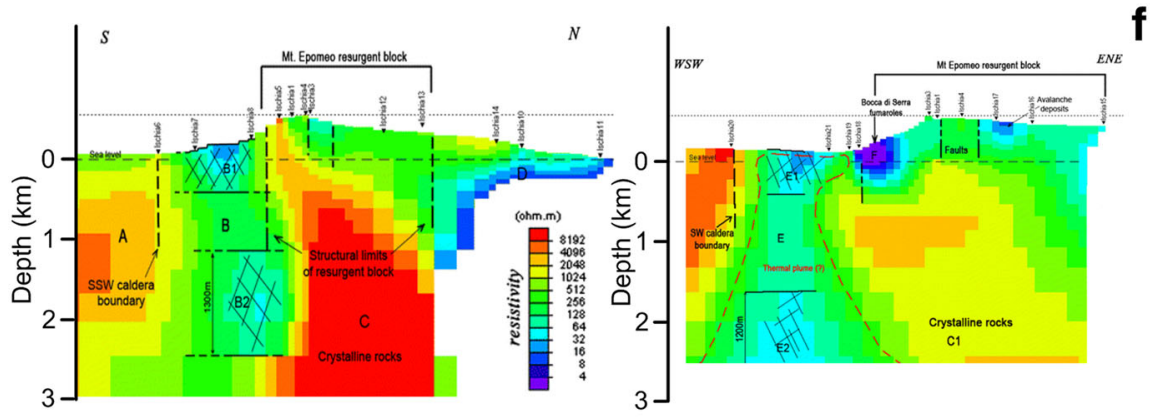

g
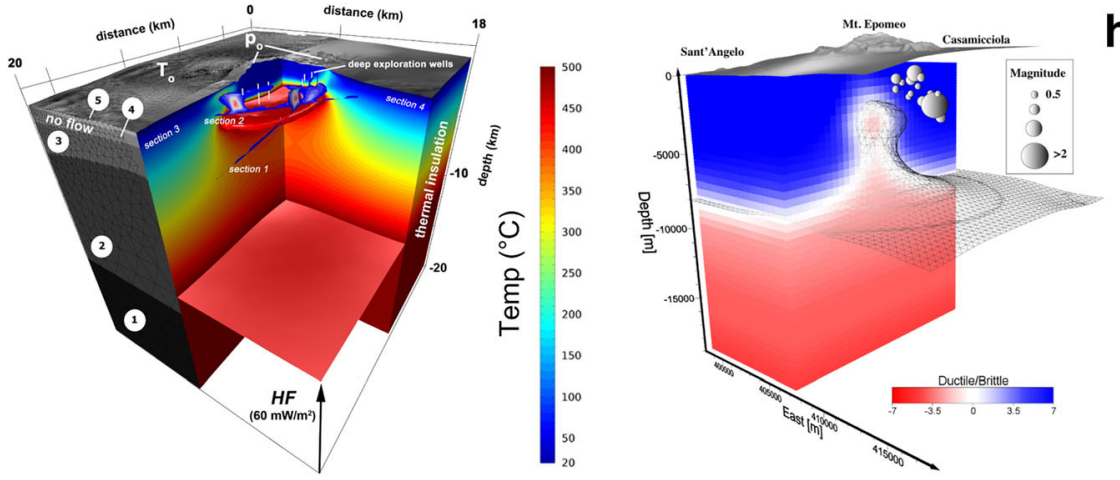

d

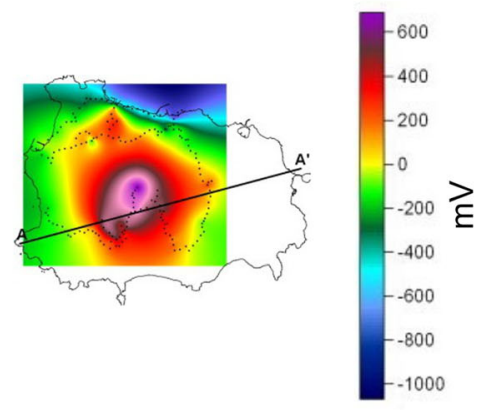

h

Fig. 3 Review of the geophysical knowledge, reporting: a Slices of 3D P-wave velocity model in the depth interval 1-4 km b.s.l. High-velocity value along the coast indicates the presence of caldera rim. $\mathbf{b}$ Slices of 3D density contrast model in the depth interval $0.3 \mathrm{~km}$ a.s..$-1.8 \mathrm{~km}$ b.s.l. High density contrasts are visible along the coast and in correspondence of Monte Epomeo (modified from Capuano et al. 2015). c Magnetic field of Ischia island obtained after pole-reduction and filtering; d Self Potential anomaly map of Ischia Island (modified from Paoletti et al. 2009). e S-N resistivity profile obtained from the inversion of the MTsurvey. Dotted lines are the faults associated with the caldera boundary and to the dislocation of the resurgent block; $\mathbf{f}$ WSWENE resistivity profile obtained from the inversion of the MT survey. The resistivity anomalies (marked as E, E1, and E2) are coincident with a thermal plume (modified from Di Giuseppe et al. 2017); $\mathbf{g}$ 3D thermal model by exploiting the thermal measurements available in literature; $\mathbf{h}$ 3D rheological model. The grey wireframe isosurface represents the B/D transition (modified from Castaldo et al. 2017) 
a

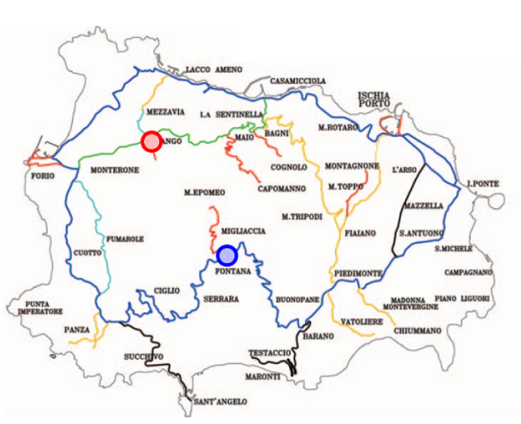

C

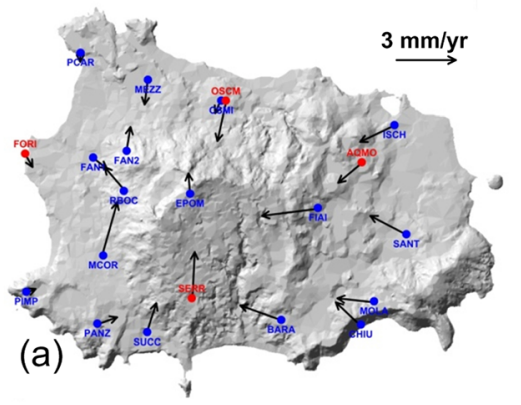

e

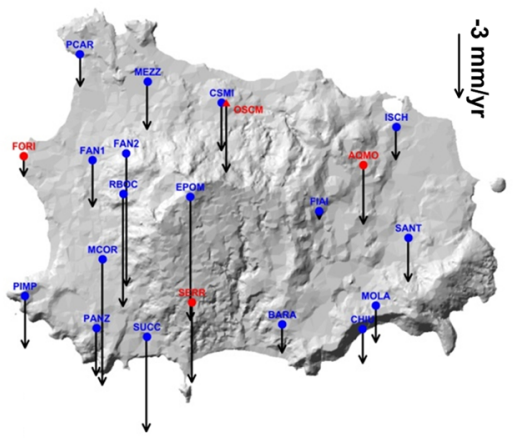

g
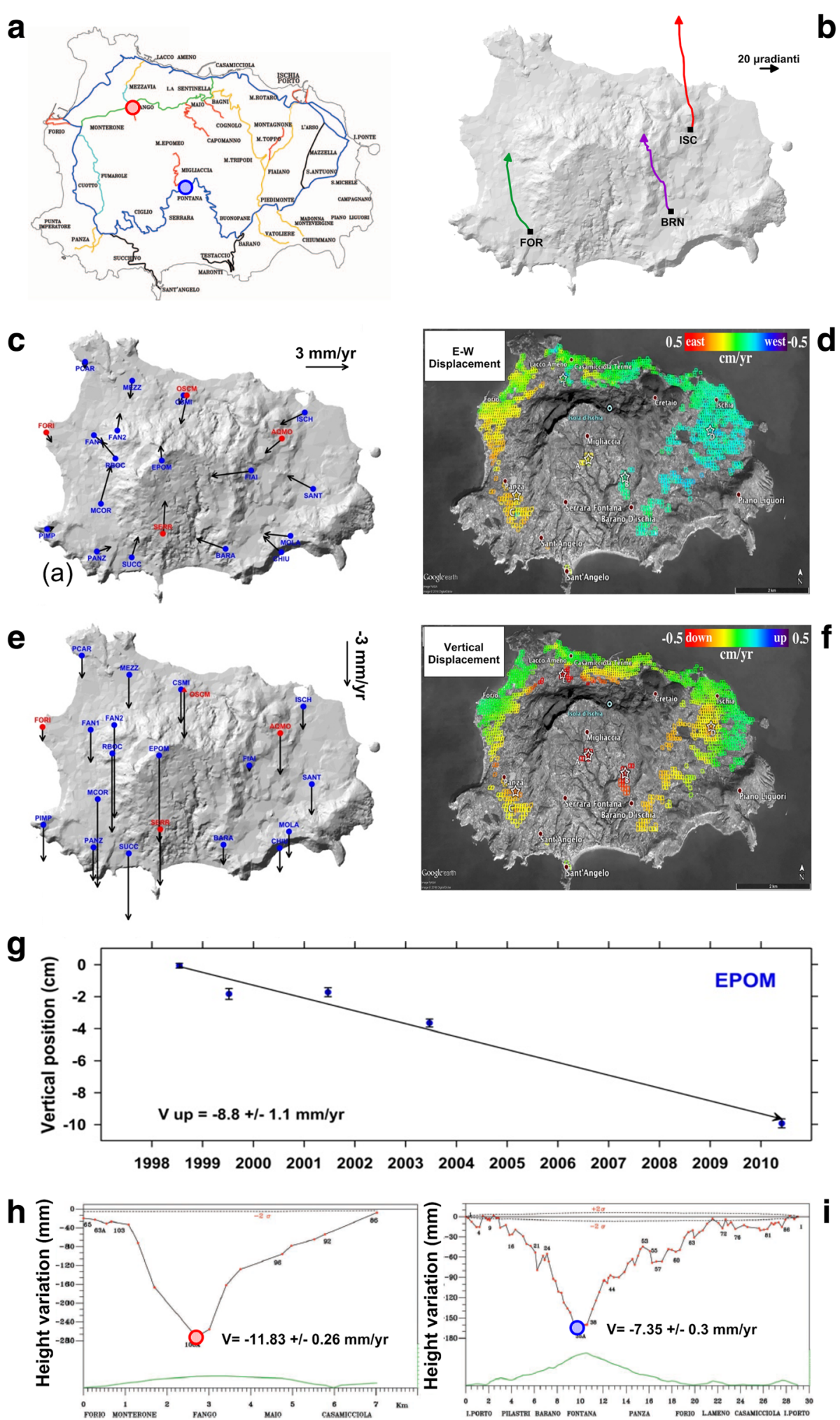

and

Fig. 4 (See legend on next page.)

\section{b}


(See figure on previous page.)

Fig. 4 Review of the ground deformation pattern, reporting: a Map of the Ischia geodetic monitoring system. $\mathbf{b}$ Cumulative Tilt recorded from the continuous titmetric network in 2015-2017 time span (modified from Ricco et al. 2017). Horizontal ground deformation pattern from c horizontal GPS velocity field in the time span 1998-2013 (modified from De Martino et al. 2011) and d mean deformation East-West velocity map from DInSAR measurements 1992-2010 (modified from Castaldo et al. 2017). General subsidence (e) from vertical GPS velocity field in the time span 1998-2013 (modified from De Martino et al. 2011); f from vertical deformation velocity map from DInSAR measurements 1992-2010 (modified from Castaldo et al. 2017); $\mathbf{g}$ from vertical GPS time series of EPOM station, located on the top of Monte Epomeo, in the time span 1998-2010 (modified from De Martino et al. 2011); h-i from vertical displacements recorded from the levelling network (in the NW and Monte Epomeo sectors, respectively) in the time span 1987-2010 (modified from Del Gaudio et al. 2011)

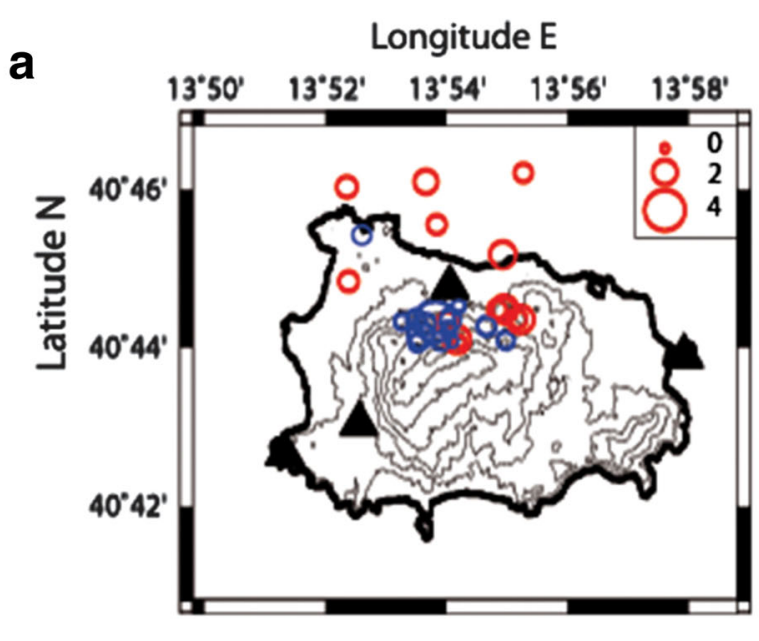

\section{Depth $(\mathbf{k m})$ \\ $\begin{array}{llllll}-1 & 0 & 1 & 2 & 3 & 4\end{array}$}

b
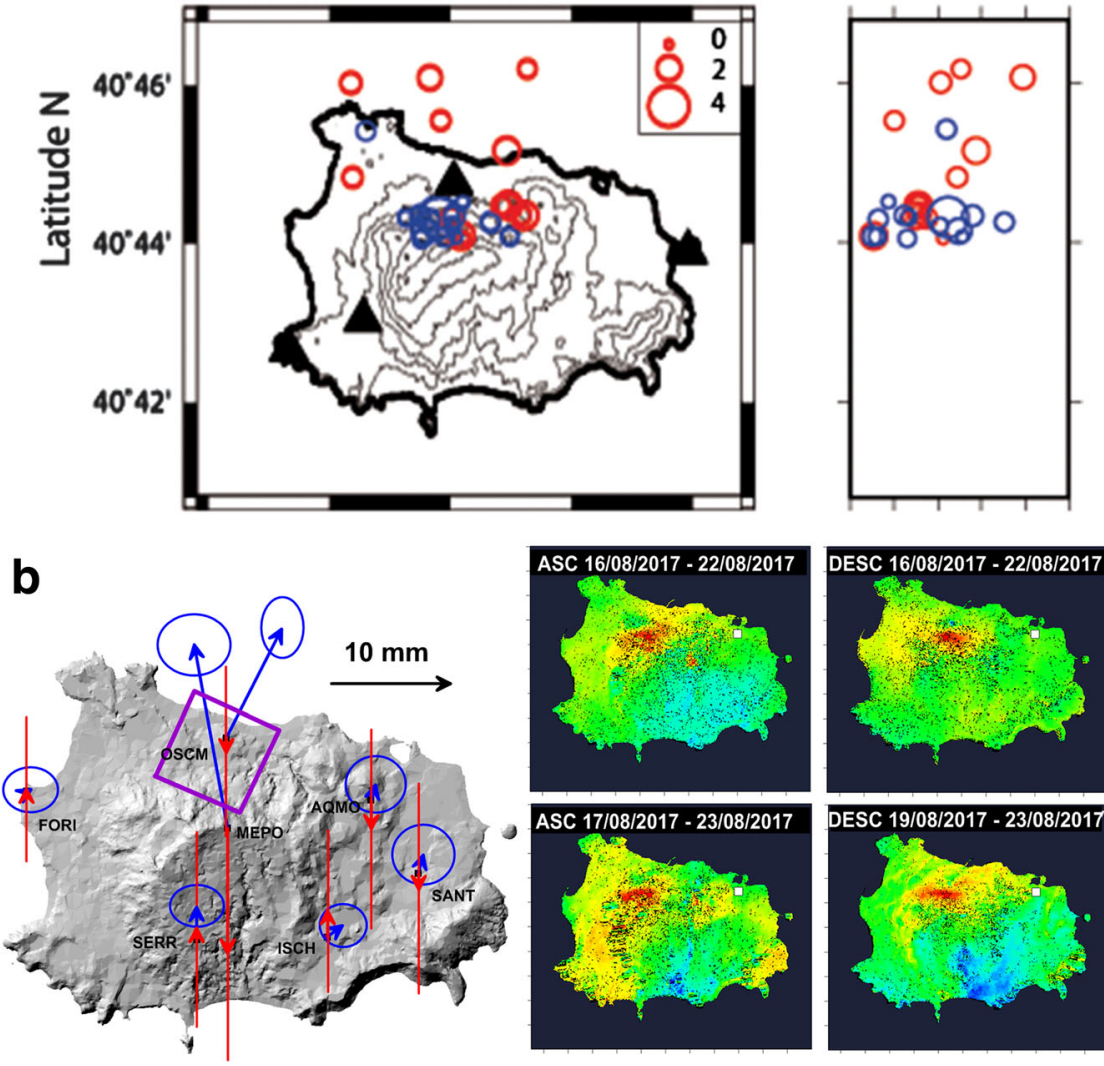

C
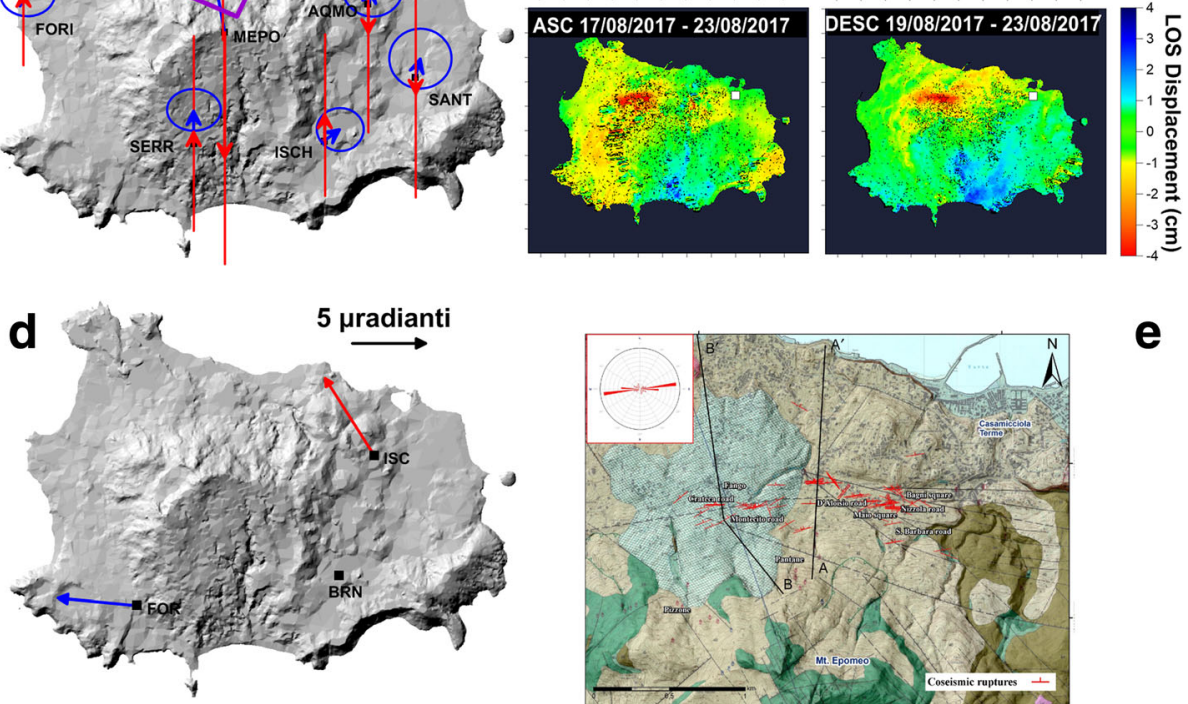

$\mathbf{e}$

Fig. 5 Review of the observed seismicity and coseismic ground effects, reporting: a I.c. earthquake hypocenters recorded between 1999 and 20 August 2017 (red circles) and after 20 August 2017 (blue circles) on a map and along a N-S cross section (modified from D'Auria et al. 2018); b coseismic displacement following the 21st August 2017 (Mw 3.9) event detected through from GPS (modified from Devoti et al. 2018), c from DInSAR (modified from De Novellis et al. 2018), and $\mathbf{d}$ tilt (modified from Ricco et al. 2017) measurements; e map of the coseismic ruptures in the Casamicciola area (modified from Nappi et al. 2018) 
The strongest seismic event instrumentally recorded occurred on 21st August 2017 (Mw 3.9 - Md 4.0, Gruppo di Lavoro INGV sul terremoto dell'isola di Ischia 2017) and was followed by a seismic sequence of almost 20 recorded earthquakes, with significantly lower magnitude (Fig. 5a). The damage level and its distribution (Gruppo di Lavoro INGV sul terremoto dell'isola di Ischia 2017; Azzaro et al. 2017) agree with the historical observations of low magnitude-high intensity events (Carlino et al. 2010). The most relevant damages affected a narrow area of Casamicciola Terme (Azzaro et al. 2017) that shows different fractures on both ground, infrastructure, on roads, and on terrain. Widespread sliding phenomena of drywalls were also observed, as well as modest gravitational phenomena and small landslides in volcanoclastic deposits (see Subsection Geological and historical instability of slopes). The observed coseismic effects cover a total length of about $2 \mathrm{~km}$ between the Fango (Lacco Ameno), to the West, and Bagni (Casamicciola), to the East, for a total area of $2.5 \mathrm{~km}^{2}$. The fracture directions range from WNW-ESE to E-W and WSW-ENE with lengths up to some tens of meters (Nappi et al. 2018).

Ground displacements caused by the earthquake were detected using DInSAR, GPS and tilt measurements. Following the main seismic event, two stations of the Ischia cGPS network showed a coseismic deformation (Fig. 5b). The cGPS station on Monte Epomeo (MEPO) shows a displacement of about $1.5 \mathrm{~cm}$ in NNW direction and the cGPS station of Casamicciola Terme (OSCM) moved about $1 \mathrm{~cm}$ toward NNE. Only at MEPO station a slight subsidence of about $1 \mathrm{~cm}$ is observed (De Novellis et al. 2018; Devoti et al. 2018). The DInSAR measurements show a localized ( $1 \mathrm{~km}^{2}$ ) subsidence up to $4 \mathrm{~cm}$ in an area $S$ of Casamicciola Terme (Fig. 5c). The shape of the displacement pattern shows an E-W alignment, which is in good agreement with aftershocks epicentres distribution in Fig. 5c (De Novellis et al. 2018). Also two tiltmetric stations recorded a coseismic tilt (Fig. 5d; Ricco et al. 2017).

With a multiparametric approach (seismic, GPS and DInSAR measurements), the seismogenetic source can be described as an E-W striking, S-dipping normal fault, with its centre located at a depth of $800 \mathrm{~m}$, consistent with the rheology of the crustal local structure (De Novellis et al. 2018). Very recently, Braun et al. (2018) and Calderoni et al. (2019) proposed more complex rupture processes, with a normal faulting displacement accompanied by underground phenomena, also potentially connected to the hydrothermal system.

\section{Present geothermal system}

The presence of a hydrothermal system characterized by energetic circulation underneath Ischia is demonstrated by the numerous surface manifestations, including fumaroles, thermal waters, steaming grounds and mud pools (Fig. 6a).

Approximately one hundred exploration wells were drilled in 1939-1954, in the W and S sectors of the island, by the SAFEN (Società Anonima Forze Endogene Napoletane). Data produced during this exploration (Ippolito 1942; Penta 1949, 1954; Penta and Conforto 1951) provide the only direct observation of the subsurface hydrothermal setting. Apart from drillings, the chemical and isotopic features of Ischia groundwaters and fumaroles have contributed to the understanding of the current hydrothermal setting of the volcano also providing information on the otherwise inaccessible present-day deep magmatic system, which is likely to act as a source of fluids feeding the hydrothermal system.

The isotopic signatures of $\mathrm{He}$ and in $\mathrm{CO}_{2}$, in both fumaroles and dissolved gases in groundwaters, suggest that the Ischia hydrothermal system is fed by a $\mathrm{CO}_{2}$-rich gas phase of deep, possibly magmatic origin (Tedesco 1996; Di Napoli et al. 2009). This deep gas component has isotopic composition similar to that of the fluids discharged at the nearby Campi Flegrei and Vesuvius volcanic systems, even if is typically characterized by lower crustal fluids contamination and higher mantle affinity than the others Campanian volcanoes.

The chemistry of Ischia groundwaters has been investigated during the last 30 years by several authors (De Gennaro et al. 1984; Panichi et al. 1992; Caliro et al. 1999; Inguaggiato et al. 2000; Aiuppa et al. 2006; Di Napoli et al. 2009, 2011, 2013). According to these studies, both cold $\left(\sim 15^{\circ} \mathrm{C}\right)$ and very hot $\left(\sim 90^{\circ} \mathrm{C}\right)$ waters coexist at Ischia (Fig. 6a). The waters with higher discharge temperatures mostly circulate in the $\mathrm{N}$ and SW sectors of the island, while the water discharged in the eastern sector show lower temperature $\left(<50{ }^{\circ} \mathrm{C}\right)$.

The cold groundwaters emerging as springs along the flanks of Monte Epomeo are typically of calciumbicarbonate nature (Fig. 6b); they are characterized by low salinities (Total Dissolved Solid - TDS $<1000 \mathrm{mg} / \mathrm{l}$ ), and low $\mathrm{Cl}(<1000 \mathrm{mg} / \mathrm{l})$ and $\mathrm{Mg}(<20 \mathrm{mg} / \mathrm{l})$ contents. The isotopic data $\left(\delta^{18} \mathrm{O}_{\mathrm{H} 2 \mathrm{O}}\right.$ from -6 to $-7 \%$; De Gennaro et al. 1984; Panichi et al. 1992; Caliro et al. 1999; Inguaggiato et al. 2000; Di Napoli et al. 2009, 2011) suggest that these diluted cold samples are representative of infiltrating meteoric waters (meteoric-derived groundwaters in Fig. 6b). Furthermore, cold groundwaters also discharge along the sea-shores of Ischia (Fig. 6a), but display distinct alkali-chloride chemical composition. In view of their high TDS $(\sim 39,000 \mathrm{mg} / \mathrm{l})$, chlorine $(\sim 21$, $000 \mathrm{mg} / \mathrm{l})$ and $\mathrm{Mg}(\sim 1,400 \mathrm{mg} / \mathrm{l})$ concentrations, and $\sim$ 0\% (referred to the SMOW, Vienna Standard Mean Ocean Waters) isotopic signature for both $\delta^{18} \mathrm{O}$ and $\delta \mathrm{D}$, these water samples (seawater-derived groundwaters in Fig. 6b) reflect extensive seawater intrusion into the 


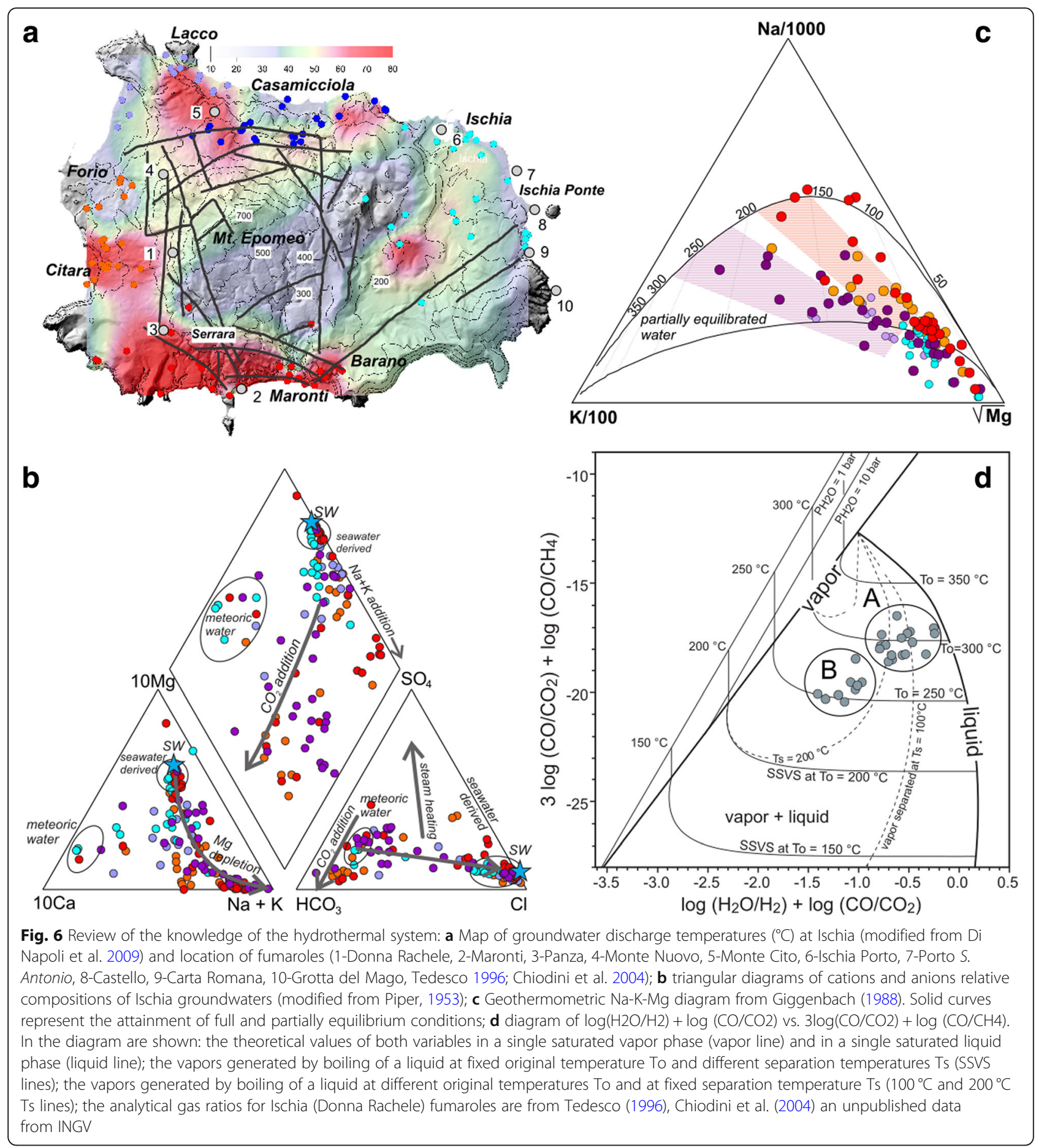

Ischia shallow aquifers (De Gennaro et al. 1984; Panichi et al. 1992; Caliro et al. 1999; Inguaggiato et al. 2000; Aiuppa et al. 2006; Di Napoli et al. 2009, 2011, 2013).

Thermal waters show variable physicochemical compositions from low salinity $(1,000<$ TDS $<4,000 \mathrm{mg} / \mathrm{l})$ $\mathrm{Ca}-\mathrm{HCO}_{3}$-compositions to high TDS (up to $39,000 \mathrm{mg} / \mathrm{l}$ ) $\mathrm{Na}-\mathrm{K}-\mathrm{Cl}$-compositions, which in general can be ascribed to mixing between meteoric water and seawater modified by the high temperature water-rock interaction occurring during hydrothermal circulation (Panichi et al. 1992; Caliro et al. 1999; Inguaggiato et al. 2000; Aiuppa et al. 2006; Di Napoli et al. 2009, 2011, 2013), supported by the heavy depletion in $\mathrm{Mg}$ and the enrichment in alkalis with respect to the meteoric-seawater mixing line. The thermal regime of the deep hydrothermal reservoirs has been investigated by a number of authors (Panichi et 
al. 1992; Inguaggiato et al. 2000; Di Napoli et al. 2009) by using $\mathrm{Na} / \mathrm{K}$ and $\mathrm{K} / \mathrm{Mg}$ solute geothermometers (Giggenbach 1988). In Fig. 6c, cold Mg-rich immature waters plot far from water-rock equilibrium conditions; these fluids have therefore compositions indicative of shallow groundwater conditions. In contrast, warm and hot thermal waters, overall describe a trend of progressive $\mathrm{Mg}$ depletion that is typical of mature fluids (Giggenbach 1988), having attained partial to full equilibrium conditions with reservoir rocks at temperatures of $150-180^{\circ} \mathrm{C}$ for the groundwaters of $\mathrm{S}$ and $\mathrm{W}$ sectors and 220 $280^{\circ} \mathrm{C}$ for thermal waters of the $\mathrm{N}$ sector (Panichi et al. 1992; Inguaggiato et al. 2000; Di Napoli et al. 2009).

Fumaroles and gas emissions are also numerous at Ischia (Fig. 6a) and their chemical and isotopic properties have been studied in the last few decades by several authors (Panichi et al. 1992; Tedesco 1996; Inguaggiato et al. 2000; Chiodini et al. 2004). Gas equilibria have been applied to Donna Rachele fumaroles (Fig. 6d), located in the NW slope of Monte Epomeo and for which the most complete chemical and isotopic dataset is available (Tedesco 1996; Chiodini et al. 2004, INGV unpublished data). According to the approach proposed by Chiodini and Marini (1998), Donna Rachele fumaroles have been classified by using the relative proportions of $\mathrm{CO}_{2}, \mathrm{CO}$, $\mathrm{CH}_{4}, \mathrm{H}_{2}$ and $\mathrm{H}_{2} \mathrm{O}$ (expressed as sums of log-ratios $\log$ $\left(\mathrm{H}_{2} \mathrm{O} / \mathrm{H}_{2}\right)+\log \left(\mathrm{CO} / \mathrm{CO}_{2}\right)$ and $3 \log \left(\mathrm{CO} / \mathrm{CO}_{2}\right)+\log$ $\left(\mathrm{CO} / \mathrm{CH}_{4}\right)$, that are controlled by two independent variables (i.e., temperature and either water fugacity or the fraction of separated vapour, Fig. 6d) and which are independent from redox potential (Chiodini et al. 2004). In Fig. 6d, most of the samples form two clusters: group A plots near the composition of the liquid phase, close to an original temperature To of $\sim 300^{\circ} \mathrm{C}$, and to a boiling temperature Ts of $100-200{ }^{\circ} \mathrm{C}$; group $\mathrm{B}$ plots at lower temperature To $\sim 250$ and $\mathrm{Ts}>200^{\circ} \mathrm{C}$ (Chiodini et al. 2004). It is worth noting that end-member A composition is close to that of the theoretical liquid phase, suggesting that, at depth, the vapour phase represents a large fraction of the bi-phase system due to a very energetic boiling of the hydrothermal liquid. Theoretically, the pure liquid composition is reached by the vapour phase only when a complete vaporization of the liquid occurs (Chiodini et al. 2004).

Overall, the geochemical investigations have led to general consensus for the existence at Ischia of two distinct geothermal reservoirs, at temperatures of 150$180^{\circ} \mathrm{C}$ (Panichi et al. 1992; Di Napoli et al. 2009) and $220-280^{\circ} \mathrm{C}$, respectively (Panichi et al. 1992; Inguaggiato et al. 2000; Di Napoli et al. 2009). The former, shallower (150-300 m of depth) and colder, is thought to be recharged by either meteoric (to the south; hydrothermal end-member $\mathrm{B}$ ) or marine (to the west; hydrothermal end-member C) fluids. The hotter $\left(220-280^{\circ} \mathrm{C}\right)$ and deeper $(\sim 1,000 \mathrm{~m})$ reservoir would instead reflect a mainly recharge by meteoric water (hydrothermal endmember A; Di Napoli et al. 2009). Energetic boiling of this high temperature aquifer would be the source of the Donna Rachele fumaroles (Chiodini et al. 2004), for which, similar high temperatures have been suggested by gas equilibria. It is worth noting that the stable isotopes of the fumarolic steam condensates leave little or no doubt about a mainly meteoric origin for the water involved in the deep hydrothermal system.

Since 2003, the geochemical monitoring of thermal water and fumarolic gases is carried out by the INGV. Observations of the data acquired in the last ten years in the framework of the geochemical monitoring have not revealed any significant variations in the chemical and isotopic composition of water and gas, neither related to the earthquake of 21st August nor clearly attributable to a massive input of magmatic fluids in the hydrothermal system (INGV-ScientRep-IISem 2017).

\section{Reference period, states of the volcano and their characterization}

The definition of the present state of Ischia volcano should be grounded in the analysis of its past and present eruptive behaviour. As we mentioned above, the last $10 \mathrm{ka}$ of volcanic activity can be differentiated with respect to the previous period based on the following distinct characteristics:

- The total number of recorded eruptions in the last $10 \mathrm{ka}$ is significantly larger (47) than the previous period. For example, in the preceding $8 \mathrm{ka}$, there are only 2 known eruptions (but with uncertain age attribution); while it is possible that some of the older eruption deposits may have been covered, we believe that the preservation of the deposits and amount of available outcrops warrant an objective increase of the eruption rates starting at $10 \mathrm{ka}$ (de Vita et al. 2010).

- The magma chemistry shows a change with respect to the preceding periods, with a change of isotopic signatures (Civetta et al. 1991; Casalini et al. 2017).

- The record of Holocene large landslides and debris avalanches from Monte Epomeo and the localization of the eruptive centres at the border of the resurgent block, suggest that the process of resurgence, although not well constrained in absolute values, was contemporaneous with volcanic activity (e.g., Tibaldi and Vezzoli 2004; de Vita et al. 2006; Della Seta et al. 2012).

Based on the above considerations, we believe that the last $10 \mathrm{ka}$ of volcanic activity can be taken as the reference for the current state of the volcano and its 
associated hazards, at least for the analysis of ordinary mean annual frequencies $\left(>10^{-4}-10^{-5}\right.$ /year; e.g., Connor 2011). Noteworthy, for most of the hazards (e.g., most of the ones not connected to eruptions) this implies that all known events should be considered, given that observations older than $10 \mathrm{ka}$ are rare.

\section{Quiescence}

At present Ischia is quiescent. As discussed in Subsections Present state of the volcanic system of Ischia, this state is mainly characterized by hydrothermal activity and a slow subsidence. The current ground deformation monitoring data indicate a generalized subsidence at a rate of 3-10 $\mathrm{mm}$ /year. Seismicity is characterized by very low rates $(<$ 10 events per year with $M>1.0)$, with sporadic intermediate-energy and very shallow $(<2 \mathrm{~km})$ earthquakes causing locally strong accelerations. However, both the occurrence of seismicity and the high enthalpy of the geothermal system suggest that the system is metastable.

\section{Unrest}

The absence of information about potential past unrest episodes does not allow any characterization of the potential state of unrest. Therefore, we cannot define a scenario for the expected changes of monitoring parameters from the present state to a state of volcanic unrest, unless considering worldwide analogs (e.g., based on existing databases like Venezky and Newhall 2007). Here, it is important to underline that some of the common expected signs of minor unrest, such as ground uplift, seismicity and geochemical variations of fluids, may occur during both a magmatic volcanic unrest and an unrest of the geothermal system (i.e. with no movement of magma toward the surface; see Newhall and Hoblitt 2002). This is a matter of large debates, for example at Campi Flegrei caldera (see, e.g., Selva et al. 2012a; D'Auria et al. 2015; and reference therein). However, in both cases, a series of hazardous phenomena may occur, as specifically discussed in Section STEP 2: the natural hazards of Ischia.

\section{Eruption}

The eruption state can be characterized by analysing the available information on the eruptions within the reference period. In the last $10 \mathrm{ka}$, volcanism has developed mostly in the eastern sector of the caldera floor as a monogenetic field with scattered (though rather close to each other) vents and relatively similar erupted volumes for each eruption roughly $10^{-2}-10^{-1} \mathrm{~km}^{3}$.

The Holocene eruptions at Ischia have not yet been further quantified in terms of magnitude and intensity, so, in the absence of more details, we classify the eruptions in two main and simple categories: effusive and explosive. Inside these simple categories, we further define: i) lava domes, ii) lava flows for the effusive, and iii) magmatic, iv) phreatomagmatic, and v) mixed for the explosive eruptions.

In Table 1 we report the catalogue of known eruptions and eruption phases, categorizing each event into the 5 classes defined above. For each class, we identified the events that, at the present state of knowledge, seem to define the variability range in each class, highlighting in green and red the smallest and largest event, respectively. In Fig. 7, we summarize the information of Table 1 by reporting the total number of eruptions subdivided in categories and the observed frequencies in the past for 2 periods (last $10 \mathrm{ka}$ and last $3 \mathrm{ka}$ ), thanks to the availability of rather precise age determinations for a significant number of those eruptions. The shorter time interval (of $3 \mathrm{ka}$ ) is selected since, within the reference period of 10 $\mathrm{ka}$, we observe a further notable change in average eruption rate that occurred at around $3 \mathrm{ka}$, after which we can count 34 eruptions until the last occurred in $1302 \mathrm{AD}$.

From Fig. 7a, we can see that the mean annual frequency of eruption (of any type) in the last $10 \mathrm{ka}$ is $4.7 \times 10^{-3} /$ year that is about 1 every 500 years in average. In the last $3 \mathrm{ka}$ the mean annual frequency is significantly higher, reaching $1.1 \times 10^{-2}$ year, i.e. about 1 every 100 years. This increase does not seem to be caused by a more complete record in recent times, but rather by a real change in the annual rate.

From the relative frequency of the different typologies, reported in Fig. $7 \mathrm{~b}$, we also notice that eruptions are subdivided almost equally between the various eruption styles, making them probabilistically indistinguishable.

The outcome of this analysis is that Ischia is indeed an active volcano with a significant eruption frequency during the Holocene, and we have no reason to consider the present state within a different framework. However, we also note that the rather high frequency of eruptions during the last $3 \mathrm{ka}$ (on average, one every 100 years) does not match the quiescence period that has existed since the last eruption occurred in $1302 \mathrm{AD}$; indeed the time from this eruption represents by far the longest inter-event time. Assuming a Poisson process with the observed mean annual rate, the probability to have no eruptions in more than 700 years is very low $(<0.001)$. This very low probability may indicate that a homogenous Poisson is not sufficient to describe the temporal distribution of eruptions at Ischia (Zaccarelli et al. 2018), and the Arso eruption may have ended a longlasting cluster of eruptions (a period of higher activity lasting on the order of centuries, as found for the near Campi Flegrei by Bevilacqua et al. 2016). This seems in agreement with the general subsidence trend characterizing the last tens of years (Subsection Active ground deformation field). However, the period of available 
Table 1 Catalogue of known stratigraphic units, categorizing each event into the 5 eruption typologies defined in Subsection Present state of the volcanic system of Ischia of STEP 1. The colour codes identify with red/green the deposits corresponding to the largest/smallest event for each typology

\begin{tabular}{|c|c|c|c|c|c|c|}
\hline \multirow[t]{2}{*}{ Lithostratigrafic Units } & \multirow[t]{2}{*}{ Age } & \multicolumn{2}{|c|}{ Effusive } & \multicolumn{3}{|c|}{ Explosive } \\
\hline & & $\begin{array}{l}\text { Lava } \\
\text { flows }\end{array}$ & Domes & Magmatic & $\begin{array}{c}\text { Phreato- } \\
\text { magmatic }\end{array}$ & Mixed \\
\hline Arso Lavas and Tephra & $1302 \mathrm{AD}$ & $x$ & & $\mathrm{x}$ & & \\
\hline Fondo Bosso Tephra & $1301 \mathrm{AD}$ & & & $\mathrm{x}$ & & \\
\hline Pietra Vono & Ca. 800 BP & & $x$ & & & \\
\hline Rotaro Lavas & Ca. $900 \mathrm{BP}$ & & $x$ & & & \\
\hline Montagnone-Maschiata & Ca. $900 \mathrm{BP}$ & & $x$ & & & \\
\hline Punta La Scrofa Lavas & Ca. $900 \mathrm{BP}$ & $\mathrm{x}$ & & & & \\
\hline Fiaiano Tephra & Ca. 900 BP & & & & & $x$ \\
\hline Bosco Maddalena Tephra & Ca. 950 BP & & & & & $x$ \\
\hline Fondo d'Oglio Tephra & Ca. 1000 BP & & & $x$ & & \\
\hline Tabor Lavas & Ca. 1000 BP & & $\mathrm{x}$ & & & \\
\hline Villammare Tephra & Ca. 1200 BP & & & $x$ & & \\
\hline Bosco Maddalena Lavas & Ca. 1350 BP & & $x$ & & & \\
\hline Bosco dei Conti Tephra & Ca. $1400 \mathrm{BP}$ & & & & & $x$ \\
\hline Cava Buceto Tephra & Ca. 1400 & & & $x$ & & \\
\hline $\begin{array}{l}\text { Arcamone Sacchetta } \\
\text { Lavas }\end{array}$ & Ca. 1600 BP & $x$ & & & & \\
\hline Cretaio Tephra & Ca. 1950 BP & & & & & $x$ \\
\hline Cava Nocelle Tephra & Ca. 2200 BP & & & $x$ & & \\
\hline Posta Lubrano Tephra & Ca. 2200 BP & & & & & $x$ \\
\hline Cafieri Lavas & Ca. 2300 BP & $x$ & & $x$ & & \\
\hline Cafieri Tephra & Ca. 2300 BP & & & & $x$ & \\
\hline Posta Lubrano Lavas & Ca. $2300 \mathrm{BP}$ & & $\mathrm{x}$ & & & \\
\hline Cava Bianca Tephra & Ca. 2300 BP & & & $x$ & & \\
\hline Vateliero Tephra & Ca. 2400 BP & & & & $x$ & \\
\hline Ischia Porto Tephra & $476 \mathrm{BC}$ & & & & & $x$ \\
\hline Molara Tephra & Ca. 2500 BP & & & & & $\mathrm{x}$ \\
\hline San Pietro Lavas & Ca. 2500 BP & & $x$ & & & \\
\hline Montagnone I Lavas & Ca. 2500 BP & $x$ & & & & \\
\hline Monte Toppo Lavas & Ca. $2600 \mathrm{BP}$ & & $x$ & & & \\
\hline Chiarito Tephra & Ca. 2700 BP & & & & & $x$ \\
\hline San Ciro Lavas & Ca. $2700 \mathrm{BP}$ & $x$ & & & & \\
\hline Marecoppo Tephra & Ca. 2700 BP & & & & $x$ & \\
\hline Punta La Scrofa Tephra & Ca. 2750 BP & & & & $x$ & \\
\hline Cantariello Lavas & Ca. 2800 BP & & $x$ & & & \\
\hline Cannavale Tephra & Ca. 2900 BP & & & & & $x$ \\
\hline S. Alessandro Lavas & $>3000 \mathrm{BP}$ & $x$ & & & & \\
\hline Castiglione Lavas & $>3400 \mathrm{BP}$ & & $x$ & & & \\
\hline Puzzillo III Tephra & $>3500 \mathrm{BP}$ & & & $x$ & & \\
\hline Costa Sparaina Lavas & Ca. 4300 BP & $\mathrm{x}$ & & & & \\
\hline Puzzillo II Tephra & Ca. 4500 BP & & & & $x$ & \\
\hline Rio Corbore Lavas & Ca. 5000 BP & $x$ & & & & \\
\hline Piano Liguori Tephra & Ca. 5500 BP & & & & $x$ & \\
\hline Catavola Tephra & Ca. 5500 BP & & & & $x$ & \\
\hline Zaro Lavas & Ca. 6000 BP & $x$ & & $x$ & & \\
\hline Puzzillo I Tephra & Ca. 7000 BP & & & & & $x$ \\
\hline Maisto Tephra & Ca. 8000 BP & & & & & $x$ \\
\hline Fundera Lavas & Ca. 8.500 BP & & $\mathrm{x}$ & $\mathrm{x}$ & & \\
\hline $\begin{array}{l}\text { Napolitano, Trippodi, } \\
\text { Cannavale Lavas }\end{array}$ & Ca. 10000 BP & & $x$ & & & \\
\hline
\end{tabular}




\begin{tabular}{|c|c|c|c|c|}
\hline \multirow{2}{*}{\multicolumn{2}{|c|}{ Type }} & \multirow{3}{*}{$\begin{array}{c}\text { Units } \\
\#\end{array}$} & \multicolumn{2}{|c|}{ Reference Period } \\
\hline & & & \multirow{2}{*}{\begin{tabular}{|c|}
$3000 \mathrm{yr}$ \\
6 \\
\end{tabular}} & \multirow{2}{*}{$\begin{array}{c}10000 \mathrm{yr} \\
10\end{array}$} \\
\hline Effusive & & & & \\
\hline & Lava & Freq $\left(y r^{-1}\right)$ & $2.0 \times 10^{-3}$ & $1.0 \times 10^{-3}$ \\
\hline & \multirow{2}{*}{ Dome } & $\#$ & 9 & 12 \\
\hline & & Freq $\left(y r^{-1}\right)$ & $3.0 \times 10^{-3}$ & $1.2 \times 10^{-3}$ \\
\hline \multirow[t]{6}{*}{ Explosive } & \multirow{2}{*}{ Magmatic } & \# & 6 & 7 \\
\hline & & Freg $\left(y r^{-1}\right)$ & $2.0 \times 10^{-3}$ & $0.7 \times 10^{-3}$ \\
\hline & \multirow{2}{*}{$\begin{array}{l}\text { Phreato- } \\
\text { magmatic }\end{array}$} & $\#$ & 4 & 7 \\
\hline & & Freq $\left(\mathrm{yr}^{-1}\right)$ & $1.3 \times 10^{-3}$ & $0.7 \times 10^{-3}$ \\
\hline & \multirow{2}{*}{ Mixed } & \# & 9 & 11 \\
\hline & & Freq $\left(y r^{-1}\right)$ & $3.0 \times 10^{-3}$ & $1.1 \times 10^{-3}$ \\
\hline
\end{tabular}

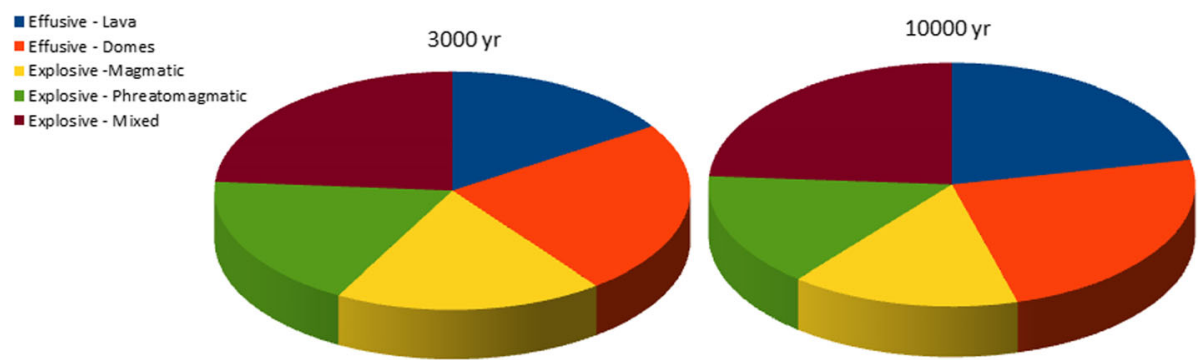

Fig. 7 Observed frequencies of eruptions for the different typologies defined in Subsection Present state of the volcanic system of Ischia of STEP 1, reporting: a table containing the number and mean annual frequency in the last $10 \mathrm{ka}$ and the last $3 \mathrm{ka}$, and the pie chart of relative frequencies of the different typologies in the last $10 \mathrm{ka}$ and the last $3 \mathrm{ka}$

monitoring is not long enough to identify any fluctuations in the process of resurgence, hence whether the current deflation of the system represents a change with respect to what is inferred (on average) for the last $10 \mathrm{ka}$ or just a natural variation of an ongoing process.

\section{STEP 2: the natural hazards of Ischia}

In this section we present a review of hazard studies at Ischia from a multi-hazard perspective, adopting for all the phenomena homogenous criteria. Eruptive and non-eruptive phenomena are discussed in the following Subsections Hazards related to eruptive activities and Non-eruptive hazards, respectively. The main results are systematically reported in Table 2. Spatial homogenization is based on adopting 5 reference areas: Monte Epomeo, N, E, S, and W sectors. Probabilistic information is instead homogenised by referring to a common verbal scale (i.e. a scale expressed through words, e.g., IPCC - Intergovernmental Panel on Climate Change 2013; ACS-CCS (American Chemical Society - Committee on Chemical Safety) 2015) in 6 levels: certain (probability =1); almost certain / very frequent $(0.9 \leq$ probability $<1)$; likely / frequent $(0.5 \leq$ probability $<0.9)$; possible $(0.1 \leq$ probability $<0.5)$; rare $(0.01 \leq$ probability $<0.1)$; very rare (probability $<0.01)$.

\section{Hazards related to eruptive activities Opening of new vents}

Vent opening is not only the starting phenomenon of an eruption, but it represents a hazardous phenomenon itself. Vents may have various geometries (from circular to fissures) and can migrate during eruptions.

The spatial distribution of the past eruptive centres (Fig. 8a) shows that the areas that most experienced opening of new vents in the past, were the $\mathrm{E}$ and NW sectors of the island. The $\mathrm{E}$ sector is dominated by the most recent eruptions (2.9 ka - $1302 \mathrm{AD})$, whereas the oldest eruptions (10-2.9 ka) are mainly concentrated in the NW sector.

For Ischia, so far, the probability of a new vent opening has been studied through two different approaches, both aimed at assigning the probability of vent opening on a spatial grid of $500 \mathrm{~m} \times 500 \mathrm{~m}$, which covers the entire territory of the island. Both approaches, mainly based on $<10 \mathrm{ka}$ data, calculate the probability combining and/or weighting the spatial distribution of some geological, geochemical, and geophysical indicators.

The first approach is more qualitative and was proposed by Alberico et al. (2008) and Sbrana and Toccaceli (2011). In detail, Alberico et al. (2008) uses 8 indicators (the position of past vents in the last $150 \mathrm{ka}$, faults, fractures, gas and hydrothermal source, radon emission, Bouguer anomaly, and earthquakes epicentres) evaluated on the area coincident with the subaerial surface of the island, whereas Sbrana and Toccaceli (2011) consider only 4 indicators (the position of past vents, faults, gas emissions, and earthquakes epicentres) evaluated on a greater area that involves also the off-shore.

The second approach (Zaccarelli et al. 2018) is more quantitative and follows a method similar to Selva et al. (2012b), combining 3 indicators (caldera extension, 
Table 2 Synthetic state of the art regarding hazard quantification

\begin{tabular}{|c|c|c|c|}
\hline Phenomenon & Past Observations & Probability in Volcano Phases & Intensity and Hazard Curves \\
\hline $\begin{array}{l}\text { Opening of new vents } \\
\text { Subsection Opening of } \\
\text { new vents in STEP } 2 \\
\text { Intensity Measures: } \\
\text { - Occurrence (Yes/No) } \\
\text { Note: Phreatic eruptions are } \\
\text { discussed in Subsection } \\
\text { Instability of the } \\
\text { hydrothermal system and } \\
\text { phreatic explosions in } \\
\text { STEP } 2\end{array}$ & $\begin{array}{l}\text { Last observation: } \\
\text { Arso (EST Sector) } \\
\text { Largest known observation: } \\
\end{array}$ & $\begin{array}{l}\text { Quiescence: - } \\
\text { Unrest: - } \\
\text { Eruption: certain } \\
\text { Note: All models have estimate } \\
\text { independent from the eruptive } \\
\text { style. }\end{array}$ & $\begin{array}{l}\text { Type: semi-quantitative } \\
\text { Spatial probability: } \\
\text { Sector E: high } \\
\text { Sector N: medium / high } \\
\text { Sector W: medium low } \\
\text { Sector S: medium low } \\
\text { Sector EPOMEO: low } \\
\text { Sector OFFSHORE: low } \\
\text { Intensity: - } \\
\text { Note: We report only a relative } \\
\text { rank of the different sectors for } \\
\text { the probability of vent opening } \\
\text { given an eruption. This is based } \\
\text { on a qualitative merging of } \\
\text { different (qualitative and } \\
\text { quantitative) models. These } \\
\text { estimates should be better } \\
\text { merged through a quantitative } \\
\text { ensemble. }\end{array}$ \\
\hline
\end{tabular}

Connected
Phenomena
- phreatic
explosions
- MRC or large
impulsive
landslides
(debris
avalanches)
- earthquakes
(weak)
Cascade:
- eruptions
- deformations
and,
consequently,
landslides (also
large)
-tsunamis
(submarine
explosions, or as
a consequence
of eruptions)
- earthquakes
- explosions
Simultaneous:
-
Trigger:
- vent opening
- phreatic
explosions
Cascade:
- fire
Simultaneous:
- tephra emission

Quiescence: -

Unrest: rare, in case of phreatic eruptions.

Eruption: certain in explosive eruptions; frequent in effusive eruptions.

\section{Arso (1302 AD)}

Largest known observation:

generated missiles in STEP Cretaio (90 \pm 87 AD)

Intensity Measures:

- Kinetic energy

- Range
Tephra fallout

Subsection Tephra

fallout in STEP 2

Intensity Measures:

- Loading $\left(\mathrm{kg} / \mathrm{m}^{2}\right)$

- Thickness (m)

- Concentration in air (kg/

$\mathrm{m}^{3}$ )

\section{Last observation:}

Arso (1302 AD, strombolian phase)

Largest known observation: Cretaio (90 $\pm 87 \mathrm{AD})$
Quiescence: -

Unrest: -

Eruption: certain in explosive eruptions (from from eruptive or co-ignimbritic plumes); possible in effusive eruptions (small quantities).
Quiescence: -

Unrest: -

Eruption: almost certain in explosive eruptions; rare in effusive eruptions (due to interaction with water).
Type: qualitative

Spatial probability:

Sector E: high

Sector N: medium

Sector W: medium

Sector S: low

Sector EPOMEO: low

Sector OFFSHORE: medium Intensity: -

Note: qualitative indication only for eruptions; in unrest, even if it is not possible to exclude phreatic eruptions, there are not known deposits of this type, therefore an evaluation is not possible in this case.

Type: qualitative Spatial probability:

Sector E: high

Sector $\mathrm{N}$ : medium

Sector W: medium

Sector S: low

Sector EPOMEO: low

Sector OFFSHORE: IOW

Intensity: from strombolian to subplinian.

Note: for small eruptions, only proximal tephra is expected (the spatial distribution may be based on the vent opening distribution). Tephra fallout from larger eruptions depend on wind (mainly toward East in this area).

Type: qualitative Spatial probability: Sector E: high

Sector N: medium / high Sector W: medium low

Sector S: medium low

Sector EPOMEO: low

Sector OFFSHORE: IOW
Trigger:

- vent opening

Cascade:

- PDCs

- atmosphere

phenomena

- lahar

Simultaneous:

- volcano generated missiles

- lava flows

(mixed

eruptions)
Note: studies or chronicles volcanic activity at Ischia do not exist.
Trigger:

- vent opening

- eruptive or coignimbric plumes (tephra fallout) - lava/water interaction (lava 
Table 2 Synthetic state of the art regarding hazard quantification (Continued)

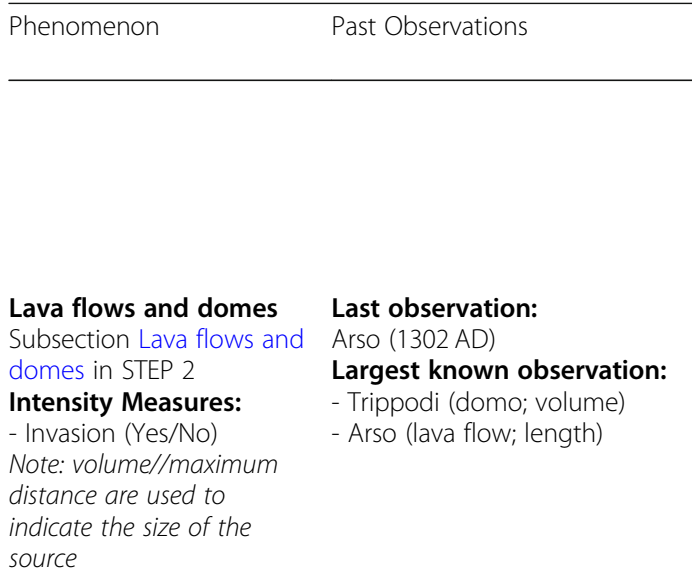

\section{Pyroclastic density} currents (PDC)

SubsectionPyroclastic Intensity Measures:

- Dynamic pressure

- Temperature

- invasion (Yes/No)

- concentration in air

\section{Last observation: \\ ash-surge of Fondo di Bosso (1301 AD)}

\section{Largest known observation:} ash-surge of Piano Liguori (5.5$5.0 \mathrm{ka})$ density currents in STEP 2
Quiescence:

Unrest: -

Eruption: certain for effusive eruptions.

Quiescence: -

Unrest: -

Eruption: very frequent in explosive eruptions (plume collapse or phreatomagmatic activity); very rare for effusive eruptions (dome collapse). Note: for effusive eruptions, never observed in Ischia.

\author{
Quiescence: possible \\ Unrest: possible, with \\ intensification of the \\ phenomena \\ Eruption: possible, with \\ intensification of the \\ phenomena \\ Last observation: \\ Geyser like activity (1940)
}

$\begin{array}{ll}\text { and phreatic explosions } & \text { Largest known observa } \\ \text { Subsection Instability of } & \text { Geyser like activity (1940) }\end{array}$

the hydrothermal system

STEP 2

Intensity Measures:

- occurrence (Yes/No)
- impacted area
Note: solely based on possible vent opening. For the intensity, not different from atmosphere phenomena from non volcanic sources.

Type: qualitative Spatial probability: Sector E: high

Sector N: medium

Sector W: very low

Sector S: very low

Sector EPOMEO: very low

Sector OFFSHORE: -

Intensity: -

Note: based only on past

deposits: quantitative hazard

studies are not available.

Type: qualitative Spatial probability: Sector E: high

Sector $\mathrm{N}$ : medium

Sector S: low

Sector EPOMEO: very low

Sector OFFSHORE: -

Intensity: -

Note: probability maps are available only for 2 "reference" scenarios (Alberico et al. 2008).

Type: qualitative, only for quiescence

Spatial probability:

Sector E: low

Sector $\mathrm{N}$ : medium

Sector W: medium / high

Sector S: medium / high

Sector EPOMEO: low

Sector OFFSHORE: -

Intensity: -

Note: based on the condition of the system in quiescence periods, in which the are with the highest propensity is South West. During unrest/eruption cannot be would significantly increase the probability of explosive events with large intensity

Type: qualitative, only for quiescence
Sector W: medium evaluated. A magmatic intrusion

Connected

Phenomena

flows)

Cascade:

- fire

Simultaneous:

Trigger:

- vent opening

Cascade:

- PDC (from

dome collapse)

- tsunami (small)

- fire

- explosions

- gas emissions

Simultaneous:

- volcano

generated

missiles

- tephra fallout

Trigger:

- vent opening

- phreatic

explosion

- plume / dome

collapse

Cascade:

- tephra fallout

(co-PDC

column)

- atmosphere

phenomena

- lahar

- tsunami

- fire

Simultaneous:

- volcano generated missiles

- lava flows

- tephra fallout

Trigger:

- increase of

magmatic fluids

- sudden

decompression

and vapour

separation

(large

landslides, earthquakes)

Cascade:

- anomalous $\mathrm{CO}_{2}$ emissions

- volcano generated missiles

- PDC

- landslide

- vent opening

and eruptions

Simultaneous:

Quiescence: possible
Trigger:

- increase in 
Table 2 Synthetic state of the art regarding hazard quantification (Continued)

\begin{tabular}{|c|c|}
\hline Phenomenon & Past Observations \\
\hline $\begin{array}{l}\text { and aerosol in STEP } 2 \\
\text { Intensity Measures: } \\
\text { - concentration in } \\
\text { atmosphere } \\
\text { - flux from soil }\end{array}$ & $\begin{array}{l}\text { The last measure campaign is in } \\
\text { May } 2007 \text { for diffuse } \mathrm{CO}_{2} \text {, March } \\
2009 \text { for Rn indoor e in water. } \\
\text { Local campaigns were } \\
\text { organized in August } 2017 \\
\text { (earthquakes) and planned for } \\
\text { June } 2018 \text {. } \\
\text { Largest known observation: } \\
\text { The largest ongoing emission is } \\
\text { at the fumarole of Donna } \\
\text { Rachele (sector West), with } \mathrm{Rn} \text { in } \\
\text { aria }=3983 \mathrm{~Bq} \mathrm{\textrm {m } ^ { - 3 }} \text {; Rn in } \\
\text { water }=98 \mathrm{~Bq} \mathrm{I}^{-1} \text {. } \\
\text { Note: paroxysm are not } \\
\text { known, nor observations } \\
\text { during unrest/eruptions. }\end{array}$ \\
\hline $\begin{array}{l}\text { Deformations } \\
\text { Subsection Ground } \\
\text { deformation in STEP } 2 \\
\text { Intensity Measures: } \\
\text { - horizontal and/or vertical } \\
\text { displacements }\end{array}$ & $\begin{array}{l}\text { Last observation: } \\
\text { the phenomenon is continuous. } \\
\text { The last } 30 \text { years are } \\
\text { characterized by a general } \\
\text { subsidence with a maximum } \\
\text { rate of } 1 \mathrm{~cm} / \mathrm{a} \text { observed in } \mathrm{S} \\
\text { and central-W sectors. } \\
\text { Largest known observation: } \\
\text { The Monte Epomeo resurgence } \\
\text { occurred at a mean velocity of } \\
\text { about } 3 \mathrm{~cm} / \mathrm{a} \text {, for approximately } \\
30 \text { ka with a total of } 1000 \mathrm{~m} \\
\text { cumulated deformations. } \\
\text { Possible peaks are not known. }\end{array}$ \\
\hline
\end{tabular}

\section{Local Seismicity}

Subsection Local

seismicity in STEP 2

Intensity Measures:

- PGA in $\mathrm{g}$

- Macroseismic scale
Probability in Volcano Phases

intensification of the

phenomena

Eruption: frequent, with intensification of the phenomena

Quiescence: -

Unrest: frequent / almost certain

Eruption: certain

Note: we refer to uplift. In quiescence, significant uplift would indicate unrest.

\section{Last observation: \\ - 31/08/2016 (negligible intensity)}

Largest known observation:

Sector E: VIII MCS (1302)

Sector N: XI MCS (1883)

Sector W: IX MCS (1883)

Sector S: VII MCS (1883)

Sector EPOMEO: IX MCS (1883)

Sector OFFSHORE: VI-VII MCS

(1883
Slope instability of Type

$1 \mathrm{~A}$ (MRC)

Subsection Gravitational instability on slopes in STEP 2

Intensity Measures:

- invasion (Yes/No)

Note: volume/areal

maximum distance are

used to indicate the size of

the source
Last observation:

the creeping is continuous and it is ongoing at Monte Nuovo, in the West sector of Monte Epomeo.

Largest known observation: the Rock Avalanche of Falanga, in sector W.
Quiescence: possible Unrest: frequent / almost certain

Eruption: certain
Type: qualitative, quantitative but regional

Spatial probability:

Sector E: low

Sector N: high

Sector W: medium /high

Sector S: medium / low

Sector EPOMEO: medium / high Sector OFFSHORE: -

Intensity: from the regional study, $0.125-0.175 \mathrm{~g}$ (mean of $10 \%$ in 50 years); $<0.3 \mathrm{~g}$ (84 $^{\mathrm{mo}}$ percentile of $1 \%$ in 50 years).

Note: The regional study provides fairly low intensity with respect to past observations. The spatial probability applies in quiescence, while do not exist studies for unrest/eruption periods.

Type: qualitative, from

Quiescence: rare

Unrest: possible / likely Eruption: possible / likely Note: the creep is certainty, so here we refer to acceleration with evolution to rock avalanche. The probability of rock avalanche cannot be defined with precision, but the mean recurrence time in Sector WEST may be smaller than 1000 year. observation

Spatial probability:

Sector E: low

Sector N: low

Sector W: medium

Sector S: low

Sector EPOMEO: high

Sector OFFSHORE: low

Intensity: documented rock

avalanche from MRC may

reached $8 \mathrm{~km}$ of run out.

Note: the spatial ranking is
Connected

Phenomena

input volcanic-

hydrothermal

fluids

- eruptive

plumes

- lava flows

Simultaneous:

Trigger:

- overpressure of

aquifers

- magmatic

intrusions in

shallow or

deep layers

- vent opening

- earthquakes

Cascade:

- landslides

- macroscopic

fractures

- eruptions (rare)

Simultaneous:

- local

earthquakes

Trigger:

- magmatic

intrusions in

shallow or

deep system

Cascade:

- tsunami

- landslides (all types)

- eruptions (rare)

- phreatic

explosions

Simultaneous:

- deformations

Trigger

- uplift (re-start

of resurgence)

- eruptions

- regional

earthquakes

- alteration or

other effects of

hydrothermal

fluids

Cascade:

- rock avalanche

- tsunami 
Table 2 Synthetic state of the art regarding hazard quantification (Continued)

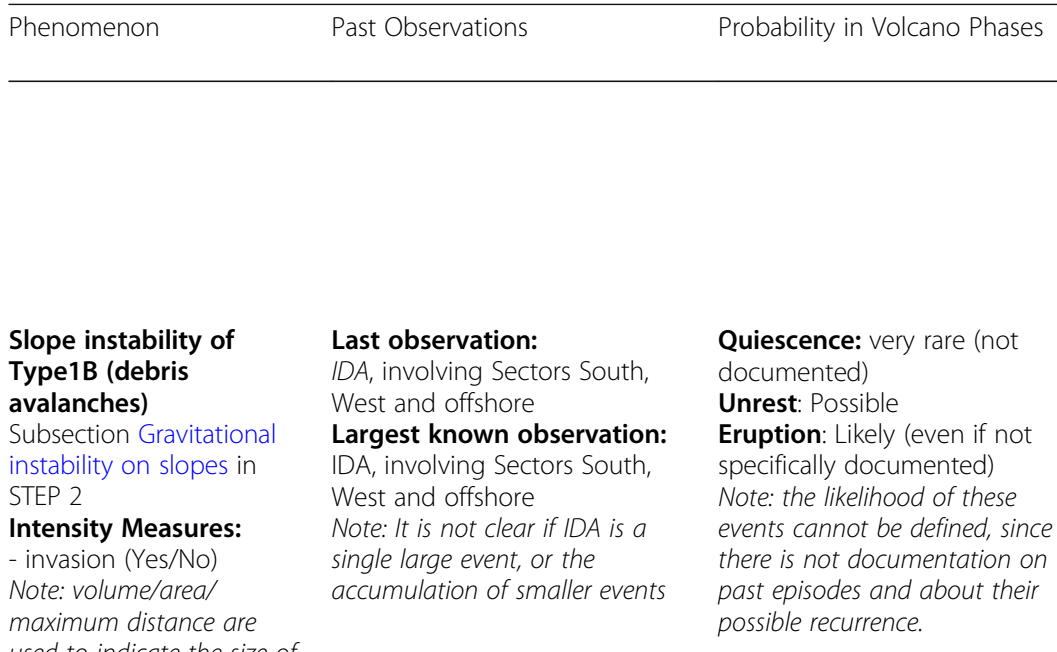

used to indicate the size of

the source

\begin{abstract}
Last observation:
Largest known observation:

DA, involving Sectors South,

Note: It is not clear if IDA is a

single large event, or the
\end{abstract}

Intensity and Hazard Curves
qualitative, reported in a relative
sense (from low to high), and
conditional upon a MRC
existence.

existence.

$$
\begin{gathered}
\text { Type: qualitative, from } \\
\text { observation } \\
\text { Spatial probability: } \\
\text { Sector E: low } \\
\text { Sector N: low } \\
\text { Sector W: low } \\
\text { Sector S: medium/high } \\
\text { Sector EPOMEO: low } \\
\text { Sector OFFSHORE: medium/high } \\
\text { Intensity: the maximum } \\
\text { distance for debris avalanche } \\
\text { documented for Ischia are of } 50 \\
\text { km. } \\
\text { Note: the spatial ranking is } \\
\text { qualitative, reported in a relative } \\
\text { sense (from low to high), and } \\
\text { (conditional upon a impulsive } \\
\text { landslides. }
\end{gathered}
$$
used to indicate the size of
Quiescence: possible to 50 years) Unrest: Possible Eruption: Likely / very frequent (even if not specifically documented)
Slope instability of Type Last observation:

2: shallow impulsive landslides

Subsection Gravitational instability on slopes in STEP 2

Intensity Measures:

- dynamic pressure - invasion (Yes/No)

Note: volume/areal maximum distance are the source
Colata 2015 - Barano; events induced by the 2017 earthquakes.

\section{Largest known observation:} Sector E: Rosato Landslide (2.6$2.3 \mathrm{ka})$

Sector N: Debris flow of San

Francesco

Sector W: Debris Flow of Citara
Type: qualitative, from

observation

\section{Spatial probability:}

Sector E: medium-low Sector N: medium

Sector W: low

Sector S: low

Sector EPOMEO: high

Sector OFFSHORE: low

Intensity: the maximum

distance for debris flow for Ischia are of $5 \mathrm{~km}$.

Note: the spatial ranking is qualitative, reported in a relative sense (from low to high), and conditional upon a impulsive landslides.

\section{Tsunami}

Subsection Tsunami in STEP 2

Intensity Measures:

- water depth at coast (m)

- flow depth (m)

- flow velocity $(\mathrm{m} / \mathrm{s})$
Quiescence: very rare (from landslides or Type 1) Unrest: rare / possible (earthquakes or landslides or Type 1)

Eruption: rare / possible (earthquakes or landslides or Type 1 or submarine explosions or PDC).

\section{Last observation:}

No observations in the EuroMediterranean Tsunami

Catalogue (Maramai et al. 2014).

Historical-archaeological data testify a tsunami event in Sector N (Pithecusa at Lacco Ameno; Buchner 1986).

Largest known observation: A large tsunami has been associated to IDA in several studies, but deposits associated to this tsunami are not known.
Type: qualitative, based on scenarios

\section{Spatial probability:}

Sector E: medium

Sector N: medium

Sector W: high

Sector S: high

Sector EPOMEO: low

Sector OFFSHORE: -

Intensity: up to tens of meters $(\sim 40 / 50 \mathrm{~m})$ in all the sectors where the tsunami is generated. Significant impact (meters) on the mainland may be possible. Note: the spatial ranking is qualitative, reported in a relative sense (from low to high), conditional upon a tsunami, and it is referred to landslide originated tsunamis. Studies of tsunamis from eruptions or earthquakes do not exist.
Connected

Phenomena

- phreatic

explosions

Simultaneous:

Note: we refer to acceleration episodes.

Trigger:

- regional

earthquakes

Cascade:

- tsunami

Simultaneous:

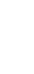

Trigger:

- meteorological

- events

explosive

eruptions with

generation of

rain

- local seismicity

Cascade:

- floods

Simultaneous: . 

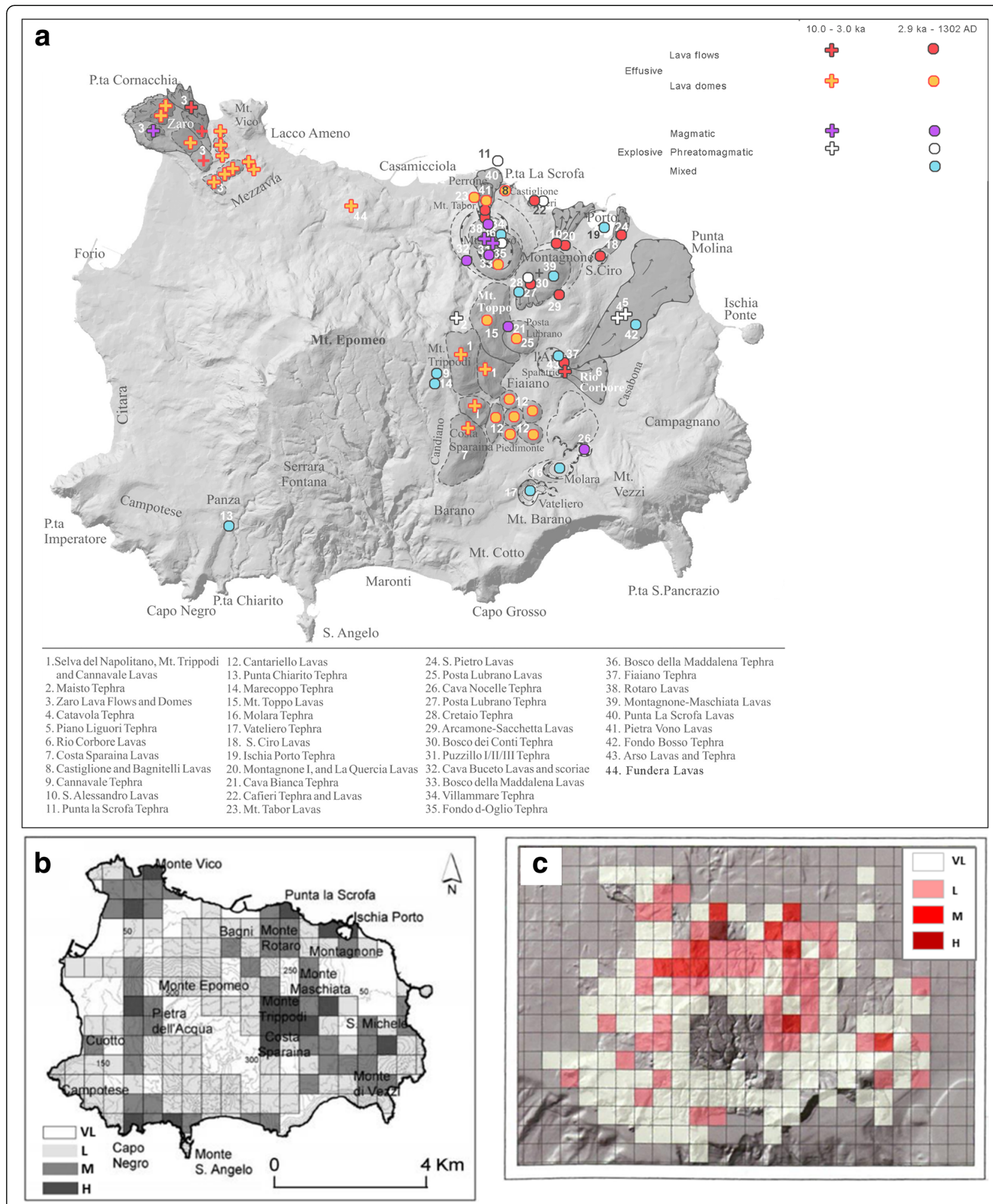

Fig. 8 a Distribution of the eruptive vents in the last 10 ka classified for typology (effusive and explosive activity): each eruptive activity is labelled with a number corresponding to the name reported in the legend; shaded in grey we report the areas covered by lavas from effusive eruptions; b vents opening probability according to Alberico et al. (2008); c vents opening probability according to Sbrana and Toccaceli (2011) 
faults, and intersection between faults), each one having a different weight in the prior, using a Bayesian inference scheme for simultaneously account for past vents (last $10 \mathrm{ka}$ ) and estimating the epistemic uncertainty.

The map of Alberico et al. (2008) indicates that the zones with highest probability are the west and east flanks of Monte Epomeo, the Monte Vico and the area of Monte Vezzi (Fig. 8b). The map of Sbrana and Toccaceli (2011) shows that the entire island, except the central part of Monte Epomeo, can be affected by the opening of new vents (Fig. 8c). The results of Zaccarelli et al. (2018) indicate that new eruptions may affect mainly the area inside the caldera, in particular the $\mathrm{E}$ and NW sectors of Monte Epomeo. From the comparison of all these maps, we can see that the E and NE sector of Monte Epomeo are the areas characterized by a high probability of vent opening for a future eruption (where most of eruptions of the last $10 \mathrm{ka}$ occurred), with the $\mathrm{N}$ sector representing the second more probable area, whereas the W and S sectors appear to have a moderate/low probability and, finally, the Central sector - Monte Epomeo, has an almost negligible probability. In the offshore areas, the probability of vents opening was studied without specific details, but all the approaches assign to this area a very low probability.

The opening of new vents is associated with all eruptions and, in all the analyses considered above, there is no distinction based on the typology of the eruptions.

In a multi-hazard perspective, vent opening may cause earthquakes, ground deformation, landslides, and tsunamis. The latter could be generated by submarine explosions or as consequence of landslides, lateral blasts, or pyroclastic flows entering in the sea.

The main critical point concerns the reliability and (spatial and temporal) completeness of the eruption catalogue used to assess the probabilities. In addition, the results of all the available methods strongly depend on the selection of the structural parameters adopted to track the potential for vent opening. This selection is rather subjective, and the available studies do not consider any formal procedure to deal with this subjectivity and/ or to estimate the impact of different choices.

\section{Volcano generated missiles}

On Ischia, bombs and ballistic blocks were found typically at distances of several hundreds of metres from the eruptive vents, whereas ballistic fragments were found in scoria cones formed during the strombolian activity and also associated to pyroclastic current deposits generated by phreatomagmatic eruptions (de Vita et al. 2010).

Bombs and ballistic blocks can be associated with a large variety of eruptions, but they are always produced during explosive eruptions, although they could also be produced during effusive activity. They are generated also when phreatic eruptions occur (unrest phase), as well as in secondary vents during lava and pyroclastic flows.

Hazard quantifications for bombs and ballistic blocks are not available for Ischia. In terms of cascading hazard, the high temperatures of bombs and blocks may cause fires on vegetation and buildings close to the eruptive vent.

The main critical points in the present-state knowledge of this hazard concerns the absence of quantitative probabilistic studies for this type of eruptive hazard and the definition of scenarios for assessing the impact of this phenomenon. Even for a simple approach, which assumes a screening distance (IAEA - International Atomic Energy Agency 2012), the main uncertainty is related to that characterizing the opening of new vents.

\section{Tephra fallout}

The main tephra fallout deposits of Ischia volcano were emplaced during the Upper Pleistocene, i.e., outside the reference period. In this period, large eruptions such as the MEGT and the Upper Monte Sant'Angelo (55-56 ka BP) eruptions (Albert et al. 2012; Brown et al. 2008, and references therein) covered most of the central Mediterranean area and represent the most important and widespread markers. During the Holocene (i.e., the reference period), there were no explosive eruptions with regional impacts. This is confirmed by the fact that only a very few ash deposits have been found in the stratigraphy of the central Mediterranean Sea (Albert et al. 2012; Morabito et al. 2014; Sulpizio et al. 2014). For the Holocene, no more than three ash deposits were found as microtephra within the stratigraphy of Lago Grande di Monticchio (ca. $150 \mathrm{~km}$ Est from Ischia; Wulf et al. 2008). All the other deposits are limited to the island, and are mainly concentrated in the east sector, close to their origin and with a prevalent SE dispersion. The most significant recent explosive eruption is the Cretaio eruption (Fig. 9a) that occurred in the I century AD (Orsi et al. 1996). An ash marine layer of about $1 \mathrm{~cm}$ of micropumices, showing a chemical affinity to Ischia and age consistent with the Cretaio tephra, was found in the CET1 marine core (Morabito et al. 2014), at about 100 $\mathrm{km}$ south of Ischia.

In the last $10 \mathrm{ka}$, the more frequent eruptions were low intensity explosions (strombolian, violentstrombolian, phreatomagmatic) generating pumice cones and tuff rings/cones (de Vita et al. 2010). The only study on the spatial dispersion of tephra deposits generated in the last $10 \mathrm{ka}$ is the work by de Vita et al. (2010; Fig. 9b).

Probabilistic quantifications of the tephra fallout are not available. Within a multi-hazard context, tephra fallout is often accompanied by partial collapses of the plume (and consequent pyroclastic flows) or base surges 

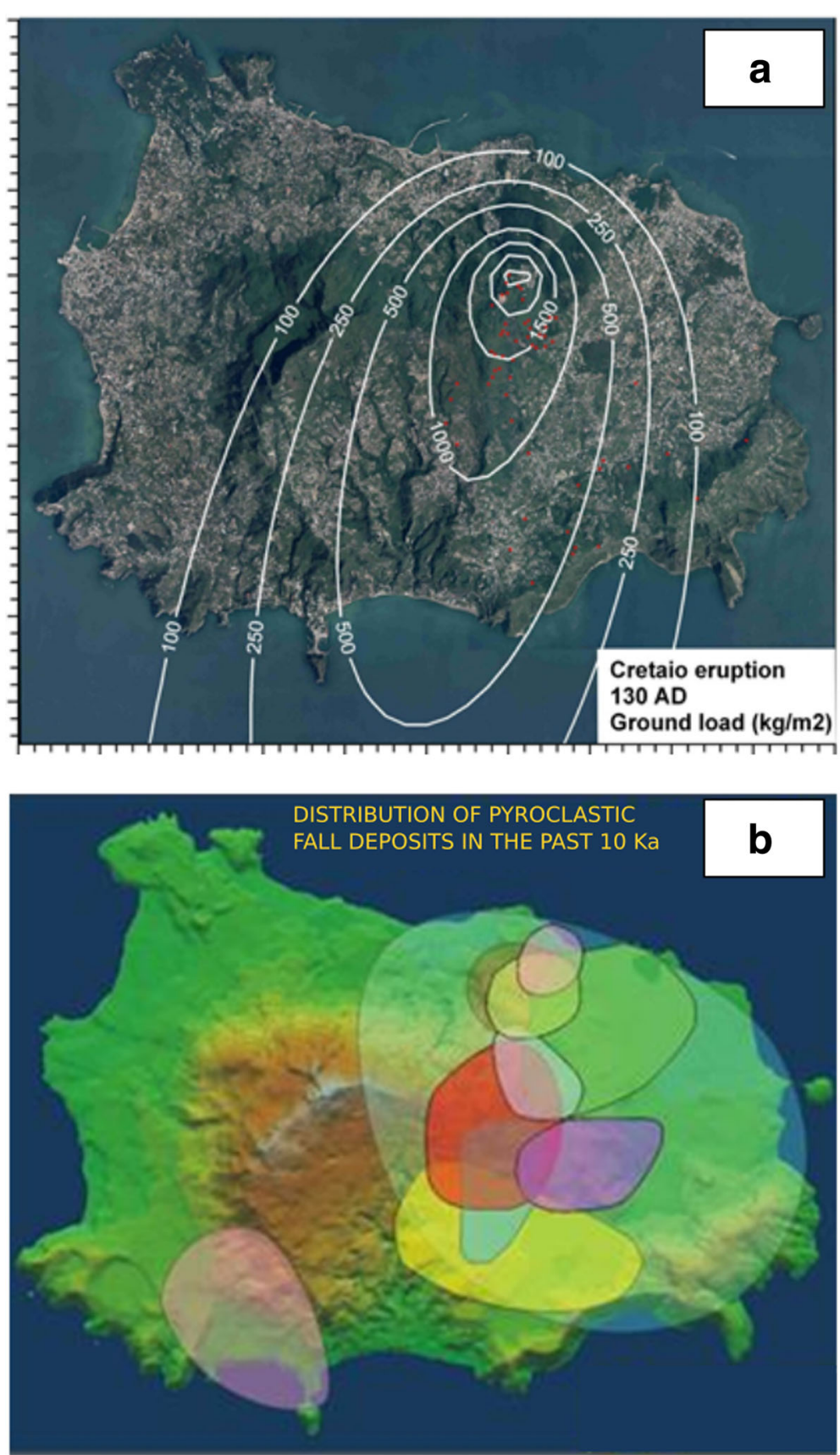

Fig. 9 Distribution of pyroclastic fall-out deposits a for the Cretaio eruption, from INGV-DPC-V3 (2005-2007), and b for all the eruptions in the last $10 \mathrm{ka}$, according (from data in de Vita et al. 2010)

and, in proximal areas, by ballistics, as well as by potential atmosphere phenomena. At the end of the explosive episode, the eruption may evolve to effusive lava flows. Tephra deposits may provide material for lahars, and may be transported by the wind even for hundreds of kilometres (Folch et al. 2014).

The main critical point here is that there have been limited accurate studies aimed at assessing magnitude, intensity, and bulk granulometry of the past explosive eruptions. This precludes probabilistic studies of tephra dispersion based on different eruptive scenarios and statistical analyses of winds and defining the areas affected by possible remobilization of tephra deposits, which can generate lahars during heavy rainfall events.

\section{Atmosphere phenomena}

During explosive volcanic eruptions, including phreatic explosions, air pressure waves, powerful enough to break 
windows at distances of several kilometres, can be generated. Violent weather phenomena can locally accompany the development of the eruptive plume, due to ash particles and magmatic water injected in the atmosphere, which can cause sudden nucleation of raindrops (with potential lahar generation). Even downbursts (i.e. very strong local winds) can occur as a result of explosive plumes. In addition, the formation of lightning accompanies many types of volcanic eruptions. However, lightning is especially common when the eruption column is higher than $10 \mathrm{~km}$ high and ice forms in the upper, cooler parts of the rising ash cloud (IAEA International Atomic Energy Agency 2016). Although such atmospheric phenomena may occur during any volcanic eruption, they are more likely in phreatomagmatic phases where more water is available in the plume. However, they can be considered rare and their effects similar to the ones due to ordinary lightening.

For Ischia there are no studies or chronicles describing atmospheric phenomena, such as shock waves, thunderstorms or lightning, due to volcanic eruptions. Hazard quantifications for atmosphere phenomena at Ischia are not available. Within a multi-hazard context, atmosphere phenomena are caused by eruptive plumes which also cause tephra fallout.

\section{Lava flows and domes}

Lava flows and domes, generated during effusive eruptions, were common at Ischia during the reference period. During the last $10 \mathrm{ka}$, lava domes and flows occurred in localized vents, sometimes aligned along fractures. Lava domes affected $\mathrm{E}$ and $\mathrm{N}$ sectors, whereas lava flows interested mainly the E sector (Fig. 8a, shaded in grey), although one of the main flows, the lava of Zaro (6.0 ka BP), emplaced in the NNW part of Ischia. This lava flow covered an area of about $1.5 \mathrm{~km}^{2}$ reaching a distance of $1.2 \mathrm{~km}$ from the vent. In the eastern sector the largest event was the Arso lava flow (1302 AD) that reached a length of $2.5 \mathrm{~km}$ with a volume of $0.03 \mathrm{~km}^{3}$ (Chiesa et al. 1986; de Vita et al. 2010).

Probabilistic quantifications of lava flows are not available for Ischia. In a multi-hazard perspective, lava flows may induce fire in vegetation and in urbanized settings. They may be associated to explosive activity, especially when they reach water surfaces, also generating small gravitational collapses, pyroclastic flows, as well as ballistics of large dimensions falling up to hundreds of meters from the flow. Lava flows are also associated to potentiallly hazardous gas emissions.

The main critical points on the present-day state-ofknowledge of this hazard regard the absence of quantitative hazard studies for lava flow propagation and lava dome emplacement. These studies should be developed combining probabilistic maps of opening vents with lava flow simulations.

\section{Pyroclastic density currents}

Among 47 eruptions recorded in the last $10 \mathrm{ka}, 20$ generated pyroclastic density currents (PDC) deposits (mostly ash surges). The distribution of such deposits is shown in Fig. 10 (de Vita et al. 2010) and highlights that such deposits affected mainly the $\mathrm{E}$ eastern sector. The deposits relative to Piano Liguori are the ones with the largest areal dispersion, covering the entire $\mathrm{E}$ and $\mathrm{SE}$ sectors, up to $400 \mathrm{~m}$ above the sea level.

The majority of the observed PDCs deposits relate to dilute and turbulent flows, associated with phreatomagmatic activity, while deposits from dense PDCs are rare and generated by partial collapses of eruptive plumes (e.g., Chiarito Tephra). Deposits from dome collapse are not known in the reference period, even if domes and high viscosity lava flows were frequent. Consequently, PDC can be considered frequent for magmatic and phreatomagmatic eruptions, and rare for effusive eruptions.

Hazard from PDCs was studied by Alberico et al. (2008) who presented semi-qualitative maps showing the frequency of PDC invasion. These maps are based on the Energy Cone model and consider the vent opening probability for an eruption with assigned VEI (3-4). Quantitative hazard assessments, estimating PDC intensity in terms of dynamic pressure, particles concentration (e.g. Dellino et al. 2004), and temperature (e.g. Giordano et al. 2018), are lacking.

In a multi-hazard perspective, PDCs can be associated with explosive eruptions also producing tephra fallout, as well as effusive phases producing lava. As tephra deposits, PDC deposits may provide material for lahars and the material may also be transported by winds even for hundreds of kilometers (Folch et al. 2014).

\section{Non-eruptive hazards Instability of the hydrothermal system and phreatic explosions}

Despite the lack of exposed deposits produced by hydrothermal or phreatic explosions at Ischia, these kinds of events are possible in all states of the volcano, either quiescence, unrest or eruption. The favourable conditions for explosions to occur are indeed observed in Ischia. The presence of an active hydrothermal aquifer, recharged by deep volcanic fluids, characterized by i) a energetic boiling (see Subsection Present geothermal system of STEP 1) or close to boiling in a large part of the island, along with ii) the poor permeability of volcanic deposits, further reduced by the precipitation of alteration minerals from circulating hot fluids, make it possible the build-up of fluid pressure, eventually leading to an explosion. 

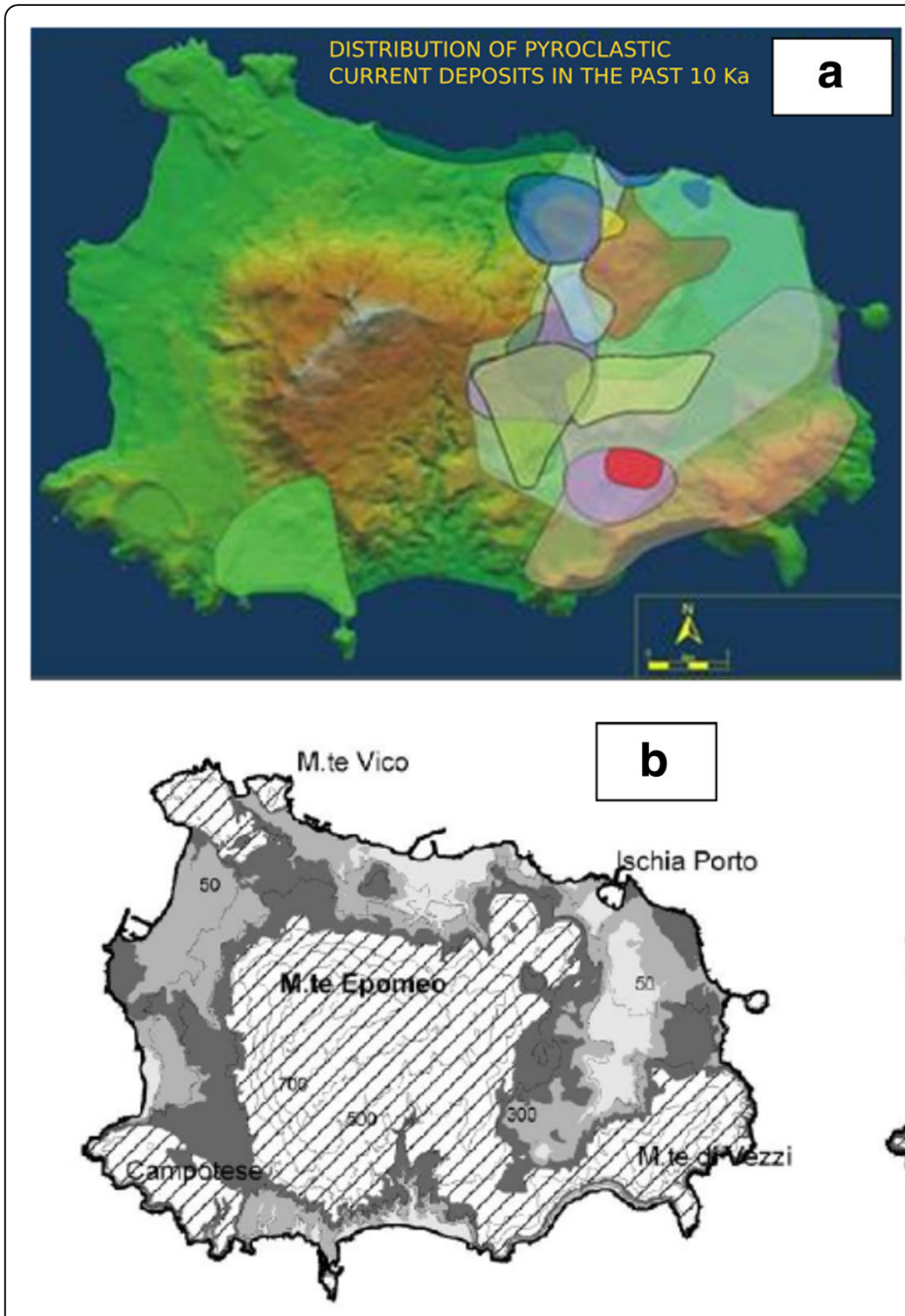

High Medium
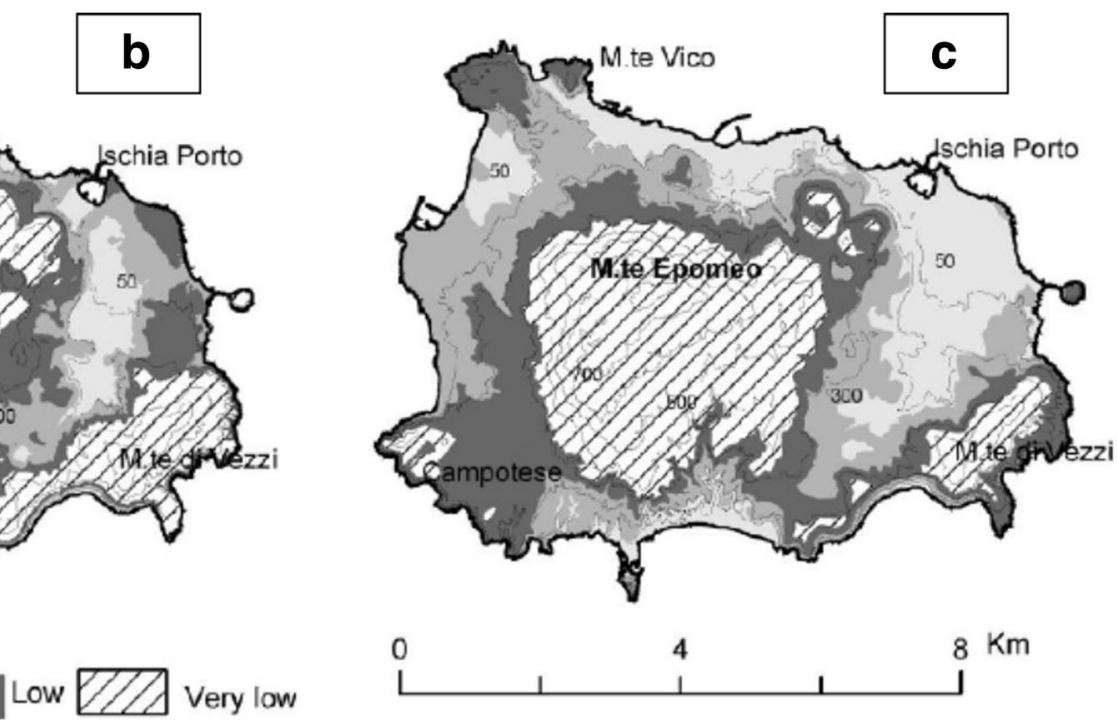

Fig. 10 a Distribution of PDC in the last $10 \mathrm{ka}$ (from data in de Vita et al. 2010); b frequency invasion map considering an eruptive event with VEI 3 (from Alberico et al. 2008); c same as b, but for VEI 4

The Ischia hydrothermal aquifer appears as partially confined at depth, and the fluid pressure is expected to be higher than the hydrostatic pressure. Indeed, the rise of the water level within geothermal wells observed during the drillings performed in the 50's would suggest local pressure build-up, promoted by self-sealing phenomena. Furthermore, some "geysering" activity was observed in the same wells, induced by the geothermal drillings, which suggests that the system is prone to the explosive vaporization of hot water, as an effect of external triggering events. Geysering activity, in one of the wells, lasted intermittently some years (Penta and Conforto 1951).

Data gathered during geothermal drillings allowed the geothermal gradients down to depths of $1,000 \mathrm{~m}$ to be estimated. The profile of temperature with depth suggests a vapour-dominated system below $200 \mathrm{~m}$ of depth (Carlino et al. 2014), and this is confirmed by the chemical composition of the fumaroles recovered on the $\mathrm{W}$ flank of Monte Epomeo (Chiodini et al. 2004), which indicate the energetic boiling of this high temperature aquifer. The shallowest part of the system (above $200 \mathrm{~m}$ ) is, conversely, liquid-dominated, as suggested by a temperature profile compatible with the boiling curve, and this implies that even a small perturbation can induce the flashing of the liquid.

On these grounds, even in absence of specific quantifications in literature, two possible scenarios are envisaged for the generation of hydrothermal or phreatic explosions: 
i) the depressurization and the downward flashing of the hydrothermal aquifer;

ii) the pressure build-up due to the input of magmatic fluids and the temperature increase of the hydrothermal system.

Scenario i) is expected in case of external triggers such as a landslide or an earthquake, able to suddenly reduce the lithostatic load. Therefore, this situation may occur in all the states of the volcano, including when it is quiescent. As the separation of a vapour phase is strictly dependent on both temperature and pressure, and the boiling temperature increases along with the confining pressure, the sudden release of pressure would make the system overheated. This condition would induce the flashing of the hot water, if it were close to the boiling point. The drastic pressure drop of the overlying aquifer would induce the downward propagation of the flashing point, thus progressively involving the deeper parts of the hydrothermal system.

Scenario ii) is related to a magmatic input of heat and volatiles into the hydrothermal aquifer that would increase the proportion of the vapour phase in a biphase (vapour and liquid) system, thus inducing an increase of fluid pressure in a partially confined system. If the fluid pressure overwhelms the rock tensile strength, an explosive fragmentation of the rocks may happen. This situation is typical of unrest phases, also in their earlier stages.

Quantifications of the probability of phreatic explosions and of their potential impact are not available for Ischia. The areas of the island where hydrothermal manifestations are widespread are the $\mathrm{W}, \mathrm{N}$ and $\mathrm{S}$ flanks of Monte Epomeo, where several active fumaroles and areas of diffuse $\mathrm{CO}_{2}$ degassing have been recorded. Furthermore, in these areas, during geothermal drillings, the highest temperatures have been recorded, in different geothermal aquifers located at $0-500 \mathrm{~m}$ and 1,000-2,500 m of depth. The chemical composition of fluids collected in an active fumarolic field in the W flank of Monte Epomeo, known as Donna Rachele fumaroles, indicates equilibrium temperatures at depth in the range $250-300^{\circ} \mathrm{C}$ with vapour composition similar to that expected for the hydrothermal liquid phase (see Subsection Present geothermal system of STEP 1). In this part of the island, moreover, a hydrological survey performed by Celico et al. (1999) has evidenced a piezometric gradient steeper than that measured in the eastern part of the island. This has to be related to lower permeability and vertical fluid transport probably focused along the fractures (often sealed by secondary minerals precipitating from circulating hot fluids) bordering Monte Epomeo.

From a multi-hazard perspective, it must be noted that phreatic explosions may be accompanied by large gas emissions (Subsection Volcanic gas and aerosol), since a significant component of the hydrothermal system is $\mathrm{CO}_{2}$. Pressure variations within the hydrothermal system may cause slope instability, especially in areas with argillification, and, the other way, variations of hydrostatic pressure can be generated by slope instability. Phreatic explosions may trigger ballistics and PDCs, and may favour magma ascent and further vent opening.

\section{Volcanic gas and aerosol}

Volcanic gases represent a significant portion of the total mass of material emitted by volcanoes, and those emitted through fumaroles are highly reactive and potentially toxic (among these, $\mathrm{CO}_{2}, \mathrm{SO}_{2}, \mathrm{H}_{2} \mathrm{~S}, \mathrm{CO}, \mathrm{HCl}$ are those that can have the most serious effect on human health).

As described in Subsection Present geothermal system (STEP 1), several fumarolic areas occur on Ischia Island. Besides water vapour, $\mathrm{CO}_{2}$, is the most abundant gas species emitted by fumaroles. It can induce asphyxia at high concentrations, as an effect of accumulation in morphological depressions or in non-ventilated cellars.

Although Rn generally occurs at concentrations lower than $\mathrm{CO}_{2}$, it is potentially harmful, because of radioactive emissions of Rn itself and its "daughter" elements. High $\mathrm{Rn}$ concentrations are expected in areas of intense degassing, or indoor, as houses are generally built with local volcanic rocks, containing "parent" elements of $\mathrm{Rn}$ in the decay chain. Pugliese et al. (2014) investigated some spas in the island, by measuring $\mathrm{Rn}$ contents indoor and dissolved in thermal water. Their results indicate that $\mathrm{Rn}$ contents in water are always below the threshold of 100 $\mathrm{Bq} / \mathrm{l}$, required by Italian regulation. Rn concentrations indoor, conversely, have often exceeded the threshold of $500 \mathrm{~Bq} / \mathrm{m}^{3}$, with maxima of $3980 \mathrm{~Bq} / \mathrm{m}^{3}$.

Detailed studies concerning the diffuse soil gas emissions have been performed in the $\mathrm{W}$ and $\mathrm{S}$ sectors of the island, both in the nearby of Donna Rachele fumaroles (Chiodini et al. 2004) and in the area between Maronti and Citara (Di Napoli et al. 2011).

On Ischia Island, an operative monitoring of the gas hazard is lacking. The available data only refer to distinct campaigns of measurements of soil $\mathrm{CO}_{2}$ degassing, carried out on April 2001 in the area of Donna Rachele fumaroles (Chiodini et al. 2004) and in May 2007 in the Maronti-Citara area (Di Napoli et al. 2011). The total diffuse $\mathrm{CO}_{2}$ flux in the area of Donna Rachele fumaroles is estimated in $9.1 \mathrm{t} / \mathrm{d}$ for the whole area, whereas in the area between Maronti and Citara only an average flux of $70 \mathrm{~g} \mathrm{~m}^{-2} \mathrm{~d}^{-1}$ has been computed.

The emission of gases from fumaroles or mofettes is effective during quiescence and is even more likely during unrest related to magma ascent or eruption. It is likely, although never measured, a parallel increase of gas concentrations in air, particularly close to the 
fumaroles or even in areas of diffuse degassing in topographic depressions or indoors. A quantitative gas hazard assessment for Ischia Island is lacking.

From a multi-hazard perspective, although the gas hazard is envisaged in any phase of volcanic activity, from quiescence to eruption, it potentially increases parallel to other events. During magmatic unrest, the movement of magma batches induces further degassing, focused either in the existing fumarolic areas or even in newly opened fractures. In case of magmatic, phreatic or hydrothermal explosions, large amounts of water vapour and other minor gas species, potentially harmful, are massively emitted, thus increasing the gas hazard in the proximity of vents. The water vapour and the acidic gases emitted during eruptions also induce the formation of acidic clouds and the generation of acidic wet and dry deposition (rainfall and particulate), able to damage spontaneous vegetation and crops, and frequently causing irritation in eyes and lungs of inhabitants in nearby settlements.

\section{Ground deformation}

Ground deformation can occur before, during or after volcanic activity. It is generally related to both magma or hydrothermal system dynamics, and tectonic processes. An increase in ground deformation could herald the beginning of a new eruptive episode and/or the opening of a new eruptive vent. This can also have indirect effects such as triggering landslides, debris flows or related phenomena.

As emerged in Subsection Present state of the volcanic system of Ischia (STEP 1), the ground deformation field in the last 30 years (levelling since 1987, GPS since 1998 and SAR since 1992) indicates relatively small displacements, with a general subsidence with higher values (up to about $1 \mathrm{~cm} /$ year) in the $S$ and central-W sectors (Fig. 4). Co-seismic deformations up to several $\mathrm{cm}$ are expected when significant seismic events occur, as observed during the 2017 earthquake (see Subsection Historical and instrumental seismicity in STEP 1). During the resurgence phase an average uplift velocity of the resurgent block of the order of $3 \mathrm{~cm} /$ year was calculated, but there is no information about its potential temporal variability. There is no quantitative information about the deformation during unrest and/or eruptions.

There are no specific hazard quantifications regarding ground deformation. The state of quiescence seems characterized by the substantial lack of uplift phenomena and by a general trend of subsidence, with maximum value on the order of $\mathrm{mm} /$ year, at least when resurgence is not active. Potential peaks in resurgence cannot be estimated. There are no available measurements of the variations (or of their orders of magnitude) that occurred based on monitoring ground deformation parameters for the unrest/eruption phases. By analogy with all volcanic systems, during the unrest phase, a significant increase in ground deformation rates is expected. Strong variations in the deformation patterns and rates are expected both in the case of a magmatic intrusion and during an eruption phase. During eruption, significant (tens of centimetres or greater), rapid (hours-days), deformation connected to intrusive phenomena is expected (Dzurisin 2007).

From a multi-hazard perspective, significant deformation may be caused by earthquakes, overpressure in the aquifers, as well as during the propagation of dykes and vent opening. Large deformation may trigger slope instability of all scales (from small landslides up to rock and debris avalanches, see Subsection Gravitational instability on slopes).

\section{Local seismicity}

Ischia has a well-known history of seismic events. Even if little information is available for ancient Greek and Roman times, more seismic events are known since the XIII century, showing activity mainly concentrated in the area $\mathrm{N}$ of Monte Epomeo, in the municipalities of Casamicciola and Lacco Ameno (Luongo and Cubellis 2018, and references therein; Fig. 5a). This activity affected small areas with impacts related to very high maximum intensities, probably due to shallow events $(<$ $2 \mathrm{~km}$ ) with a strong attenuation (e.g., Carlino et al. 2010). As reported by the Database Macrosismico Italiano 2015 (Locati et al. 2016), local intensity records in Casamicciola show a rather intense seismic activity starting in the eighteenth century that culminated with the 1881 and 1883 earthquakes (Fig. 11a). In particular, the catastrophic event of 1883 reached in Casamicciola a very large intensity (ranging from IX to XI in the different studies), which attenuated very rapidly in space suggesting a probable surficial source located $\mathrm{N}$ of Monte Epomeo (Luongo et al. 2006; Fig. 11b). After this strong activity at the end of the nineteenth century, only sporadic and low magnitude $\left(M_{d}<2.5\right)$ earthquakes have been registered (D'Auria et al. 2018), until the recent $\mathrm{M}_{\mathrm{w}}=4.0$ event that struck Casamicciola in August 2017, with a source that shows strong geometrical similarities with the ones inferred for the previous events (e.g., De Novellis et al. 2018; Braun et al. 2018; Calderoni et al. 2019).

Earthquakes may occur in all the phases of the volcano, including in quiet periods. The recent 2017 event shows that relatively small and shallow $(\mathrm{M}<5$ and depth $<2 \mathrm{~km}$ ) events may have large impacts, without requiring the onset of a volcanic unrest. In unrest and eruptive phases, an increase in seismic activity is expected; this heightened seismic activity will not necessarily correlate with the spatial distribution of known 

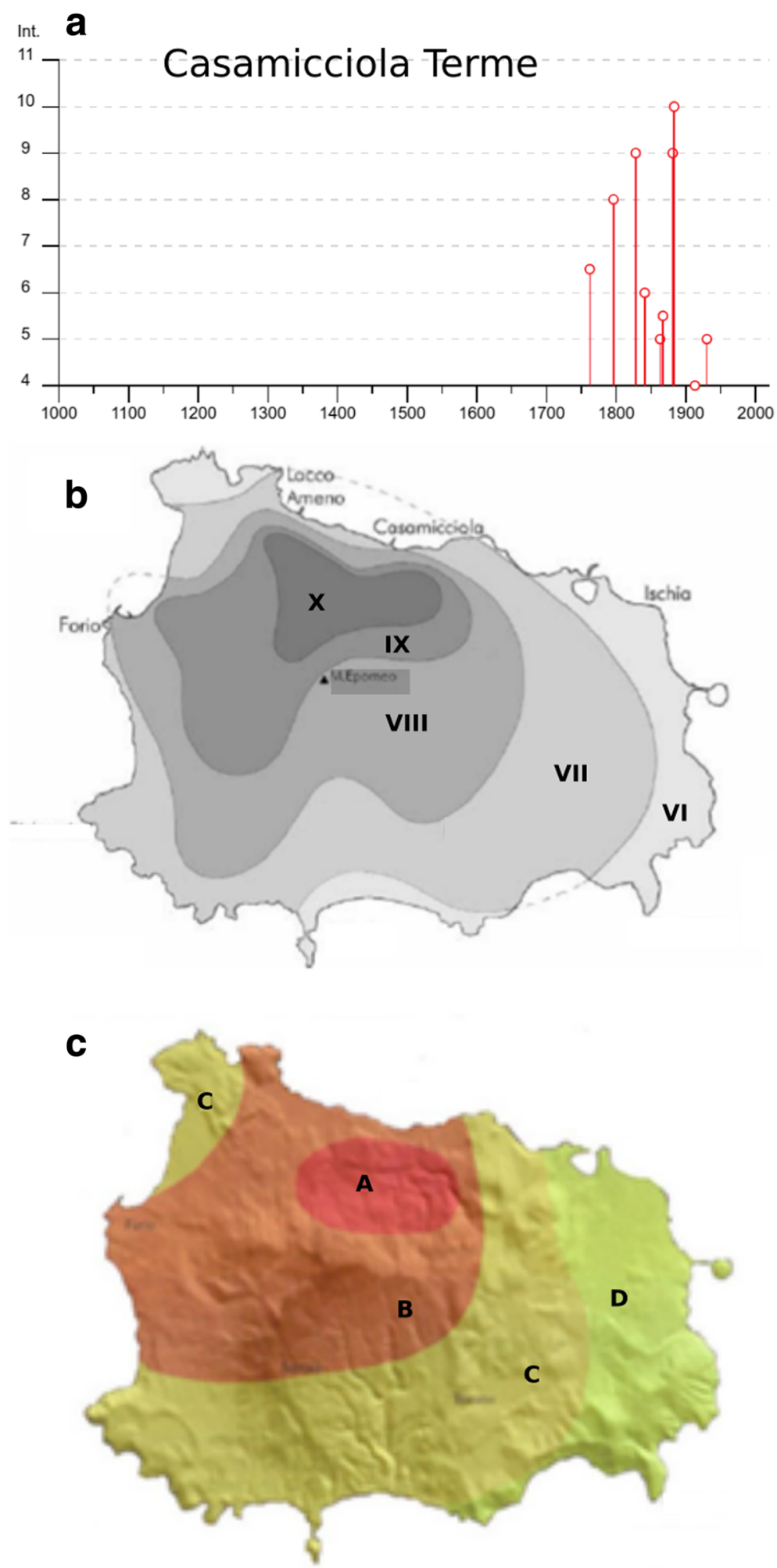

Fig. 11 Knowledge of seismic hazard: a record of observed intensities observed in Casamicciola ( $\mathrm{N}$ of Ischia), as reported in the DBMI catalogue (modified from Locati et al. 2016); b isoseismic intensities for the 1883 event, adopting the MCS scale (modified from Luongo et al. 2006); c qualitative risk map elaborated in Sbrana and Toccaceli (2011), with a qualitative scale proportional to the percentage of collapsed buildings expected in case on future earthquakes (A - high: > 75\% of collapsed buildings; B - medium-high, about 50\% of collapsed buildings; C intermediate, rare collapses and severe damages in about 25\% of buildings; D - low: diffuse damages; modified from Sbrana and Toccaceli 2011) 
seismic activity, given that it is potentially connected to magma movements.

Local and quantitative probabilistic seismic hazard analyses do not exist. The national probabilistic hazard map (Gruppo di Lavoro Mappa di Pericolosità Sismica 2004; Stucchi et al. 2011) puts Ischia within a large seismic zone extending from Ischia to the Appennines and including all the Neapolitan volcanic district (e.g. Campi Flegrei and Vesuvius), characterized by a maximum magnitude $\mathrm{Mw}$ of 5.91 and relatively low annual rates, leading to an intensity PGA between 0.12 and $0.17 \mathrm{~g}$ for the $10 \%$ probability of exceedance in 50 years (average of the epistemic uncertainty; Alberico and Petrosino 2015). Sbrana and Toccaceli (2011) report a qualitative risk map for future significant events, based on the historical seismicity (especially the 1883 event) together with geological and tectonic data (Cubellis et al. 2004). This map considers 4 levels of risk, with a spatial distribution similar to the one of the macroseismic intensity of the 1883 earthquake (Fig. 11c).

Earthquakes may trigger landslides, debris and rock avalanches, important deformations (co- and postseismic), as well as important changes in the hydrothermal system, causing sudden depressurization and vaporization. These events may trigger important multihazard scenarios (see Section Discussions and conclusions). Conversely, earthquakes may be generated by magma movements, opening of vents, deformations, as well as any event modifying significantly the stress/strain fields and/or the fault conditions (e.g., the pore pressure), including changes in the hydrothermal system.

\section{Gravitational instability on slopes}

The geological record indicates a recurrence of impulsive shallow landslides on the order of one every 100-500 years, while the recurrence of MRC is significantly larger (on the order of one every 2,000 years in the geological record, see Subsection Present geothermal system in STEP 1). The largest MRC occurred in the area of the Falanga (W of Monte Epomeo), with a volume of $125 \times 10^{6} \mathrm{~m}^{3}$. The Ischia Debris Avalanche (IDA) may correspond to an even larger event, but a certain degree of uncertainty is still associated with IDA's age and emplacement mechanism (i.e. single event/multiple event; Chiocci and de Alteriis 2006; see Subsection Present geothermal system in STEP 1). The only documented ongoing slope deformation MRC affects the NW sector of Monte Epomeo (Della Seta et al. 2012, 2015) over an area of about 1.6 $\mathrm{km}^{2}$. The geometry and depth of the involved volume is controlled by the mechanical behaviour of the Green Tuff (Marmoni et al. 2017) and was estimated by Della Seta et al. (2015) at about 190 million $\mathrm{m}^{3}$.

The impulsive nature of the trigger that activates the shallow landslides makes them associated to all phases (quiescence, unrest and eruptive). Also rock avalanches (as ultimate stage of MRC) can be associated with all phases, since they may be triggered by weathering and related rock mass damage during quiescence, as well as by internal stresses (magmatic ascents, thermo-baric variations of the hydrothermal system) or external forcing (earthquakes) during unrest or eruption. In addition, it is not possible to exclude that earthquakes and/or eruptions can trigger landslides in the submarine environment and that any landslides detached from the emergent landmass may cause subsequent phenomena of gravitational instability at sea.

Quantitative probabilistic hazard studies of the potential impact of gravitational instability on slopes are not available. Given the present state of knowledge, we can depict two main hazard scenarios, the first related to recurrent landslide activity and the second connected to MRC processes.

Intermittent landslide activity has recurrence times of the order of tens or hundreds of years, with probability related to the one of the following triggers: a) eruptive events; b) ground explosions and earthquakes; c) meteorological events. In the first case, landslides can have both small and medium-intensity (volumes of thousands and tens of thousands of $\mathrm{m}^{3}$, distance travelled ranging between tens and thousands of meters) and large volumes (large flows in rock or debris avalanche). The most predisposed areas are concentrated along the $\mathrm{N}$ and $\mathrm{W}$ sectors of the Monte Epomeo resurgent block (Casamicciola, Monte Nuovo, Ciglio). In the case of explosive eruptions with tephra fallout, volcanoclastic flows or lahars could be triggered by anomalous and intense rains generated by the dynamics of the plume itself. In the case of meteorological events, landslides are characterised by rock falls on the sea cliffs and volcanoclastic flows or lahars, sometimes evolving to floods, with high sediment concentrations and volumes from thousands to tens of thousands of $\mathrm{m}^{3}$. These flows can travel distances up to thousand meters.

Continuous deformation connected to MRC processes implies an evolution with phases of acceleration/deceleration that can culminate in a final paroxysm with collapse of entire portions of slopes, generating rock avalanches with volumes of hundreds of millions of cubic meters, speeds of hundreds of kilometers per hour and runout distances of several kilometers. The MRCinduced deformations develop over long times $\left(10^{4}-10^{5}\right.$ years) and the collapse can also occur independently from external factors, due to the evolution of the creep processes. However, external forcing (such as close or even distant earthquakes, eruptions, or explosions) can accelerate the collapse. The spatial distribution of the rock avalanche deposits that can be surveyed at Ischia suggests that the whole western and $\mathrm{N}$ side of the 
resurgent block of Monte Epomeo have been affected by this scenario. At this stage, the only documented MRC process is at Monte Nuovo and it involves the western slopes of Monte Epomeo.

The evolution of the MRC process should be strictly connected to: i) nature and style of the eruptive activity as well as of the associated deformation processes during unrest or eruptions (with particular reference to internal pressures related to magmatic intrusion effects, see Subsection Ground deformation); ii) tectonic stress field and related faulting and fracturing (Subsection Local seismicity); iii) hydrothermal activity, pressure of fluids and effects of chemical alteration of rocks and soils (Subsection Instability of the hydrothermal system and phreatic explosions; Lopez and Williams 1993, Reid et al. 2001, Reid 2004, Kiryukhin et al. 2012; Kiryukhin 2016; Chen et al. 2014; Ye et al. 2015; Marmoni et al. 2017); iv) intervention of external impulsive forcing linked to the dynamics of the volcanic system (e.g., earthquakes, deformations). Regarding the seismic trigger, low frequency contributions (also from far events) have been suggested to be more efficient in triggering MRC (Lenti et al. 2015), even if also high frequency local events have been suggested as potential triggers (Paparo and Tinti 2017).

The lack of historical observations does not allow a robust statistical analysis of the occurrence and of the possible cause/effect relationships (i.e. trigger/landslide), between types of destabilizing action and intensity of the triggered phenomenon, for neither MRC nor the impulsive landslides and lahars. In both cases, more study is necessary to constrain potential behaviours in the case of stress changes induced by regional and local earthquakes.

The ultimate evolution of MRC into rock avalanche can lead to multi-hazard scenarios such as instantaneous decompression effects of the underlying hydrothermal systems, inducing phreatic or hydrothermal eruptions, phreatic explosions (Subsection Instability of the hydrothermal system and phreatic explosions), as well as tsunamis (Subsection Tsunami) when the coast is reached.

\section{Tsunami}

The Euro-Mediterranean Tsunami Catalog (Maramai et al. 2014; EMTC - Euro-Mediterranean Tsunami Catalog 2018) does report several tsunami events in the gulf of Naples, none of them generated by the volcanic system of Ischia. In the archeological-historical record, a tsunami is reported to have occurred in the time span between the first century $\mathrm{BC}$ and the first century $\mathrm{AD}$ during a volcanic eruption, possibly caused by a volcanic earthquake (Buchner 1986). Geological surveys along the coasts of Ischia have identified several landslide deposits that may have generated tsunamis, in particular in the $\mathrm{N}, \mathrm{W}$ and S sectors, probably connected to debris and/ or rock avalanches originated at Monte Epomeo (Della Seta et al. 2012). The largest of these deposits (IDA) has been recognized offshore at the south of Ischia, occurred in prehistorical times (Chiocci and de Alteriis 2006), but the origin and the nature of this deposit is still debated (see Subsection Present geothermal system of STEP 1). Assuming that it has been generated by one single catastrophic event, this avalanche would have caused a huge tsunami (Tinti et al. 2011).

Tsunamis generated in Ischia may occur in all the states of the volcano. There are no quantitative studies about the probability of occurrence of tsunamis in the future. In general, large tsunamis seem quite rare (no observations in historical times), but they may be catastrophic when they occur. During quiet periods, tsunamis may be generated mainly by rock or debris avalanches, which are possible but rare. The occurrence of these events may be triggered by regional seismic activity, as well as by deformations and local seismic activity typical of unrest and eruptive phases. During unrest, tsunamis may be additionally caused by earthquakes, even if large offshore events $\left(M_{w}>6.5\right)$ seem to be quite unlikely. During eruptive phases, tsunamis may also be caused by submarine explosions and dense pyroclastic flows. Vent opening at sea is considered possible, even if with relatively small probabilities (see Subsection Opening of new vents).

Probabilistic tsunami hazard analyses from Ischia sources are not available. For the tsunamis generated by subaerial landslides, several scenarios were simulated, providing an indication of the potential spatial distribution of tsunami intensities for different scales of landslides. We can provide a reasonable coverage of the possible scales with: i) large impulsive avalanches like IDA; ii) large rock avalanches (with volumes $10^{8}-10^{9}$ $\mathrm{m}^{3}$ ), as the potential collapse of Monte Nuovo; iii) smaller shallow landslides. The occurrence of events of types i), ii) and iii) in the different sectors of Ischia is discussed in Subsection Gravitational instability on slopes. An event like IDA may cause a huge tsunami with waves of tens of meters in Ischia and in many areas in the gulf of Naples, and an impacted area extending to a large sector of the surrounding Tyrrhenian coast (Tinti et al. 2011; Fig. 12a). Large rock avalanches like the one potentially originated by the MRC of Monte Nuovo (NW of Monte Epomeo, see Subsection Gravitational instability on slopes) would also cause large tsunamis. In the case of Monte Nuovo, the tsunami would impact with waves of tens of meters along the western and, locally, the $\mathrm{N}$ coast of Ischia (Zaniboni et al. 2013; Fig. 12b), and with waves several meters along the coast to the $\mathrm{N}$ of the gulf of Naples. Shallow impulsive 

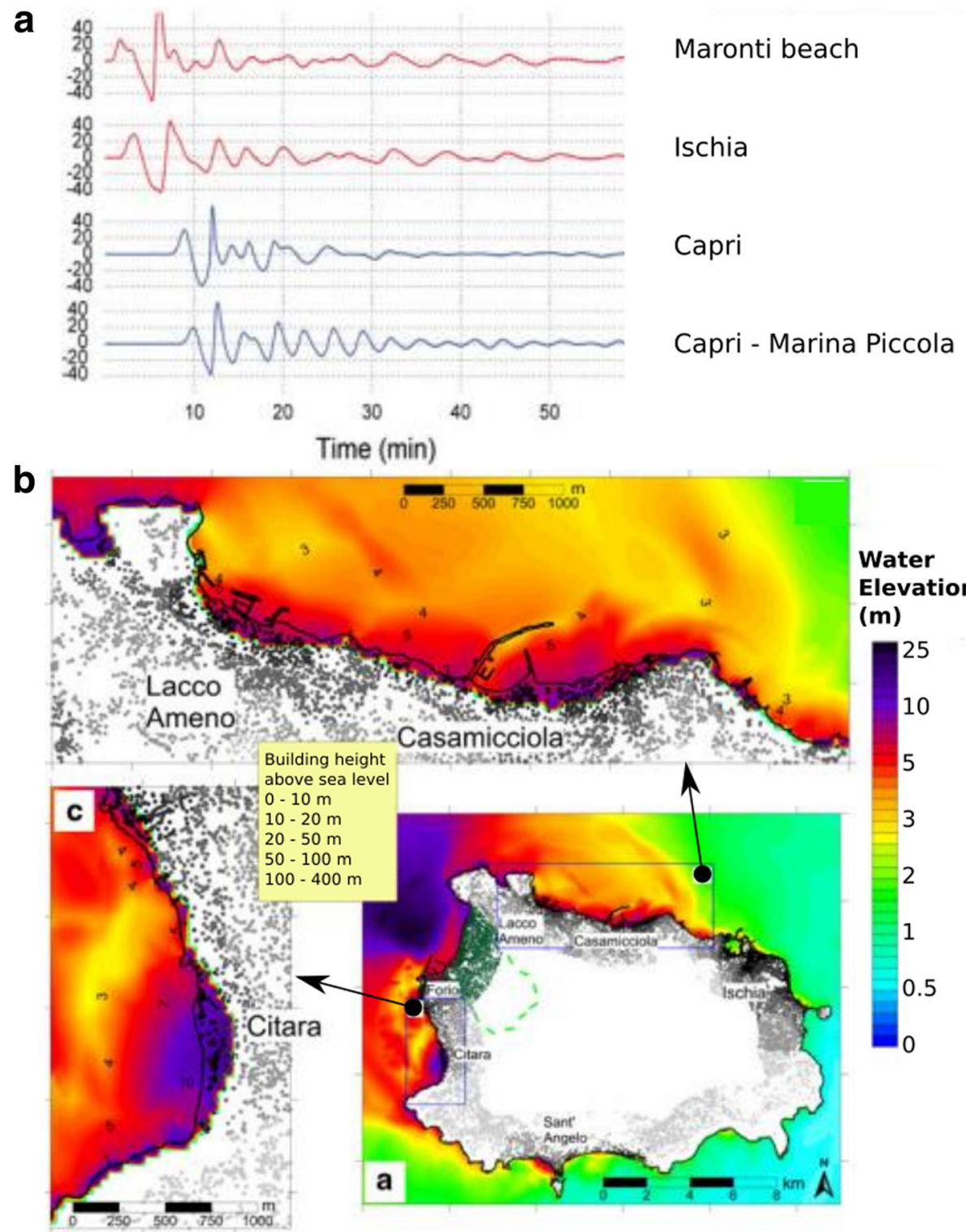

Fig. 12 Knowledge of tsunami hazard: a Synthetic mareograms in different areas for the tsunami potentially generated by the Ischia debris avalanche (modified from Tinti et al. 2011); b maximum elevation height close to the coast for the tsunami potentially generated by the Monte Nuovo rock avalanche (modified from Zaniboni et al. 2013)

landslides may generate tsunamis with much smaller intensities, but with a propagation pattern similar to the Monte Nuovo for events in N and W sectors, and similar to IDA for events generated in the $\mathrm{S}$ sector of Ischia (Tinti, personal communication).

Regarding potential regional tsunamis impacting Ischia, Grezio et al. (2015), based on a simplified propagation models, concluded that the main cause for potential tsunami at Ischia seems to be earthquakes, followed by landslides and submarine slumps, all of them with very small mean annual frequencies $\left(<10^{-6} /\right.$ year $)$. Volcanic tsunamis originated at Campi Flegrei or Vesuvius have not been investigated. In the regional seismic probabilistic tsunami hazard analysis of TSUMAPS-NEAM Probabilistic Tsunami Hazard Maps for the NEAM region (2018), the area of Ischia has a relatively small hazard, with a maximum inundation height $(\mathrm{MIH}) \leq 0.5 \mathrm{~m}$ (corresponding to local maxima in the order of $1.5 \mathrm{~m}$ ) for an exceedance probability of $2 \%$ in 50 years.

In a multi-hazard perspective, tsunamis of different potential sizes may be generated by a long list of phenomena, especially in a volcanic environment, including underwater explosions, pyroclastic flows, earthquakes, flank failures and large landslides, 
caldera subsidence, shock waves, lahars, collapse of lava bench (Paris et al. 2013; Grezio et al. 2017) that, in turn, may be triggered by other phenomena, as discussed in more detail in the respective subsections of STEP 2.

\section{STEP 3: conceptual interpretative framework}

Here we develop a interpretative framework connecting the multiple hazards generated at Ischia. This type of conceptual models may provide a basis for future singleand multi-hazard and risk analyses (e.g., IAEA - International Atomic Energy Agency 2012, 2016). Its rationale is discussed in Subsection The conceptual multihazard framework, while the related single and multihazard scenarios are discussed in Subsections The hazard scenarios within the CMF and Multi-hazard scenarios, respectively.

\section{The conceptual multi-hazard framework}

The Conceptual Multi-hazard Framework (CMF) is based on the geologic evidence available for the reference period (last $10 \mathrm{ka}$ ) and relies on the dichotomy expressed by extensive peripheral eruptive activity and no eruption in the resurgent block (see Subsections Resurgence of STEP 1 and Opening of new vents of STEP 2). More specifically, within the resurgence (Subsection Resurgence in STEP 1), no eruptions have occurred in the last $10 \mathrm{ka}$ (observation extendible also to $\sim 30 \mathrm{ka}$ ). In the last $10 \mathrm{ka}$, syn-resurgence eruptions focused outside and along the resurgent block, in particular to the east (Fig. 8), with 43 , small size (mostly $<0.1 \mathrm{~km}^{3}$ ) eruptions that formed a monogenetic field, probably fed by several, limited and independent reservoirs within a crystalline mush (Subsection Magmatic system of STEP 1; e.g., Casalini et al. 2017). The eruptive styles (Subsection Eruption of STEP 1) ranged from effusive to explosive and phreato-magmatic.

The distribution of the syn-resurgence vents suggests that the shallowest rise and extrusion of magma has been hindered below the resurgent block. Indeed, the uplift of $\sim 1000 \mathrm{~m}$ of the resurgent block testifies to the accumulation of magma. Therefore, the resurgence confirms the difficulty of magma to extrude, accumulating and triggering uplift. The unbalance between the volume uplifted by resurgence $\left(\sim 10 \mathrm{~km}^{3}\right.$, suggesting the intrusion of at least a similar amount of magma) and that erupted on the island during resurgence $\left(<1 \mathrm{~km}^{3}\right)$ indicates that most of the magma responsible for resurgence has not (yet) erupted. This has been related to the presence of intermediate-viscosity residual magma at depth, whose low viscosity contrast with the newly injected magma hinders the propagation of the latter through dikes, thus hindering eruptions (Galletto et al. 2017).
The resurgent area is also connected with the origin of different distribution and types of landslides (Subsection Present geothermal system of STEP 1), providing a rapidly uplifting sector in the last tens of ka. The sides of the resurgent block mainly show mass rock creep (MRC, Subsection Geological and historical instability of slopes of STEP 1), possibly evolving in widespread collapses forming rock avalanches (especially to the $\mathrm{N}$ and W) or shallow impulsive landslides (e.g., Della Seta et al. 2012). Conversely, both the area within the block and outside have mainly experienced impulsive landslides.

Resurgence is also related to the seismicity (Subsection Historical and instrumental seismicity of STEP 1), which has been mostly affecting the northern boundary of the block. Seismogenic structures coincide with those developed during resurgence (e.g., Luongo and Cubellis 2018), even though the co-seismic deformation during the 2017 earthquake suggests subsidence (e.g., de Novellis et al. 2018). Lastly, hydrothermal activity also focuses along the border of the block (Subsection Present geothermal system of STEP 1).

Based on what has been discussed so far, we may distinguish selected areas where sources of specific hazards dominate (Fig. 13):

a) The inner part of the resurgent block (Sector 1; Fig. 13), with impulsive landslides or debris avalanches. Here eruptions are unlikely, as the shallow rise of magma appears hindered. Hydrothermal activity occurs mainly in the southern portion.

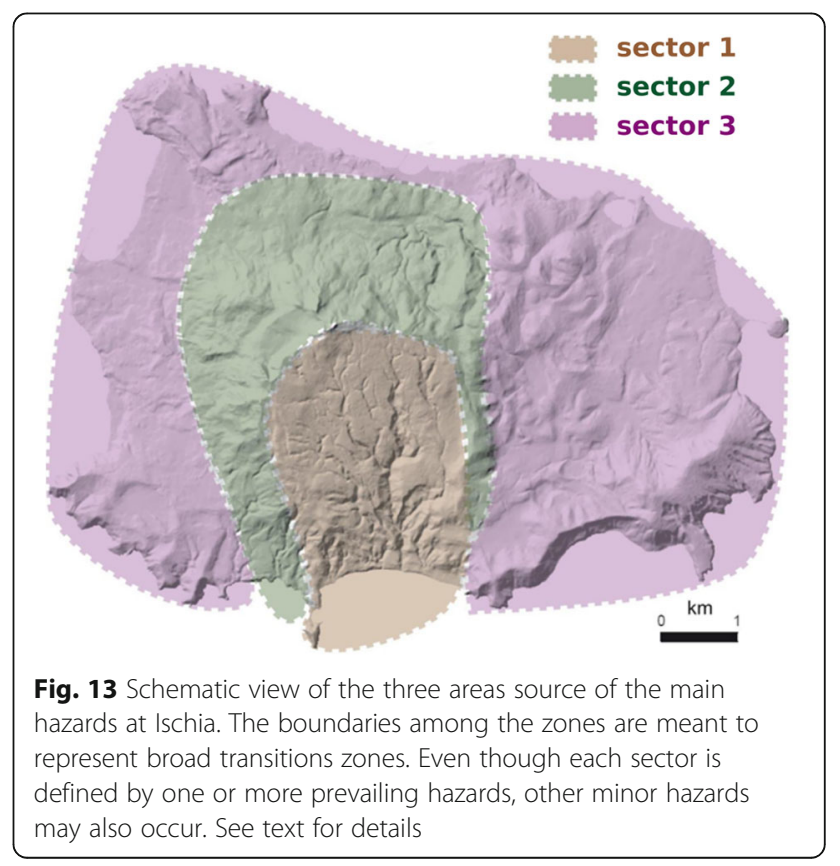


b) The border of resurgent block (Sector 2, Fig. 13), where mass rock creep (MRC) may evolve into widespread collapses, especially to the $\mathrm{N}$ and $\mathrm{W}$ (as at Monte Nuovo). Eruptive activity may occur along the faults bordering the resurgence (especially to the E), while seismicity occurs along the faults to the $\mathrm{N}$. The western and northern borders of the block also show hydrothermal activity.

c) The area outside the resurgent block (Sector 3, Fig. 13), with eruptive activity (mainly along regional fault systems to the E) and, subordinately, shallow impulsive landslides, mostly in the SE and SW.

In synthesis, the current setting of Ischia results from important asymmetries in the magmatic system, topography, instability of the slopes, seismicity, and hydrothermal system. This asymmetric distribution reflects the interdependence among resurgence, magmatic-eruptive activity, hydrothermal, seismic, and gravitational activity and controls the distribution of the sources of different natural hazards. This resurgence-driven asymmetry, and its related processes, defines the core of our CMF for Ischia, providing a descriptive and qualitative reference to interpret the types and distributions of hazards, as well as their inter-dependence.

\section{The hazard scenarios within the CMF}

With hazard scenarios here we mean typologies of hazardous events that may occur and trigger to each other within the CMF, taking into account the triggering factors and source areas. These typologies are related to the different observed hazards (magmatic, eruptive, seismic, gravitational, hydrothermal), or to their combination (multi-hazard).

\section{Eruptive hazards}

According to the CMF, an eruption may occur along the margins of the resurgent block, or, most likely, outside, along the major structures, that is, in Sectors 2 and 3 of Fig. 13. The focusing of vents on the E sector suggests a higher probability for a future eruption here (Subsection Opening of new vents in STEP 2). This possibly agrees with the asymmetry of the hazards emerging from the CMF. Nevertheless, we lack adequate information to provide a more detailed zonation for the opening of vents in this area, fearing the potential overfitting of the few available data. This suggests that the area outside the resurgence may have a relatively homogeneous probability of opening of new vents, with a possible predominance in the eastern sector. This conclusion, also based on an interpretation of the processes driving resurgence (e.g. Galletto et al. 2017), generally agrees with the observed past vents and the available previous studies, but it differs from them when they show a higher resolution in the distribution of the probability of opening of new vents (see Subsection Opening of new vents in STEP 2).

Based on what is observed for the last $10 \mathrm{ka}$, any eruption should erupt no more than a few tens of millions of $\mathrm{m}^{3}$ of magma (very likely $\leq 0.1 \mathrm{~km}^{3}$; see Subsection Eruption in STEP 1). All eruption types are possible and the explosive ones, based on the stratigraphic record, very unlikely can be larger than VEI 3-4 (e.g. Cretaio eruption, Orsi et al. 1992). Effusive eruptions may produce thick and viscous flows and domes, with a likely duration of up to a few months; explosive eruptions may range from Strombolian to violent Strombolian, lasting hours to days; phreato-magmatic surges may last from a few hours to a few days, and cross topographic barriers.

The eruptions of Arso, Cretaio, and Piano Liguori may be taken as a reference for potential maximum event for each type of eruption, given that these are the largest within the reference period (Subsection Eruption in STEP 1).

\section{Hydrothermal hazard}

Even though phreatic explosions have not been recognized, we cannot exclude their future occurrence, also during unrest (Subsection Instability of the hydrothermal system and phreatic explosions in STEP 2). The most favourable conditions occur in the N, W and S sectors, where there are the most active fumaroles and diffuse $\mathrm{CO}_{2}$ degassing. Within the $\mathrm{CMF}$, we may envisage two main scenarios for phreatic explosions:

a) Depressurization of an aquifer close to boiling, resulting in the explosive flashing of the liquid water, triggered by sufficiently deep landslides. This possibility is most likely in Sector 1 of Fig. 13, in particular on its $\mathrm{W}$ side.

b) A pressure build-up of the aquifer caused by a magmatic intrusion releasing heat and volatiles, increasing the temperature and the pressure of the hydrothermal system. This may occur in Sectors 2 and 3 of Fig. 13.

\section{Gravitational instability hazard}

By "gravitational instability" we mean the deformation and/or mobilization of the volcano slopes under the effect of gravity. This may occur with different processes and modalities (Subsections Gravitational instability on slopes in STEP 1), related to different volumes and velocities. Within the CMF, we may envisage two main scenarios for large gravitational instability (categories $1 \mathrm{a}$ or b in Subsection Geological and historical instability of slopes in STEP 1): 
a) Large impulsive landslides, triggered by eruptions and seismicity; these are more likely in Sectors 1 and 2 of Fig. 13, along the $\mathrm{N}$ and $\mathrm{W}$ borders of the block. Smaller landslides may be triggered also by meteorological events, throughout the island.

b) Large landslides connected to the acceleration of long-term mass rock creep, not requiring a triggering factor, even though seismicity, magma intrusions and eruptions may accelerate their failure. These collapses, especially if located in the $\mathrm{N}$ and $\mathrm{W}$ sectors, can reach the coastline and trigger potentially large tsunamis.

\section{Earthquake hazard}

Here we focus on the earthquakes whose epicentres lies within the caldera (Subsection Volcanological evolution of STEP 1). Focusing only on relevant seismicity (e.g., $M_{w}>2.0$ ), within the CMF we may envisage two main scenarios: a) The very shallow ( $<2 \mathrm{~km}$ deep) activity of the E-W structures along the northern margin of the resurgent block ( $\mathrm{N}$ of Sector 2 of Fig. 13). This seismicity may reach magnitude 5-5.5 (for the 1881 and 1883 events). The seismicity does not appear to be induced by reactivation of the resurgence (i.e. is not associated with any uplift on the block); rather it is reactivating the inward-dipping resurgence border faults with an extensional motion (De Novellis et al. 2018).

b) The seismicity related to the emplacement of an intrusion, probably a sill or a laccolith, during unrest, due to the fracturing of the host rock. This may occur anywhere below the island, probably focusing along its periphery during the rise of the magma.

\section{Multi-hazard scenarios}

The multi-hazard scenarios consider likely combinations of the four main hazards: eruptive (including preeruptive unrest), landslide, seismicity, and hydrothermal,

a

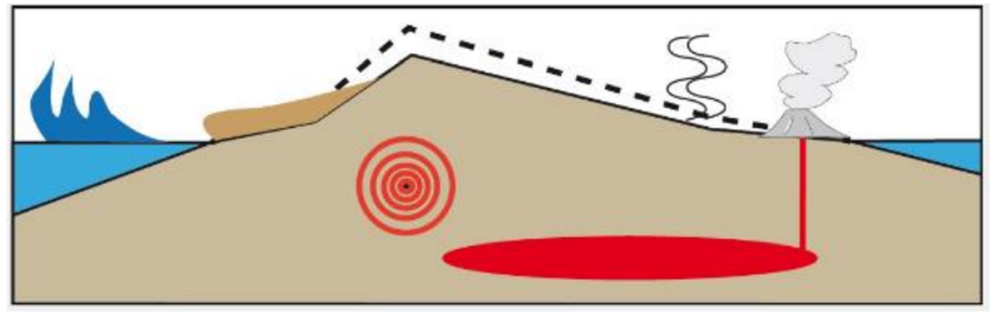

b

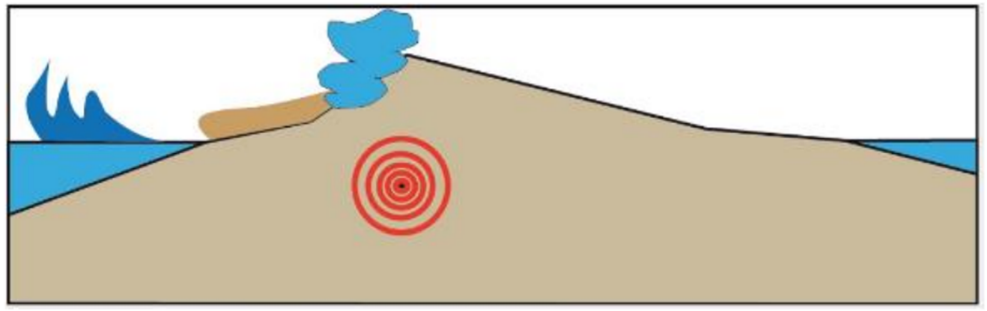

C

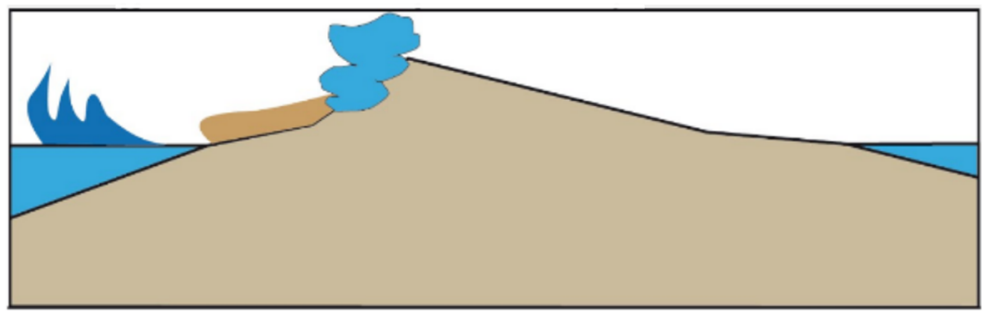

Fig. 14 Sketches illustrating the possible multi-hazard scenarios occurring at Ischia. Not to scale. a Magma-induced multi hazard: the emplacement of a shallow intrusion (1) induces seismicity (2) and deformation (3), possibly destabilizing the resurgence border (4) and, in the case of the landslide products entering the sea, triggering a tsunami (5). Eventually, the intruded magma may erupt (6). b Seismicity-induced multi-hazard: one or more earthquakes (1) may trigger the collapse along the border of the resurgence (2), eventually promoting phreatic explosions for decompression (3) or tsunamis (4), if the collapsed deposits enter the sea. c landslide induced multi-hazard: a collapse along the border of the resurgence (1) may, eventually promote phreatic explosions for decompression (2) or tsunamis (3), if the collapsed deposits enter the sea 
adopting a what if logic. To develop the multi-hazard scenarios, we consider that each hazard may trigger other hazards, producing wider and stronger impacts than the ones expected from a single hazard. This possibility is highlighted within the CMF, which shows (Fig. 13) how hazards of different nature may originate in the same area or in nearby areas.

Several combinations of multi-hazard scenarios may be expected; however, the main hazards triggering a potential sequence of other hazards are magma movements, seismicity, and landslides, described below.

\section{Scenario triggered by magmatic processes}

This scenario, schematically represented in Fig. 14a, includes a sequence of hazards triggered by unrest, culminating or not in an eruption.

During unrest, surface deformation and/or seismicity may destabilize several parts of the island, most notably those bordering the resurgent block. These destabilized portions (e.g., a rock avalanche), in turn, may reach the coast, triggering tsunamis possibly also reaching the mainland. Magmatic fluids or rock avalanches may cause sudden pressure changes in the hydrothermal system, triggering phreatic explosions in any portion of Ischia, with a focus along the $\mathrm{N}$ and $\mathrm{W}$ borders of the resurgent block,.

In case of eruption, the hazards will vary according to the eruptive style and intensity. If an explosive eruptive column forms the blanket of tephra may also trigger syn-eruptive lahars during or after rainfall events.

\section{Scenario triggered by seismicity}

This scenario, schematically represented in Fig. 14b, may be triggered by unrest, or simply start as an isolated seismic event.

Both prolonged unrest-related or sudden and isolated seismicity may trigger impulsive landslides, especially within the block. The high frequency volcano-tectonic seismicity beneath Ischia (Subsection Historical and instrumental seismicity in STEP 1) appears less effective than the longer period seismicity or the stronger regional earthquakes (see Subsection Gravitational instability on slopes in STEP 2) in triggering rock avalanches from MRC processes along the borders of the block. Therefore, the destabilizing effect of an earthquake may partly depend on the nature of the seismic event. Looking at the seismicity generated at Ischia, the likelihood of large landslides (Subsection Scenario triggered by landslides above) potentially triggering tsunamis seems larger for seismic scenarios of type 2 (due to magma intrusion) than of type 1 (related to the structure, see Subsection Earthquake hazard above).

Any sudden depressurization, caused by fracturing or landslides, may lead to the sudden vaporization of the shallow (150-300 m) hydrothermal system, generating phreatic or hydrothermal explosions.

\section{Scenario triggered by landslides}

This multi-hazard scenario, schematically represented in Fig. 14c, is triggered by mass rock creep processes along the slopes of the block, independently of any unrest or non-magmatic seismicity.

Such a slope destabilization may induce a sudden decompression in the hydrothermal system, triggering phreatic eruptions. The generated rock avalanches may, in turn, reach the coastline, generating tsunamis. The possibility that an important landslide occurs along the border of resurgence (as the Monte Nuovo area) decompresses the magmatic system and generates an eruption appears unlikely, unless any magma has been already emplaced at very shallow depths $(<2-3 \mathrm{~km})$ during a previous unrest.

\section{Discussions and conclusions}

This paper is focused on building a foundation for future single- and multi-hazard assessments at Ischia Island through a comprehensive review of the state of knowledge about Ischia volcanic system (STEP 1) and about available hazard studies (STEP 2), and the development of a conceptual interpretative multi-hazard framework that deepens the relationship between the hazards and the structure of the resurgence (STEP 3). The focus was on the whole island of Ischia and included all potential hazards generated by the volcanic systemwith ordinary mean return periods (shorter than tens of thousands of years).

In STEP 1, considering the evolution of Ischia volcanic system, it was found that a period of $10 \mathrm{ka}$, characterized by the renewal of volcanic activity after a period of low or no activity also marked by changes in magma chemistry, can be considered representative of the present state of the volcano for the purposes of most ordinary hazards assessments. Of course, considering that hazards analyses should not be reliant on a subset of available information, this period should be taken as a minimum for ordinary hazard analyses (noteworthy, critical infrastructures such as nuclear power plants may require longer reference periods, see IAEA - International Atomic Energy Agency 2012).

Since at least the 1980s, Ischia has been at rest and this quiescence is characterized by subsidence, lowenergy seismicity with sporadic shallow $(<2 \mathrm{~km})$ events locally causing large ground accelerations, important gravitational instability phenomena and hydrothermal activity. From geological and historical records, unrest seems to be characterized by the potential simultaneous occurrence of significant seismic activity and gravitational failures, possibly connected with volcanism. The 
records of past eruptions in the last 10 ka include 5 typologies: i) effusive with lava domes or ii) with lava flows; iii) explosive with prevalence of magmatic explosions, iv) with prevalence of phreatomagmatic explosions, or v) with mixed magmatic and phreatomagmatic phases. The magnitude and intensity of past events is not well constrained, highlighting an important limit for hazard quantifications. The different typologies are almost equally represented in the known record, with annual frequencies on the order of $10^{-3} /$ year in the last $3 \mathrm{ka}$ and lower frequencies in the last $10 \mathrm{ka}$. While these numbers are uncertain, the higher frequencies in recent times seem to correspond to an increase in the activity in this period more than due to data incompleteness. The period from the last eruption (1302 AD) is by far the largest inter-event time in the last $3 \mathrm{ka}$, possibly indicating that the last eruption concluded this period of higher activity.

The review of available hazard analyses of STEP 2 is summarized in Table 2. Quantitative probabilistic hazard assessments are almost absent, in part related to a scarce availability of the required input data. In the literature on Ischia, hazards are often characterized through semiqualitative indexes (ash, pyroclastic flows, earthquakes) and/or through single or few rather arbitrary scenarios (tsunamis, landslides, earthquakes), and/or simply through past events (lava, ballistics). In some cases (deformations, atmospheric phenomena, gas), the hazards are characterized mainly by analogy with other volcanoes. In all cases, the exploration of natural variability is too poor considering the vast variety of phenomena that may contribute to risk in an intensely urbanized island like Ischia.

The available knowledge allows us to infer that in quiescence, surficial landslides, hydrothermal activity and degassing are frequent hazards, while more potentially damaging phenomena like earthquakes, tsunamis, and rock avalanches are quite rare, but still possible. In unrest, hydrothermal activity and degassing may increase, and earthquakes, tsunamis, and rock avalanches become more probable. In eruptions, tephra fallout and pyroclastic flows dominate for explosive eruptions, while lava flows dominate for effusive eruptions. The available quantifications also suggest that all the phenomena may have a limited effect on the mainland, with the exception of tsunamis and tephra fall. As the dominant winds blow westwards, volcanic plumes may affect the city of Naples with tephra fall. The likelihood of such an event, as deduced from the last $10 \mathrm{ka}$ of activity, remains low, albeit not negligible. Regarding tsunamis, even though the Ischia Debris Avalanche may have occurred in the reference period, the present-day conditions do not seem favourable for the repetition of a similar large-scale event, while smaller (but still very large) mass rock creep processes are more likely, potentially triggering tsunamis hitting the nearby mainland.

The interpretative multi-hazard framework developed in STEP 3 is based on the inferred relationship between the asymmetric structure generated by the resurgence and the processes generating the different hazards, considering that most of the gravitational flows originated from the area of greatest resurgence; the observed nonmagmatic seismicity is concentrated in the northernmost part of this resurgent area; and that eruptions occurred outside of this area. Following a what if scheme, we envisaged scenarios for single and multiple hazards related to magmatic, seismic, and gravitational activity.

The overall state of knowledge regarding the hazards at Ischia seems to be rather poor. The lack of the required input data seems to be the main reason for the lack of probabilistic volcanic hazard. For tsunami hazard, the emerging picture is quite ambiguous, with many studies indicating the potential for large tsunamis, but neither historical nor geological confirmation, even for the largest sizes. Given the potential risk demonstrated by past (e.g., 1883) and recent (August 2017) earthquakes, the lack of local probabilistic seismic hazard models is quite striking, and future efforts should focus on this possibly also investigating the cause of the apparent significant variability in time of the seismic rate. Equally striking seems to be a substantial lack of specific studies on Ischia about the triggering mechanisms of large scale landslides and of phreatic explosions. Finally, there is also lack of analyses for potential short-term evolution (days to years) connected to a re-activation of the magmatic system of Ischia.

To specifically improve this situation, different types of analyses are necessary. A general improvement of basic data and monitoring is necessary, including (i) the characterization of seismic source and their relation to the hydrothermal system and the resurgence; (ii) the characterization of the magnitude and the intensity of past eruptions, including the potential for phreatic and phreato-magmatic activity; (iii) the analysis of magma ascent patterns, their time-scale, and their relationship with the resurgence; (iv) the better definition of the mechanism of acceleration of deep creeping and/or (re) activation of impulsive large landslides; (v) the definition of the potential for (deep) phreatic activity; (vi) the characterization of the potential sources for local tsunamis; (vii) the definition of magnitude/intensity distribution of eruptions. It is also fundamental to develop local probabilistic hazard models, especially for earthquakes, ash fall, pyroclastic flows, lava flows, as well as phreatic eruptions.

Important developments of the monitoring system are also required, including the permanent monitoring of the Monte Nuovo creep, the permanent geodetic network (to 
enable an early detection of a potential reversal and to improve the source inversion capability in case of unrest), as well as the improvement of the geochemical monitoring (e.g., for monitoring temperatures and $\mathrm{CO}_{2}$ ), and more frequent campaigns for tracking potential changes in the deep hydrothermal system and wells. The seismic network has recently improved after the 2017 seismic sequence, leading to a relatively good coverage of local seismicity.

\section{Abbreviations \\ CEDIT: Italian Catalogue of Earthquake-Induced Ground Failures in Italy (For- tunato et al. 2012, Martino et al. 2014, http://www.ceri.uniroma1.it/index_ cedit.html); CM: Conceptual Model; CMF: Conceptual multi-hazard framework; CPT115: Catalogo Parametrico dei Terremoti Italiani 2015 - CPTI15 (Rovida et al. 2016; https://emidius.mi.ingv.t//CPTI15-DBMI15/); DBMI15: Database Macrosismico Italiano 2015 (Locati et al. 2016; https://emidius.mi.ingv.it/ CPTI15-DBMI15/); DPC: Italian Department of Civil Protection (http://www. protezionecivile.gov.it); GdL_MPS: Gruppo di Lavoro Mappa di Pericolosità Sismica (2004) and Stucchi et al. (2011); IDA: Ischia Debris Avalanche (Chiocci et al. 2001); INGV: Istituto Nazionale di Geofisica e Vulcanologia (http://www. ingv.it/); INGV-OV: Osservatorio Vesuviano of INGV (http://www.ov.ingv.it/ov/); INGV-PA: Sezione di Palermo of INGV (http://www.pa.ingv.it/); MCS: Mercalli- Cancani-Sieberg macroseismic scale; MEGT: Monte Epomeo Green Tuff (Brown et al. 2008); MIH: Maximum Inundation Height; MRC: Mass Rock Creep (Chigira 1992); PDCs: Pyroclastic density currents; PGA: Peak Ground Acceleration; SAFEN: Società Anonima Forze Endogene Napoletane; SMOWV: Vienna Standard Mean Ocean Water (Coplen 1994); TDS: Total Dissolved Solid; WG: Working Group}

\section{Acknowledgements}

The authors thank for the fruitful discussions and the constructive suggestions I. Arienzo, M. D’Antonio, R. Avanzinelli, L. D'Auria, F. Bianco, V. Convertito, G. Chiodini, R. Di Napoli, S. Carlino, M.R. Manzo, R. Castaldo, P. Tizzani, R. Lanari, C. Ciuccarelli, R. Comastri, F. Chiocci, F. Budillon, S. Tinti, G. Mastronuzzi, P. Albert, R. Sulpizio, L. Zaccarelli, L. Sandri, A. Sbrana, R. Toccaceli, L. Vezzoli, and all the participants to the Workshop "Pericolosità a Ischia e Vulcano" held in Rome the 30 and 31st May 2017 at the Istituto Nazionale di Geofisica e Vulcanologia. We also thank C. Connors, J. Lindsay and two anonymous reviewers for their useful and constructive comments. This work benefited of the agreement between Istituto Nazionale di Geofisica e Vulcanologia and the Italian Presidenza del Consiglio dei Ministri, Dipartimento della Protezione Civile (DPC). This paper does not necessarily represent DPC official opinion and policies.

\section{Authors' contributions}

All the authors contributed in elaborating, writing and revising the manuscript. JS coordinated the writing. CC coordinated the link between WG and DPC. All authors read and approved the final manuscript.

\section{Funding}

This work has been produced within the agreement between Istituto Nazionale di Geofisica e Vulcanologia (INGV) and the Italian Presidenza del Consiglio dei Ministri, Dipartimento della Protezione Civile (DPC). This paper does not necessarily represent DPC official opinion and policies.

\section{Availability of data and materials}

All the data used supporting the findings of this paper can be found in this referenced literature.

\section{Competing interests}

The authors declare that they have no competing interests.

\section{Author details}

'Istituto Nazionale di Geofisica e Vulcanologia, Sezione di Bologna, Bologna, Italy. ${ }^{2}$ Dipartimento Scienze, Università di Roma Tre, Rome, Italy. ${ }^{3}$ Istituto Nazionale di Geofisica e Vulcanologia, Sezione di Pisa, Pisa, Italy. ${ }^{4}$ sttituto Nazionale di Geofisica e Vulcanologia, Osservatorio Vesuviano, Naples, Italy. ${ }^{5}$ Dipartimento di Scienze della Terra, Sapienza Università di Roma, Rome,
Italy. ${ }^{6}$ Istituto Nazionale di Geofisica e Vulcanologia, Sezione di Palermo, Palermo, Italy. ${ }^{7}$ Dipartimento della Protezione Civile, Rome, Italy.

Received: 30 October 2018 Accepted: 5 July 2019

Published online: 26 July 2019

\section{References}

Acocella V, Funiciello R. The interaction between regional and local tectonics during resurgent doming: the case of the island of Ischia, Italy. J. Volcanol Geotherm Res. 1999;88:109-23.

Acocella V, Funiciello R. Transverse systems along the extensional Tyrrhenian margin of Central Italy and their influence on volcanism. Tectonics. 2006;25 TC2003. https://doi.org/10.1029/2005TC001845.

ACS-CCS (American Chemical Society - Committee on Chemical Safety). Identifying and evaluating hazards in research laboratories - guidelines developed by the Hazard identification and evaluation task force of the American Chemical Society's committee on chemical safety. Washington, D. C.: American Chemecial Society; 2015.

Aiello G. New insights on the late Quaternary geologic evolution of the Ischia Island coastal belt based on high-resolution seismic profilesital. J Geosci. 2018;137(1):87-106. https://doi.org/10.3301/IJG.2017.19.

Aiuppa A, Avino R, Brusca L, Caliro S, Chiodini G, D'Alessandro W, Favara R, Federico C, Ginevra W, Inguaggiato S, Longo M, Pecoraino G, Valenza M. Mineral control of arsenic content in thermal waters from volcano-hosted hydrothermal systems: insights from island of Ischia and Phlegrean fields (Campanian Volcanic Province, Italy). Chem Geol. 2006;229(4):313-30.

Alberico I, Lirer L, Petrosino P, Scandone R. Volcanic hazard and risk assessment from pyroclastic flows at Ischia Island (southern Italy). J Volcanol Geotherm Res. 2008;171:118-36.

Alberico I, Petrosino P. The hazard indices as a tool to support the territorial planning: the case study of Ischia island (southern Italy). Eng Geol. 2015; 197(2015):225-39.

Albert PG, Tomlinson EL, Smith VC, Di Roberto A, Todman A, Rosi M, Marani M, Muller W, Menzies MA. Marine-continental tephra corre- lations: volcanic glass geochemistry from the Marsili Basin and the Aeolian Islands, southern Tyrrhenian Sea, Italy. J Volcanol Geotherm Res. 2012;229-230:74-94.

Angiulli G, De Francesco AM, Lomonaco L. Nuovi dati geochimica sull'Isola di Ischia Mineral. Petrogrl Acta. 1985;29:41-60.

Aspinall WP, Woo G, Voight B, Baxter PJ. Evidence-based volcanology; application to eruption crises. J Volcanol Geotherm Res. 2003;128:273-85. https://doi. org/10.1016/S0377-0273(03)00260-9.

Azzaro R, Del Mese S, Graziani L, Maramai A, Martini G, Paolini S, Screpanti A, Verrubbi V, Arcoraci L, Tertulliani A. QUEST- Rilievo macrosismico per il terremoto dell'isola di Ischia del 21 agosto 2017. Rapporto finale Rapporto interno. 2017. https://doi.org/10.5281/zenodo.886047.

Bartole R. Tectonic structures of the Latian-Campanian shelf (Tyrrhenian Sea). Boll Ocean Teor Appl. 1984;2:197-230.

Berrino G, Corrado G, Riccardi U. Sea gravity data in the Gulf of Naples: a contribution to delineating the structural pattern of the Vesuvian area. J Volcanol Geotherm Res. 1998:82:139-50.

Berrino G, Corrado G, Riccardi U. Sea gravity data in the Gulf of Naples: a contribution to delineating the structural pattern of the Phlegrean Volcanic District. J Volcanol Geotherm Res. 2008;175:241-52.

Bevilacqua A, Flandoli F, Neri A, Isaia R, Vitale S. Temporal models for the episodic volcanism of Campi Flegrei caldera (Italy) with uncertainty quantification. J Geophys Res Solid Earth. 2016;121:7821-45. https://doi.org/1 $0.1002 / 2016 J B 013171$

Biass S, Bonadonna C. A fast GIS-based risk assessment for tephra fallout: the example of Cotopaxi volcano, Ecuador - Part I: Probabilistic hazard assessment. Nat Hazards. 2012. https://doi.org/10.1007/s11069-012-0378-z.

Bonadonna C, Connor CB, Houghton BF, Connor L, Byrne M, Laing A, Hincks TK. Probabilistic modeling of tephra dispersal: Hazard assessment of a multiphase rhyolitic eruption at Tarawera, New Zealand. J Geophys Res. 2005; 110(B03203):1-21.

Braun T, Famiani D, Cesca S. Seismological constraints on the source mechanism of the damaging seismic event of 21 august 2017 on Ischia Island (Southern Italy). Seismilog Res Lett. 2018; https://doi.org/10.1785/0220170274.

Brown RJ, Civetta L, Arienzo I, D'Antonio M, Moretti R, Orsi G, Tomlinson EL, Albert PG, Menzies MA. Geochemical and isotopic insights into the assembly, evolution and disruption of a magmatic plumbing system before and after a 
cataclysmic caldera-collapse eruption at Ischia volcano (Italy). Contrib Mineral Petrol. 2014;168(3):1035.

Brown RJ, Orsi G, de Vita S. New insights into Late Pleistocene explosive volcanic activity and caldera formation on Ischia (southern Italy). Bull Volcanol. 2008; 70(5):583-603.

Bruno $P$, de Alteriis $G$, Florio $G$. The western undersea section of the Ischia volcanic complex (Italy, Tyrrhenian Sea) inferred by marine geophysical data. Geophys Res Lett. 2002;23:2689-92.

Buchner G. Eruzioni vulcaniche e fenomeni vulcanotettonici di età preistorica e storica nell'isola d'Ischia. In: Centre Jean Bérard, Institut Français de Naples (ed), Tremblements de terre, eruptions volcaniques et vie des hommes dans la Campanie antique, vol. 7; 1986. p. 145-88.

Buchner G, Italiano A, Vita-Finzi C. Recent uplift of Ischia, southern Italy. In: Mc Guire WJ, Jones AP, Neuberg J, editors. Volcano Instability on the Earth and Other Planets, Geol. Soc. (Special Paper), vol. 110; 1996. p. 249-52.

Buchner P. Formazione e sviluppo dell'isola d'Ischia. Rivista di Scienze Naturali «Natura». 1943:34:39-62 Milano.

Calderoni G, Di Giovambattista R, Pezzo G, Albano M, Atzori S, Tolomei C, Ventura G. Seismic and Geodetic Evidences of a Hydrothermal Source in the Md 4.0, 2017, Ischia earthquake (Italy). J Geophys Res Solid Earth. 2019;124(5):5014-29 https://doi.org/10.1029/2018JB016431.

Caliro S, Panichi C, Stanzione D. Variation in the total dissolved carbon isotope composition of thermal waters of the island of Ischia (Italy) and its implications for volcanic surveillance. J Volcanol Geotherm Res. 1999;90(3):219-40.

Capuano P, De Matteis R, Russo G. The structural setting of the Ischia Island caldera (Italy): first evidence fromseismic and gravity data. Bull Volcanol. 2015; 77:79. https://doi.org/10.1007/s00445-015-0965-4.

Carey S, Sigurdsson H, Mandeville C, Bronto S. Pyroclastic flows and surges over water: an example from the 1883 Krakatau eruption. Bull Volcanol. 1996;57(7): 493-511 https://doi.org/10.1007/BF00304435.

Carlino S, Cubellis E, Luongo G, Obrizzo F. On the mechanics of caldera resurgence of Ischia Island (southern Italy). In: Troise C, De Natale G, Kilburn CRJ, editors. Mechanisms of activity and unrest at large calderas, Geological society, vol. 269. London: Special Publications; 2006. p. 181-93.

Carlino S, Cubellis E, Marturano A. The catastrophic 1883 earthquake at the island of Ischia (southern Italy): macroseismic data and the role of geological conditions. Nat Hazards. 2010;52:231-47.

Carlino S, Somma R, Troiano A, Di Giuseppe MG, Troise C, De Natale G. The geothermal system of Ischia Island (southern Italy): critical review and sustainability analysis of geothermal resource for electricity generation. Renew Energy. 2014;62:177-96.

Casalbore D, Romagnoli C, Bosman A, De Astis G, Lucchi F, Tranne CA, Chiocci L. Multi-stage formation of La Fossa caldera (Vulcano Island, Italy) from an integrated subaerial and submarine analysis, et al. Mar Geophys Res. 2018; https://doi.org/10.1007/s11001-018-9358-3.

Casalini M, Avanzinelli R, Heumann A, de Vita S, Sansivero F, Conticelli S, Tommasini S. Geochemical and radiogenic isotope probes of Ischia volcano, southern Italy: constraints on magma chamber dynamics and residence time. Am Mineral. 2017;102:262-74.

Castaldo R, Gola G, Santilano A, De Novellis V, Pepe S, Manzo M, Manzella A, Tizzani $P$. The role of thermo-rheological properties of the crust beneath Ischia Island (southern Italy) in the modulation of the ground deformation pattern. J Volcanol Geotherm Res. 2017. https://doi.org/10.1016/j.jvolgeores.2017.03.003.

Catenacci V. II dissesto idrogeologico e geoambientale in Italia dal dopoguerra al 1990. Mem Descr Carta Geol d'Italia. 1992;47 Roma.

CEDIT - Italian Catalogue of Earthquake-Induced Ground Failures (2017). [Martino S, Prestininzi A, Romeo RW, Fantini A, Fortunato C, Sanandrea P], Newrelease, Update 27/01/2017. http://www.ceri.uniroma1.it/index_cedit.html. Last check Aug 2018

Celico P, Stanzione D, Esposito L, Formica F, Piscopo V, De Rosa BM. La complessita idrogeologica di un'area vulcanica attiva; I'Isola d'Ischia (Napoli, Campania). Bollettino della Società Geologica Italiana. 1999;118(3):485-504.

Chen L, Wang C, Liu JF, Liu Y, Liu J, Wang J. A damage-mechanism-based creep model considering temperature effect in granite. Mech Res Commun. 2014;56:76-82.

Chiesa S, Poli S, Vezzoli L. Studio dell'ultima eruzione storica dell'isola di Ischia, Bollettino del Gruppo Nazionale di Vulcanologia; 1986. p. 153-6.

Chigira M. Long-term gravitational deformation of rocks by mass rock creep. Eng Geol. 1992;32:157-84. https://doi.org/10.1016/0013-7952(92)90043-X.

Chiocci FL, Bosman A, Martorelli E. Long range side scan sonar analysis of instability phenomena on the submerged flanks of Ischia and Stromboli islands. Roma: Assemblea Annuale, Gruppo Nazionale per la Vulcanologia; 2001.
Chiocci FL, de Alteriis G. The Ischia debris avalanche: first clear submarine evidence in the Mediterranean of a volcanic island prehistorical collapse. Terra Nova. 2006;18:202-9.

Chiodini G, Avino R, Brombach T, Caliro S, Cardellini C, de Vita S, Frondini F, Marotta E, Ventura G. Fumarolic and diffuse soil degassing west of mount Epomeo, Ischia (Italy). J Volcanol Geoth Res. 2004;133:291-309.

Chiodini G, Marini L. Hydrothermal gas equilibria: the $\mathrm{H} 2 \mathrm{O}-\mathrm{H} 2$ - $\mathrm{CO} 2-\mathrm{CO}-\mathrm{CH} 4$ system. Geochim Cosmochim Acta. 1998;62(15):2673-87.

Civetta L, Gallo G, Orsi G. Sr- and Nd- isotope and trace-element constraints on the chemical evolution of the magmatic system of Ischia (Italy) in the last 55 ka. J Volcanol Geotherm Res. 1991:46:213-30.

Connor CB. A Quantitative Literacy View of Natural Disasters and Nuclear Facilities. Numeracy. 2011;4(2):2. https://doi.org/10.5038/1936-4660.4.2.2.

Coplen TB. Reporting of stable hydrogen, carbon and oxygen isotopic abundances. Pure Appl Chem. 1994;6(6):273-6.

Costa A, DellErba F, Di Vito MA, Isaia R, Macedonio G, Orsi G, Pfeiffer T. Tephra fallout hazard assessment at the Campi Flegrei caldera (Italy). Bull Volcanol. 2009;71:259-73. https://doi.org/10.1007/s00445-008-0220-3.

Crisci GM, De Franesco AM, Mazzuoli R, Poli G, Stanzione D. Geochemistry of recent volcanics of Ischia Island, Italy: evidences of fractional crystallization and magma mixing. Chem Geol. 1989;78:15-33.

Cubellis E, Carlino S, lannuzzi R, Luongo G, Obrizzo F. Management of historical seismic data using GIS: the island of Ischia (Southern Italy). Natural Hazard. 2004;33:379-93.

Cubellis E, Luongo G. II terremoto del 28 luglio 1883 a Casamicciola nell'isola d'Ischia - "Il contesto fisico". Monografia n.1, Servizio Sismico Nazionale. Roma: Istituto Poligrafico e Zecca dello Stato; 1998. p. 49-123.

Cubellis E, Marturano A (2009). II terremoto del 5 aprile 2008 nell'isola d'Ischia: studio macrosismico. Open File Report - Osservatorio Vesuviano, N.1.

Cubellis S, Lungo G. History of Ischian earthquakes, Ed. Napoli: Bibliopolis; 2018. p. 168.

D'Antonio M, Tonarini S, Arienzo I, Civetta L, Dallai L, Moretti R, Orsi G, Andria M, Trecalli A. Mantle and crustal processes in the magmatism of the Campania region: inferences from mineralogy, geochemistry, and $\mathrm{Sr}-\mathrm{Nd}-\mathrm{O}$ isotopes of young hybrid volcanics of the Ischia island (South Italy). Contrib Mineral Petrol. 2013;165(6):1173-94.

D'Argenio B, Pescatore T, Scandone P (1973). Schema geologico dell'Appennino meridionale (Campania e Lucania). Atti Conv. Moderne vedute sulla geologia dell'Appennino. Roma. Acc. Naz. Lincei, q.183.

D'Auria L, Pepe S, Castaldo R, Giudicepietro F, Macedonio G, Ricciolino P, Tizzani P, Casu F, Lanari R, Manzo M, Martini M, Sansosti E, Zinno I. Magma injection beneath the urban area of Naples: a new mechanism for the 2012-2013 volcanic unrest at Campi Flegrei caldera. Sci Rep. 2015;5:13100.

D'Argenio B, Aiello G, de Alteriis G, Milia A, Sacchi M, Tonielli R, Budillon F, Chiocci FL, Conforti A, De Lauro M, Disanto C, Esposito E, Ferraro L, Insinga D, lorio M, Marsella E, Molisso F, Morra V, Passaro S, Pelosi N, Porfido S, Raspini A, Ruggieri S, Terranova C, Vilardo G, Violante C. Digital elevation model of the Naples Bay and adjacent areas, Eastern Tyrrhenian sea. In: Pasquarè G, Venturini C, Groppelli G, editors. Atlante di Cartografia Geologica, Servizio Geologico APAT. Firenze: S.E.L.C.A; 2004.

D'Auria L, Giudicepietro F, Tramelli A, Ricciolino P, Lo Bascio D, Orazi M, Martini M, Peluso R, Scarpato G, Esposito A. The seismicity of Ischia Island. Seismol Res Lett. 2018. https://doi.org/10.1785/0220180084.

de Alteriis G, Violante C. Catastrophic landslides off Ischia volcanic island (Italy) during prehistory. Geol Soc London Special Publ. 2009;322:73-104.

De Gennaro M, Ferreri M, Ghiara MR, Stanzione D. Geochemistry of thermal waters on the island of Ischia (Campania, Italy). Geothermics. 1984;13: $361-74$.

De Martino P, Tammaro U, Obrizzo F, Sepe V, Brandi G, D'Alessandro A, Dolce M, Pingue F. La rete GPS dell'isola di Ischia: deformazioni del suolo in un'area vulcanica attiva (1998-2010). Quaderni di Geofisica ISSN. 2011;1590-2595(95):1-61.

De Novellis V, Carlino S, Castaldo R, Tramelli A, De Luca C, Pino NA, et al. The 21 august 2017 Ischia (Italy) earthquake source model inferred from seismological, GPS, and DInSAR measurements. Geophys Res Lett. 2018;45: 2193-202 https://doi.org/10.1002/2017GL076336.

de Vita S, Di Vito M, Gialanella C, Sansivero F. The impact of the Ischia Porto tephra eruption (Italy) on the Greek colony of Pithekoussai. Quat Int. 2013; 303:142-52.

de Vita S, Sansivero F, Orsi G, Marotta E. Cyclical slope instability and volcanism related to volcano-tectonism in resurgent calderas: the Ischia island (Italy) case study. Eng Geol. 2006;86:148-65. 
de Vita S, Sansivero F, Orsi G, Marotta E, Piochi M. Volcanological and structural evolution of the Ischia resurgent caldera (Italy) over the past $10 \mathrm{ka}$. In: Groppelli G, Viereck L, editors. "Stratigraphy and geology in volcanic areas", GSA book series, Special paper n, vol. 464; 2010. p. 193-239.

Del Gaudio C, Aquino I, Ricco C, Sepe V, Serio C. Monitoraggio geodetico dell'isola d'Ischia: risultati della livellazione geometricadi precisione eseguita a Giugno 2010. Quaderni di Geofisica ISSN. 2011;1590-2595(87):1-20.

Del Prete S, Mele R. L'influenza dei fenomeni d'instabilità di versante nel quadro morfoevolutivo della costa dell'isola d'Ischia. Boll Soc Geol Ital. 1999;118:339-60

Del Prete S, Mele R. II contributo delle informazioni storiche per la valutazione della propensione al dissesto nell'Isola d'Ischia. Rend Soc Geol It Nuova Serie. 2006;2:29-47.

Della Seta M, Esposito C, Marmoni GM, Martino S, Paciello A, Perinelli C, Sottili G. Geological constraints for a conceptual evolutionary model of the slope deformations affecting Mt. Nuovo at Ischia (Italy). Ital J Eng Geol Env. 2015;2: 15-28. https://doi.org/10.4408/JJEGE.2015-02.0-04.

Della Seta M, Marotta E, Orsi G, De Vita S, Sansivero F, Fredi P. Slope instability induced by volcano-tectonics as an additional source of hazard in active volcanic areas: the case of Ischia island (Italy). B Volcanol. 2012;74:79-106.

Dellino $P$, Isaia $R$, Veneruso M. Turbulent boundary layer shear flows as an approximation of base surges at Campi Flegrei (Southern Italy). J Volcanol Geotherm Res. 2004;133(1-4):211-28.

Devoti R, De Martino P, Pietrantonio G, Dolce M. Coseismic displacements on Ischia island, real-time GPS positioning constraints on earthquake source location. Ann Geophys. 2018;61(3):SE337. https://doi.org/10.4401/ag-7656.

Di Giuseppe MG, Troiano A, Carlino S. Magnetotelluric imaging of the resurgent caldera on the island of Ischia (southern Italy): inferences for its structure and activity. Bull Volcanol. 2017;79:85. https://doi.org/10.1007/s00445-017-1170-4.

Di Martire D, De Rosa M, Pesce V, Santangelo MA, Calcaterra D. Landslide hazard and land management in high-density urban areas of Campania region, Italy. Nat Hazards Earth Syst Sci. 2012;12:905-26

Di Napoli R, Aiuppa A, Bellomo S, Brusca L, D'Alessandro W, Candela EG, Longo M, Pecoraino G, Valenza M. A model for Ischia hydrothermal system: evidences from the chemistry of thermal groundwaters. J Volcanol Geotherm Res. 2009;186(3):133-59.

Di Napoli R, Federico C, Aiuppa A, D'Antonio M, Valenza M. Quantitative models of hydrothermal fluid-mineral reaction: the Ischia case. Geochim Cosmochim Acta. 2013;105:108-29.

Di Napoli R, Martorana R, Orsi G, Aiuppa A, Camarda M, De Gregorio S, Gagliano Candela E, Luzio D, Messina N, Pecoraino G, Bitetto M, de Vita S, Valenza M. The structure of a hydrothermal system from an integrated geochemical, geophysical, and geological approach: The Ischia Island case study. Geochem Geophys Geosyst. 2011;12(7);79-85. https://doi.org/10.1029/2010GC003476.

Dzurisin D. Volcano deformation: new geodetic monitoring techniques. Berlin Heidelberg: Springer; 2007. p. 442. isbn:9783540493020

EMTC - Euro-Mediterranean Tsunami Catalog (2018). http://roma2.rm.ingv.it/en/ facilities/data_bases/52/euro-mediterranean_tsunami_catalogue, last check Sept 2018.

Faccenna C, Funiciello R, Bruni A, Mattei M, Cagnotti L. Evolution of a transfer related basin: the Ardea basin (Latium, Central Italy). Basin Res. 1994;6:35-46.

Finetti I, Morelli C. Esplorazione sismica a riflessione dei Golfi di Napoli e Pozzuoli. Boll Geof Teor Appl. 1974;16:175-222.

Folch A, Mingari L, Osores MS, Collini E. Modeling volcanic ash resuspension application to the 14-18 October 2011 outbreak episode in Central Patagonia Argentina. Nat Hazards Earth Syst Sci. 2014;14:119-33. https://doi. org/10.5194/nhess-14-119-2014.

Fortunato C, Martino S, Prestininzi A, Romeo RW, Fantini A, Sarandrea A. New release of the Italian catalogue of earthquake-induced ground failures (CEDIT). Ital J Eng Geol Environ. 2012;2-5:63-74.

Galletto F, Acocella V, Caricchi L. Caldera resurgence driven by magma viscosity contrasts. Nat Commun. 2017;8:1750. https://doi.org/10.1038/s41467-01701632-y.

GdL_DST-CentroMS (2018). Relazione finale sui dati risultanti da attività di ricerca condotte nel comune di Forio (Ischia, NA) e validi ai fini degli studi di risposta sismica locale. Convention CNR-IGAG and DST Sapienza (000401010/11/2017) prot. 0004286, cfr. Art. 8 OCDPC n. 476/2017.

Gruppo di Lavoro Mappa di Pericolosità Sismica (2004). Redazione della mappa di pericolosità sismica prevista dall'Ordinanza PCM 3274 del 20 marzo 2003, rapporto conclusivo per il Dipartimento della Protezione Civile, INGV, Milano-Roma, aprile 2004, 65 pp. +5 appendici.
Gruppo di Lavoro INGV sul terremoto dell'isola di Ischia (2017). Rapporto di sintesi preliminare sul Terremoto dell'isola d'Ischia (Casamicciola) M4.0 del 21 agosto 2017 (6 settembre 2017), doi: https://doi.org/10.52 $81 /$ zenodo.886045

Giachetti T, Paris R, Kelfoun K, Ontowirjo B. Tsunami hazard related to a flank collapse of Anak Krakatau volcano, Sunda Strait, Indonesia. Geol Soc Lond, Spec Publ. 2012;361(1):79-90. https://doi.org/10.1144/SP361.7.

Giggenbach WF. Geothermal solute equilibria derivation of Na-K-mg-ca geoindicators. Geochim Cosmochim Acta. 1988;52(12):2749-65.

Giordano G, Zanella E, Trolese M, Baffion C, Vona A, Caricch C, Gesh N. Thermal interactions of the AD79 Vesuvius pyroclastic density currents and their deposits at Villa Dei Papiri (Herculaneum archaeological site, Italy). Earth Planet Sci Lett. 2018;490:180-92.

Grezio A, Babeyko A, Baptista MA, Behrens J, Costa A, Davies G, Geist E, Glimsdal S, Gonzales Fl, Griffin J, Harbitz C, LeVeque RJ, Lorito S, Lovholt F, Omira R, Mueller C, Paris R, Parsons T, Polet J, Power W, Selva J, Sorensen MB, Thio HK. Probabilistic tsunami Hazard analysis: multiple sources and global applications. Rev Geophys. 2017;55. https://doi.org/10.1002/2017RG000579.

Grezio A, Tonini R, Sandri L, Pierdominici S, Selva J. A comprehensive probabilistic tsunami Hazard assessment: multiple sources and short-term interactions. J Mar Sci Eng. 2015;3:23-51. https://doi.org/10.3390/jmse3010023.

Hincks TK, Komorowski J-C, Sparks SR, Aspinall WP. Retrospective analysis of uncertain eruption precursors at La Soufrière volcano, Guadeloupe, 1975-77: volcanic hazard assessment using a Bayesian belief network approach. J Appl Volcanol. 2014;3:3. https://doi.org/10.1186/2191-5040-3-3.

Hunt JE, Cassidy M, Talling PJ. Multi-stage volcanic island flank collapses with coeval explosive caldera-forming eruptions. Sci Rep. 2018;8:1146. https://doi. org/10.1038/s41598-018-19285-2.

Iacono A. La "Guerra d'Ischia" nel De Bello Neapolitano di G. Pontano Quaderni dell'Accademia Pontaniana. 1996;19:1-90.

IAEA - International Atomic Energy Agency. Volcanic Hazards in site evaluation for nuclear installations - Specific Safety Guide, in IAEA Safety Standards Series No. SSG-21, Vienna, vol. 2012; 2012.

IAEA - International Atomic Energy Agency. Volcanic Hazard Assessments for Nuclear Installations: Methods and Examples in Site Evaluation, IAEA Tecdoc Series, IAEA-TECDOC-1795, vol. 2016; 2016.

Inguaggiato S, Pecoraino G, D'Amore F. Chemical and isotopical characterisation of fluid manifestations of Ischia Island (Italy). J Volcanol Geotherm Res. 2000; 99(1):151-78.

INGV-DPC-T4C (2016-2017), Convenzione tra il Dipartimento della Protezione Civile e l'INGV per l'attività di sorveglianza sismica e vulcanica sul territorio nazionale, di consulenza tecnico-scientifica e di studi sui rischi sismico e vulcanico, Obiettivo 4 - Task C.

INGV-DPC-V3. Ricerche sui vulcani attivi, precursori, scenari, pericolosità e rischio, UR Orsi (Campi Flegrei and Ischia). Roma: Internal Report, INGV; 2005-2007.

INGV-ScientRep-IISem. Bollettino di Sorveglianza Vulcani Campani - Secondo Semestre 2017. Napoli: INGV Report; 2017.

IPCC - Intergovernmental Panel on Climate Change. Summary for policymakers In: Stocker TF, Qin D, Plattner G-K, Tignor M, Allen SK, Boschung J, Nauels A, Xia Y, Bex V, Midgley PM, editors. Climate Change 2013: The Physical Science Basis. Contribution of Working Group I to the Fifth Assessment Report of the Intergovernmental Panel on Climate Change. Cambridge, United Kingdom and New York, NY, USA: Cambridge University Press; 2013.

Ippolito F. Su alcuni pozzi profondi del napoletano. Boll Soc Nat Napoli. 1942; 1942(53):134-40

Ippolito F, Ortolani F, Russo M. Struttura marginale tirrenica dell'Appennino Campano: reinterpretazione di dati di antiche ricerche di idrocarburi. Mem Soc Geol It. 1973;12:227-50.

Jenkins S, Magill C, McAneney J, Blong R. Regional ash fall hazard I: a probabilistic assessment methodology. Bull Volcanol. 2012;74(7):1699-712.

Jordan TH. Marzocchi W, Michael AJ, Gerstenberger MC (2014). Operational earthquake forecasting can enhance earthquake preparedness. Seismol Res Lett. 2014;85:955-9. https://doi.org/10.1785/0220140143.

Kiryukhin A. Modeling and observations of geyser activity in relation to catastrophic landslides-mudflows (Kronotsky nature reserve, Kamchatka, Russia). J Volcanol Geothermal Res. 2016;323:129-47.

Kiryukhin A, Rychkova TV, Dubrovskaya IK. Hydrothermal system in Geysers Valley (Kamchatka) and triggers of the Giant landslide. Appl Geochem J. 2012;27:1753-66.

Lavigne F, Thouret JC, Voight B, Suwa H, Sumaryono A. Lahars at Merapi volcano, Central Java: an overview. J Volcanol Geoth Res. 2000;100:423-56. 
Lenti L, Martino S, Paciello A, Prestininzi A, Rivellino S. Recorded displacements in a landslide slope due to regional and teleseismic earthquakes. Geophys J Int. 2015;201:1335-45, ISSN: 0956-540X. https://doi.org/10.1093/gji/ggv063.

Liu Z, Nadim F, Garcia-Aristizabal A, Mignan A, Fleming K, Luna BQ. A three-level framework for multi-risk assessment. Georisk Assess Manage Risk Eng Syst Geohazards. 2015;9(2):59-74. https://doi.org/10.1080/17499518.2015.1041989.

Locati M, Camassi R, Rovida A, Ercolani E, Bernardini F, Castelli V, Caracciolo CH, Tertulliani A, Rossi A, Azzaro R, D’Amico S, Conte S, Rocchetti E. DBMI15, the 2015 version of the Italian macroseismic database. Istituto Nazionale di Geofisica e Vulcanologia. 2016. https://doi.org/10.6092/INGV.IT-DBMI15.

Lopez DL, Williams NS. Catastrophic volcanic collapse: relation to hydrothermal processes. Science. 1993;20:1974-6.

Luongo G, Carlino S, Cubellis E, Delizia I, lannuzzi R, Obrizzo F. Il terremoto di Casamicciola del 1883: una ricostruzione mancata. Napoli: Alfa Tipografia; 2006. p. 64.

Luongo G, Carlino S, Cubellis E, Ferri M, Obrizzo F. Seismic hazard in the island of Ischia (Italy). In: Buccianti A, Nardi G, Potenza R, editors. Proc of IAMG '98 the fourth annual conference of International Association for Mathematical Geology. Naples: De Frede; 1998. p. 938-43.

Luongo G, Cubellis, E (2018). History of Ischian earthquakes, 168pp, Bibliopolis, ISBN-10: 8870886522, ISBN-13: 978-8870886528.

Luongo G, Cubellis E, Di Vito MA, Cascone E. L'isola d'Ischia: dinamica e struttura del M. Epomeo. In: Bonardi G, De Vivo B, Gasparini P, Vallario A, editors. Cinquant'anni di attività didattica e scientifica del Prof. Felice Ippolito. Napoli: Liguori Editore; 1995.

Luongo G, Cubellis E, Obrizzo F. Ischia storia di un'isola vulcanica. Napoli: Liguori; 1987. p. 164

Manzo M, Ricciardi GP, Casu F, Ventura G, Zeni G, Borgstroem S, Berardino V, Del Gaudio C, Lanari R. Surface deformation analysis in the Ischia Island (Italy) based on spaceborne radar interferometry. J Volcanol Geotherm Res. 2006;151:399-416.

Maramai A, Brizuela B, Graziani L. The Euro-Mediterranean tsunami catalogue. Ann Geophys. 2014;57(4):S0435. https://doi.org/10.4401/ag-6437.

Mariani M, Prato R. I bacini neogenici costieri del margine tirrenico: approccio sismico-stratigrafico. Mem Soc Geol It. 1988;41:519-31.

Marmoni G, Martino S, Heap MJ, Reuschlé T. Gravitational slope deformation of a resurgent caldera: new insights from the mechanical behaviour of Mt. Nuovo tuffs (Ischia Island, Italy). J Volcanol Geotherm Res. 2017:345:1-20. https://doi. org/10.1016/j.jvolgeores.2017.07.019.

Marotta $\mathrm{E}$, de Vita $\mathrm{S}$. The role of pre-existing tectonic structures and magma chamber shape on the geometry of resurgent blocks: analogue models. J Volcanol Geotherm Res. 2014;272:23-38 https://doi.org/10.1016/j.jvolgeores.2013.12.005.

Marti J, Sobradelo R, Felpeto A. Hazard assessment at Teide-Pico Viejo volcanic complex (Tenerife, Canary Islands), vol. 12; 2010. p. 5774.

Martino S, Prestininzi A, Romeo RW. Earthquake-induced ground failures in Italy from a reviewed database. Nat Hazards Earth Syst Sci. 2014;14:799-814.

Marzocchi W, Garcia-Aristizabal A, Gasparini P, Mastellone M, Di Ruocco A. Basic principles of multi-risk assessment: a case study in Italy. Nat Hazards. 2012:123. https://doi.org/10.1007/s11069-012-0092-x

Marzocchi W, Sandri L, Selva J (2008), BET_EF: a probabilistic tool for long- and short-term eruption forecasting, Bull. Volcan., 70, 623 632, DOl:https://doi.org/1 0.1007/s00445-007-0157-y. and relative electronic supplementary material.

Marzocchi W, Woo G. Probabilistic eruption forecasting and the call for an evacuation. Geophys Res Lett. 2007;34:L22310. https://doi.org/10.1029/2 007GL031922.

McGuire WJ. Volcano instability: a review of contemporary themes. In: McGuire WJ, Jones AP, Neuberg J, editors. Volcano instability on the earth and other planets, Geological Society, London, Special Publication, vol. 110; 1996. p. 1-23.

Mignan A, Wiemer S, Giardini D. The quantification of low probability-high consequences events: part I. Generic Multi Risk Approach Nat Hazards. 2014; 73:1999-2022. https://doi.org/10.1007/s11069-014-1178-4.

Molin P, Acocella V, Funiciello R. Structural, seismic and hydrothermal features at the border of an active intermittent resurgent block: Ischia Island (Italy). J Volcanol Geotherm Res. 2003;121(1):65-81.

Morabito S, Petrosino P, Milia A, Sprovieri M, Tamburrino S. A multidisciplinary approach for reconstructing the stratigraphic framework of the last $40 \mathrm{ka}$ in a bathyal area of the eastern Tyrrhenian Sea. Glob Planet Chang. 2014;123:121-38.

Moretti R, Arienzo I, Orsi G, Civetta L, D'Antonio M. The deep plumbing system of Ischia: a physico-chemical window on the fluid-saturated and CO2-sustained Neapolitan volcanism (southern Italy). J Petrol. 2013;54:951-84. https://doi. org/10.1093/petrology/egt002.

Nappi R, Alessio G, Gaudiosi G, Nave R, Marotta E, Siniscalchi V, Civico R, Pizzimenti L, Peluso R, Belviso P, Porfido S. The 21 august 2017 md 4.0
Casamicciola earthquake: first evidence of Coseismic Normal surface faulting at the Ischia Volcanic Island. Seismological Res Lett. 2018;89:1323-34. https:// doi.org/10.1785/0220180063.

Newhall CG, Hoblitt RP. Constructing event trees for volcanic crises. Bull Volcanol. 2002;64:3-20. https://doi.org/10.1007/s004450100173.

Newhall CG, Pallister JS. Using multiple data sets to populate probabilistic volcanic event trees. Volcanic Hazards Risks Disasters. 2015; https://doi.org/1 0.1016/B978-0-12-396453-3.00008-3. (Eds JF Shroder and P Papale).

Nunziata C, Rapolla A. A gravity and magnetic study of the volcanic island of Ischia, Naples (Italy). J Volcanol Geotherm Res. 1987;31:333-44.

Orsi G, Chiesa S. The uplift of the Mt. Epomeo block at the island of Ischia (Gulf of Naples): geological and geochemical constraints. Eos. 1988;69(44):1473.

Orsi G, Gallo G, Heiken G, Wohletz K, Yu E, Bonani G. A comprehensive study of pumice formation and dispersal: the Cretaio tephra of Ischia (Italy). J Volcanol Geotherm Res. 1992;53:329-54.

Orsi G, Gallo G, Zanchi A (1991). Simple-shearing block resurgence in caldera depression. A model from Pantelleria and Ischia. J Volcanol Geotherm Res 47, 1-11.

Orsi G, Patella D, Piochi M, Tramacere A. Magnetic modelling of the Phlegrean volcanic district with extension to the Ponza archipelago, Italy. J Volcanol Geotherm Res. 1999;91:345-60.

Orsi G, Piochi M, Campajola L, D'Onofrio A, Gialanella L, Terrasi F. 14C geochronological constraints for the volcanic history of the island of Ischia (Italy) over the last 5,000 years. J Volcanol Geotherm Res. 1996;71:249-57.

Pallister J, Papale P, Eichelberger J, Newhall C, Mandeville C, Nakada S, Marzocchi W, Loughlin S, Jolly G, Ewert J. Selva J (2019) volcano observatory best practices (VOBP) workshops - a summary of findings and best-practice recommendations. J Appl Volcanol Soc Volcan. 2019:8:2

Panichi C, Bolognesi L, Ghiara MR, Noto P, Stanzione D. Geothermal assessment of the island of Ischia (southern Italy) from isotopic and chemical composition of the delivered fluids. J Volcanol Geotherm Res. 1992:49(3-4):329-48.

Paoletti V, D'Antonio M, Rapolla A. The structural setting of the Ischia Island (Phlegrean Volcanic District, southern Italy): inferences from geophysics and geochemistry. J Volcanol Geotherm Res. 2013;249:155-73. https://doi.org/10.1 016/j.jvolgeores.2012.10.002

Paoletti V, Di Maio R, Cella F, Florio G, Motschka K, Roberti N, Secomandi M, Supper R, Fedi M, Rapolla A. The Ischia volcanic island (southern Italy): inferences from potential field data interpretation. J Volcanol Geotherm Res. 2009;179:69-86.

Papale P. Rational volcanic hazard forecasts and the use of volcanic alert levels. J Applied Volcan. 2017;6:13 https://doi.org/10.1186/s13617-017-0064-7.

Paparo MA, Tinti S. Analysis of seismic-driven instability of Mt. Nuovo in the Ischia Island, Italy. Bull Seismol Soc Am. 2017;107(2):750-9 https://doi.org/10.1785/ 0120160139.

Paris R, Belousova M, Belousov A, Ontowirjo B, Whelley PL. Volcanic tsunami: a review o source mechanisms, past events and hazards in Southeast Asia (Indonesia, Philippines, Papua New Guinea). Nat Hazards. 2013;70:447. https:// doi.org/10.1007/s11069-013-0822-8.

Penta F. Temperature nel sottosuolo della regione flegrea. Ann Geofis. 1949;2:338-46.

Penta F. Ricerche e studi sui fenomeni esalativo-idrotermall ed il problema delle forze endogene. Ann Geofis. 1954;8:1-94.

Penta F, Conforto B. Risultati di sondaggi e ricerche geominerarie nell'isola di Ischia dal al nel campo del vapore, delle acque termali e delle forze endogene in generale. Ann Geofis. 1951;4:1-33.

Piochi M, Civetta L, Orsi G. Mingling in the magmatic system of Ischia (Italy) in the past 5ka. Mineral Petrol. 1999;66:227-58.

Piochi M, Pappalardo L, De Astis G. Geochemical and isotopical variations within the Campanian Comagmatic Province: implications onmagma source composition. Ann Geophys. 2004;47:1485-99.

Piper, A.M. (1953) A Graphic Procedure in the Chemical Interpretation of Water Analysis. US Geological Survey Groundwater Note, 12.

Poli S, Chiesa S, Gillot PY, Gregnanin A, Guichard F. Chemistry versus time in the volcanic complex of Ischia (gulf of Naples, Italy): evidence of successive magmatic cycles. Contrib Mineral Petrol. 1987;95:322-35.

Poli S, Chiesa S, Gillot PY, Guichard F, Vezzoli L. Time dimension in the geochemical approach and hazard estimation of a volcanic area: the Isle of Ischia case (Italy). J Volcanol Geotherm Res. 1989;36:327-35.

Pugliese M, Quarto M, Roca V. Radon concentrations in air and water in the thermal spas of Ischia Island. Indoor Built Environ. 2014;23(6):823-7.

Rapolla A, Fedi M, Fiume MG. Crustal structure of the Ischia - Phlegrean geothermal fields, near Naples, Italy, from gravity and aeromagnetic data. Geophys J Int. 1989;97:409-19. 
Reid ME. Massive collapse of volcano edifices triggered by hydrothermal pressurization. Geology. 2004;32:373-6. https://doi.org/10.1130/G20300.1.

Reid ME, Sisson TW, Brien DL. Volcano collapse promoted by hydrothermal alteration and edifice shape, Mount Rainier, Washington. Geology. 2001;29: 779-82.

Ricco C, Aquino I, Augusti V, D'Auria L, Del Gaudio C, Scarpato G. Improvement and development of the tiltmetric monitoring networks of Neapolitan volcanoes. Ann Geophys. 2018;61(1):SE114. https://doi.org/10.4401/ag-7496.

Ricco C, Augusti V, Scarpato G, Aquino I (2017), La deformazione del suolo ad Ischia rilevata dalla Rete tiltmetrica, blogingvterremoti, https://ingvterremoti. wordpress.com/2017/12/12/la-deformazione-del-suolo-ad-ischia-rilevata-dallarete-tiltmetrica/

Rittmann A. Geologie der Insel Ischia. Z. f. Vulkanol. Erganzungsband. 1930. p. 6.

Rittmann A. Origine e differenziazione del magma ischitano. Schweiz Miner Petrogr Mitt. 1948;28:643-98.

Rittmann A, Gottini V. L'Isola d'Ischia - Geologia. Boll Serv Geol It. 1980;101:131-274

Rosi M, Levi ST, Pistolesi M, Bertagnini A, Brunelli D, Cannavò V, Di Renzoni A, Ferranti F, Renzulli A, Yoon D. Geoarchaeological evidence of middle-age tsunamis at Stromboli and consequences for the tsunami Hazard in the southern Tyrrhenian Sea. Sci Rep. 2019;9(1):677 https://doi.org/10.1038/s415 98-018-37050-3.

Rovida A, Locati M, Camassi R, Lolli B, Gasperini P [eds] (2016). CPTI15, the 2015 version of the parametric catalogue of Italian earthquakes. Istituto Nazionale di Geofisica e Vulcanologia doi: https://doi.org/10.6092/INGV.IT-CPTI15, last check Aug 2018.

Sbrana A, Marianelli P, Pasquini G. Volcanology of Ischia (Italy). J Maps. 2018;14(2): 494-503. https://doi.org/10.1080/17445647.2018.1498811.

Sbrana A, Toccaceli RM (2011). Carta Geologica della Regione Campania - Foglio 464 - Isola di Ischia, Progetto GARG Regione Campania - Assessorato Difesa del Suolo, Litografia Artistica Cartografica, Firenze. 216 pp + 1 carta: 10.000.

Scott KM, Macias JL, Vallance JW, Naranjo JA, Rodriguez-Elizarrarás SR, McGeehin JP. Catastrophic debris flows transformed from landslides in volcanic terrains: mobility, hazard assessment, and mitigation strategies. Reston: U.S. Geological Survey Professional Paper 1630. 2002. p. 61

Selva J. Long-term multi-risk assessment: statistical treatment of interaction among risks. Nat Hazards. 2013. https://doi.org/10.1007/s11069-013-0599-9.

Selva J, Costa A, De Natale G, Di Vito MA, Isaia R, Macedonio G. Sensitivity test and ensemble hazard assessment for tephra fallout at Campi Flegrei, Italy. Volcanol Geotherm Res. 2018;351:1-28. https://doi.org/10.1016/j.jvolgeores.2017.11.024.

Selva J, Costa A, Marzocchi W, Sandri L. BET VH: exploring the influence of natural uncertainties on long-term hazard from tephra fallout at Campi Flegrei (Italy). Bull Volcanol. 2010;72(6):705-16.

Selva J, Costa A, Sandri L, Marzocchi W. Probabilistic short-term volcanic hazard in phases of unrest: a case study for tephra fallout. J Geophys Res. 2014; 119(12):8805-5526. https://doi.org/10.1002/2014JB011252.

Selva J, Marzocchi W, Papale P, Sandri L. Operational eruption forecasting at high-risk volcanoes: the case of Campi Flegrei, Naples. J Appl Volcanol. 2012a;1:5. https://doi.org/10.1186/2191-5040-1-5, https://appliedvolc. biomedcentral.com/articles/10.1186/2191-5040-1-5.

Selva J, Orsi G, Di Vito MA, Marzocchi W, Sandri L. Probability hazard map for future vent opening at Campi Flegrei caldera, Italy. Bull Volcanol. 2012b;74 497-510. https://doi.org/10.1007/s00445-011-0528-2.

Sepe V, Atzori S, Ventura G. Subsidence due to crack closure and depressurization of hydrothermal systems: a case study from Mt Epomeo (Ischia Island, Italy). Terra Nova. 2007;19(2):127-32. https://doi.org/10.1111/ j.1365-3121.2006.00727.x.

SSHAC - Senior Seismic Hazard Analysis Committee (1997). Recommendations for Probabilistic Seismic Hazard Analysis: Guidance on Uncertainty and Use of Experts, U.S. Nuclear Regulatory Commission, U.S. Dept. of Energy, Electric Power Research Institute, NUREG/CR-6372, UCRL-ID-122160, Vols. 1/2. [Senior Seismic Hazard Analysis Committee: R.J. Budnitz, Chairman, G. Apostolakis, D. M. Boore, L.S. Cluff, K.J. Coppersmith, C.A. Cornell, and P.A. Morris].

Stucchi M, Meletti C, Montaldo V, Crowley H, Calvi GM, Boschi E. Seismic hazard assessment (2003-2009) for the Italian building code. Bull Seismol Soc Am. 2011;101:1885-911.

Sulpizio R, Zanchetta G, Caron B, Dellino P, Mele D, Giaccio B, Insinga D, Paterne M, Siani G, Costa A, Macedonio G, Santacroce R. Volcanic ash hazard in the Central Mediterranean assessed from geological data. Bull Volcanol. 2014;76:866.

Tedesco D. Chemical and isotopic investigations of fumarolic gases from Ischia island (southern Italy): evidences of magmatic and crustal contribution. J Volcanol Geotherm Res. 1996;74(3-4):233-42.
Tibaldi A, Vezzoli L. Intermittenza e struttura della caldera risorgente attiva dell'isola di Ischia. II Quaternario. 1997:10:465-70.

Tibaldi A, Vezzoli L. The space problem of caldera resurgence: an example from Ischia Island, Italy. Geol Rundsch. 1998:87:53-66.

Tibaldi A, Vezzoli L. A new type of volcano flank failure: the resurgent caldera sector collapse, Ischia, Italy. Geophys Res Lett. 2004;31:L14605.

Tierz P, Woodhouse MJ, Phillips JC, Sandri L, Selva J, Marzocchi W, Odbert HM. A framework for probabilistic multi-Hazard assessment of rain-triggered lahars using Bayesian belief networks. Front Earth Sci. 2017;5:73. https://doi.org/1 0.3389/feart.2017.00073

Tinti S, Chiocci FL, Zaniboni F, Pagnoni G, de Alteriis G. Numerical simulation of the tsunami generated by a past catastrophic landslide on the volcanic island of Ischia, Italy. Mar Geophys Res. 2011;32(1):287-97. https://doi.org/10.1 007/s11001-010-9109-6.

TSUMAPS-NEAM - Probabilistic Tsunami Hazard Maps for the NEAM region (2018), http://www.tsumaps-neam.eu/; results at http://ai2lab.org/ tsumapsneam/interactive-hazard-curve-tool/, last check Sept 2018.

Vallance JW, Scott KM. The Osceola mudflow from Mount Rainier: sedimentological and hazard implication of a huge clay-rich debris flow. Geol Soc Am Bull. 1997;109:143-63.

Venezky D, Newhall C (2007). WOVOdat design document: the schema, table descrip-tions, and create -table statement for the database of worldwide volcanic unrest (WOVOdat v. 1.0). US Geol. Surv. Open-File Report 2007-1117, https://pubs.usgs.gov/of/2007/1117/of2007-1117.pdf.

Vezzoli L. Island of Ischia. In: Vezzoli L, editor. CNR Quaderni de "La ricerca scientifica": 1988. p. 114-0. 122 pp.

Vezzoli L, Principe C, Malfatti J, Arrighi S, Tanguy JC, Le Goff M. Modes and times of caldera resurgence: the $<10$ ka evolution of Ischia caldera, Italy, from highprecision archaeomagnetic dating. J Volcanol Geotherm Res. 2009;186(3):305-19.

Vilardo G, Ventura G, Terranova C, Matano F, Nardò S. Ground deformation due to tectonic, hydrothermal, gravity, hydrogeological, and anthropic processes in the Campania region (southern Italy) from permanent Scatterers synthetic aperture radar interferometry. Remote Sens Environ. 2009;113:197-212.

Winson AEF, Costa F, Newhall CG, Woo G. An analysis of the issuance of volcanic alert levels during volcanic crises. J Appl Volcanol. 2014;3:14 https://doi.org/1 0.1186/s13617-014-0014-6.

Woo G. Cost-benefit analysis is volcanic risk. In: Papale P, Shroder J, editors. Volcanic Hazards, Risks And Disasters. United States: Springer; 2015. p. 289-300.

Wulf S, Kraml M, Keller J. Towards a detailed distal tephrostratigraphy in the Mediterranean: the last 20 kyrs record of Lago Grande di Monticchio. J Volcanol Geotherm Res. 2008;177:118-32.

Ye Gl, Nishimura T, Zhang F. Experimental study on shear and creep behaviour of green tuff at high temperatures. Int J Rock Mech Min Sci. 2015;79:19-28.

Zaccarelli L, Sandri L, De Vita S, Di Vito M, Sansivero F. Long-term eruption forecasting at Ischia volcano, cities on volcanoes 10, Naples, Italy, 2-7 September 2018; 2018.

Zaniboni F, Pagnoni G, Tinti S, Della Seta M, Fredi P, Marotta E, Orsi G. The potential failure of Monte Nuovo at Ischia Island (southern Italy): numerical assessment of a likely induced tsunami and its effects on a densely inhabited area (2013). Bull Volcanol. 2013;75(11). https://doi.org/10.1007/s00445-013-0763-9.

\section{Publisher's Note}

Springer Nature remains neutral with regard to jurisdictional claims in published maps and institutional affiliations.

Ready to submit your research? Choose BMC and benefit from

- fast, convenient online submission

- thorough peer review by experienced researchers in your field

- rapid publication on acceptance

- support for research data, including large and complex data types

- gold Open Access which fosters wider collaboration and increased citations

- maximum visibility for your research: over $100 \mathrm{M}$ website views per year

At $\mathrm{BMC}$, research is always in progress.

Learn more biomedcentral.com/submission 